\title{
Surgery for knee osteoarthritis : outcome measurements and their clinimetric implications
}

Citation for published version (APA):

Hemert, W. L. W. (2010). Surgery for knee osteoarthritis : outcome measurements and their clinimetric implications. [Doctoral Thesis, Maastricht University]. www.dlgraphics.nl. https://doi.org/10.26481/dis.20101215wh

Document status and date:

Published: 01/01/2010

DOI:

10.26481/dis.20101215wh

Document Version:

Publisher's PDF, also known as Version of record

\section{Please check the document version of this publication:}

- A submitted manuscript is the version of the article upon submission and before peer-review. There can be important differences between the submitted version and the official published version of record.

People interested in the research are advised to contact the author for the final version of the publication, or visit the DOI to the publisher's website.

- The final author version and the galley proof are versions of the publication after peer review.

- The final published version features the final layout of the paper including the volume, issue and page numbers.

Link to publication

\footnotetext{
General rights rights.

- You may freely distribute the URL identifying the publication in the public portal. please follow below link for the End User Agreement:

www.umlib.nl/taverne-license

Take down policy

If you believe that this document breaches copyright please contact us at:

repository@maastrichtuniversity.nl

providing details and we will investigate your claim.
}

Copyright and moral rights for the publications made accessible in the public portal are retained by the authors and/or other copyright owners and it is a condition of accessing publications that users recognise and abide by the legal requirements associated with these

- Users may download and print one copy of any publication from the public portal for the purpose of private study or research.

- You may not further distribute the material or use it for any profit-making activity or commercial gain

If the publication is distributed under the terms of Article $25 \mathrm{fa}$ of the Dutch Copyright Act, indicated by the "Taverne" license above, 


\section{Surgery for knee osteoarthritis: outcome measurements and their clinimetric implications}

Wouter L.W. van Hemert 
Voor mijn ouders 


\title{
Surgery for knee osteoarthritis: outcome measurements and their clinimetric implications
}

\author{
Proefschrift
}

ter verkrijging van de graad van doctor aan de Universiteit Maastricht op gezag van Rector Magnificus Prof. mr. G.P.M.F. Mols

volgens het besluit van het College van Decanen in het openbaar te verdedigen op woensdag 15 december 2010 om 12.00 uur

door

Wouter Leonard Willem van Hemert

Geboren op 14 mei 1977 te Numansdorp 


\section{Promotor}

Prof. dr. G.H.I.M. Walenkamp

\section{Copromotores}

Dr. B. Grimm

AtriumMC Heerlen

Dr. R. van Heerwaarden

Sint Maartenskliniek

Dr. I.C. Heyligers

AtriumMC Heerlen

\section{Beoordelingscommissie}

Prof.dr. M. van Kleef (voorzitter)

Prof.dr. S.K. Bulstra

Universiteit Groningen

Prof.dr. H. Kuipers

Prof.dr. L.W. van Rhijn

The reproduction of this thesis was generously supported by:

Annafonds, Arthrex Nederland, Bauerfeind, Biomet Nederland, Boehringer Ingelheim BV, Endocare BV, Hansen Footcare, Nederlandse Orthopaedische Vereniging, Orthovision, Oudshoorn chirurgische techniek, Spronken Orthopedie, Stryker Nederland, Synthes Nederland, Tornier 
"quisbusdam remedia monstranda, quibusdam inculcanda sunt." "Bij sommigen is het genoeg om geneesmethoden uit te leggen, bij anderen moet het erin gestampt worden."

\section{Lucius Annaeus Seneca}

Epistulae morales ad lucilium, liber III, Ep.XXVII 
ISBN/EAN

978-90-8590-043-6

Cover

idee: Wouter van Hemert

uitvoering: Eric Lemmens

Lay-out and design

Babs Grit / Eric Lemmens

Published by

www.dlgraphics.nl

Printed by

Schrijen-Lippertz 


\section{TABLE OF CONTENTS}

\section{Chapter 1}

Introduction

\section{Chapter 2}

Functional outcome after knee arthroplasty is dependent upon evaluation method employed

\section{Chapter 3}

Tricalcium phosphate granules or rigid wedge preforms in open wedge high tibial osteotomy: a radiological study

with a new evaluation system

\section{Chapter 4}

Functional improvement after unicompartmental knee replacement;

a follow-up study with a performance based knee test

\section{Chapter 5}

Early functional outcome after subvastus or parapatellar approach in knee arthroplasty is comparable

\section{Chapter 6}

Patella retention versus replacement in total knee arthroplasty; functional and clinimetric aspects

\section{Chapter 7}

Answers to the questions

\section{Chapter 8}

General discussion

\section{Chapter 9}

Summary

\section{Chapter 10}

Samenvatting

List of publications

Dankwoord 


\section{Chapter 1}

\section{General introduction}


Chapter 1 


\section{INTRODUCTION AND RATIONALE}

\section{General overview}

Osteoarthritis is the most common occurring joint disorder in the world ${ }^{5}$. This process of cartilage destruction is thought to evolve from a normal loading force on abnormal cartilage structure or an abnormal loading on normal cartilage. In western society the latter occurs more frequently, as is the case with obesity ${ }^{93}$. Patients suffering from osteoarthritis usually complain about pain, joint stiffness and loss of function. The initial treatment consists of medication as non-steroid anti inflammatory drugs (NSAID), as well as orthotics and physical therapy ${ }^{31}$. In the event of obesity weight reduction results in pain relief and avoids short term needed arthoplasty ${ }^{28}$. In the end a surgical intervention may become inevitable, when these treatments fail to reduce pain.

Concerning the knee, localized cartilage defects can be restored or treated in early phases using cartilage restoring treatments ${ }^{49}$, such as microfracturing ${ }^{65}$, mosaicplasty ${ }^{36}$ or autologous chondrocyte transplantation ${ }^{29}$. Those options are subject to extensive research but still have limited indications, do not last endlessly and especially the latter remains experimental.

Deviations from normal anatomic relation can increase forces across cartilage and therefore enhance the progression of degenerative arthrosis. Abnormal tibiofemoral relationship also increases ligamentous imbalance, further advancing the deformity. Osteotomy around the knee is well established to correct malalignment and treat unicompartmental osteoarthritis as a joint preserving treatment ${ }^{18,39}$. Both femoral and tibial corrective procedures are pursued. High tibial osteotomy is far more common, mainly to correct varus malalignment. Coventry popularized the closed wedge technique ${ }^{17}$. It has become evident that correction of malalignment slows down the degenerative process and delays the need for joint replacement ${ }^{72}$. Typically high demand activity patients between 40 and 60 years of age with Body Mass Index $<30$ are suitable to undergo this procedure ${ }^{79}$. An osteotomy should not be performed in case of bicompartmental involvement and in case of fixed flexion contracture ${ }^{79}$.

\section{Knee replacement}

In the advanced stages of cartilage destruction, knee replacement is currently the best option for a long term pain free joint with acceptable function and a long term survival. It is one of the most performed operations in orthopaedic practice $^{78}$. Two different main options are available and consist of total knee 
replacement and medial unicompartmental replacement. Isolated patellafemoral joint replacement or lateral unicompartmental replacement have limited indications and are performed less frequent ${ }^{2}$.

Today's total knee replacement is in essential a condylar total knee and this idea has evolved in the early 1970's when Gunston ${ }^{34}$ reported on his Polycentric knee which was basically a bicondylar unicompartmental metal femoral component and a high density polyethylene tibial component. The modern era of total knee replacement is related to the total condylar knee replacement as was introduced by Ranawat and Insall ${ }^{43}$. This has become synonymous for replacing diseased cartilage with femoral resurfacing, a stemmed tibial component and patellofemoral resurfacing option ${ }^{81}$.

The development of knee arthroplasty has essentially arisen from the need to replace the diseased cartilage ${ }^{80}$. At first experiments with resection arthroplasty were performed with an inserted flap of knee capsule. In the early decades of the $20^{\text {th }}$ century the interposition was altered to artificial substances such as ivory and plaster ${ }^{80}$. After early failures other materials as vitallium and acrylic designs were introduced ${ }^{47}$. This eventually led to the use of hinged replacements in the $1940 \mathrm{~s}^{96}$. Problems with biocompatibility and fixation resulted in inefficient results of long-term pain free joints. A major improvement to successful fixation was found when the constrained character was abandoned and the problems of a metal-metal articulation were solved ${ }^{13}$.

Based on the successful work on low friction Total Hip Arthroplasty, pioneered by Charnley ${ }^{15}$ en $\mathrm{McKee}^{62}$, this concept of metal and polyethylene surfaces proved to be the basis for further development of total knee replacement. A lubricated polyethylene insert duplicated the idea of low friction arthoplasty. As development continued a condylar design was sought to ensure large polyethylene contact areas and the importance of metal backing was recognized for polyethylene modularity ${ }^{23,30}$. Nowadays it is well established that the polyethylene component of a joint replacement undergoes a process of degeneration and wear and then produces polyethylene particles ${ }^{45}$. This not only damages the articulation surface but also causes bone resorption which eventually leads to implant failure ${ }^{8}$.

In order to reduce polyethylene wear several modifications and alternative designs have been introduced. Rotating platforms and mobile bearings were designed to minimize wear and loosening. Whereas superiority to traditional design still has not been elucidated ${ }^{46}$, it introduced problems of dislocation and breakage. 
Continued development led to improved conformity of inserts but also alterations in the molecular structure by means of processing, sterilization and designing made dramatic improvement in wear characteristics of polyethylene $\mathrm{e}^{52,53}$.

Next to the challenge of reducing polyethylene wear other conditions are of importance to the survival of the prosthesis. Cementless fixation was pursued since concerns about the long-term durability of cemented versions existed ${ }^{68}$. Despite early excitement of a more biological fixation and contrary to the success of the uncemented application in total hip arthroplasty, the cemented alternative remains superior in knee replacement ${ }^{83}$.

Based on the mobile bearing concept the medial unicompartmental knee replacement with a mobile meniscal bearing was developed in the 1970's in the United Kingdom ${ }^{32}$ to replace the diseased medial compartment. Parallel to the fixed bearing option of Marmor ${ }^{60}$ alternatives were developed to treat unicompartmental involvement thereby preserving all the undamaged structures of the knee, in particular the cruciate ligaments. Medial unicompartmental knee replacement can be considered when the anterior cruciate ligament is observed to be intact ${ }^{33}$ and the fixed flexion deformity is less than $90^{\circ}$. The varus deformity should be correctable to neutral and the lateral compartment should be undamaged, which is best demonstrated on valgus stress X-rays with the knee in $20^{\circ}$ of flexion ${ }^{97}$.

Indication for knee replacement in general is severe unrelenting pain due to cartilage damage, which remains refractory to other treatment modularities, in absence of contraindications as present infection or patient related risks factors. Once it has been established that arthoplasty is warranted there are many issues to be dealt with, both patient and surgeon related, to ensure satisfactory outcome.

\section{Outcome assessment}

Several issues play an important role in the success of orthopaedic surgery. Next to the design and choice of materials an accurate indication and patient selection is vital. Technical and surgical aspects are crucial; performing an osteotomy in a knee that is already in the range of normal alignment or placing the components of a knee arthroplasty in an abnormal position will likely fail the treatment. Both in total and unicompartmental knee arthroplasty long term success has been well established by means of implant survival. Several reports with documented survival rates from $95-98 \%$ between 10 and 15 years are available $\mathrm{e}^{71,77}$. 
Reporting results of treatment is essential, concerning both the successful options as well as the less frequently reported failures. In the modern era of evidence-based medicine it is important to use adequate tools to measure outcome of different treatments. Whereas a treatment may seem to work, or one option does not seem to be better as the alternative, and this reflects the best knowledge, this may not exactly be the case. Examining our measurement tools is vital in the judgment of this knowledge.

The purpose of any rating system is to provide objective assessment of the subject in direct comparison with other examples of the same condition, to a condition prior or after an intervention, or to compare different techniques and implants. With regard to knee replacement a rating system should be applicable both before and after surgery to establish the level of effect achieved by surgery. Certain features feed the desirability of a tool that assesses the knee independently. Such tool should use important and measurable characteristics of the knee, it should avoid arbitrary assignment of point values, it must relate to clinical results. It also should include easy quantifiable variables and simplicity, and yet be reproducible.

\section{Clinimetrics}

Clinimetrics focuses on the quality of clinical measurement and on ways to improve this quality ${ }^{25}$. Quality of measurement includes both the quality of the measurement instruments and the quality of the performance of the actual measurements ${ }^{26,27}$. The range of clinical measurement instruments encompasses not only X-rays and other imaging techniques, clinical chemistry measurements in serum and urine samples, questionnaires and interviews, but also patient history-taking and physical clinical examinations performed by care-providers. The quality of the performance of the measurements depends, for example, on the expertise of the persons carrying out the measurements, the quality of samples, or the amount of attention that patients pay to a questionnaire.

In order to choose the best available measurement instrument, either for research purposes or for clinical practice, the literature should be searched thoroughly for available instruments ${ }^{20}$. The clinimetric properties of possible instruments should be examined and, if necessary, the most promising instrument should be further validated. Only if no suitable measurement instrument is available, should the development of a new instrument be considered. If a new instrument is developed, its clinimetric properties must, of course, be evaluated ${ }^{85}$.

The clinimetric properties of a measurement instrument always encompass 
validity (does it measure what it intends to measure?) and reproducibility (do repeated measurements yield similar results?). Internal consistency is important for multiple-item instruments, but only if these items intend to measure the same construct. The responsiveness of evaluative instruments must be studied ${ }^{90}$, i.e. the instrument should be able to detect relevant changes in health status over time $^{35}$. Responsiveness can be considered as longitudinal validity ${ }^{41}$. Finally, the interpretability of the instrument must be clear, in other words: what is the meaning of the scores?

Essentially, validity holds the quality of the measurement. Based on the report of de Vet et al. ${ }^{20}$ there are different types of validity. Criterion validity is most powerful as a gold standard is available as proof to which a measurement can be tested. In absence of the gold standard construct validity is the best option. Construct validity indicates whether the instrument correlates with other measures or attributes that have an established relationship with the domain of interest. Content validity concerns judgment whether all important components of the construct to be measured are covered by the instrument. Face validity implies an overall judgment of adequacy 'on the face of it'.

Reproducibility includes reliability and agreement. Agreement represents lack of measurement error, whereas reliability represents the extent to which individuals can be distinguished from each other, despite agreement. Responsiveness is an important parameter for measurement instruments that aim to measure change over time such as outcome measures in treatment effects.

\section{Outcome after knee surgery}

To value outcome after knee surgery, over 30 different rating scales for knee assessment are available in literature ${ }^{21}$, but only two of those are in widespread use. Already in 1975 Kettlekamp and Thompson ${ }^{50}$ postulated criteria that should be included in a useful system for knee evaluation and include simplicity, measurable items and a score to clinical results relation.

There are the joint related scoring systems, such as the American based Knee Society Score (KSS) ${ }^{44}$ which basically is the successor of the Hospital for Special Surgery score and is holds knee score and function score as two subscores. Another less frequent employed example is the Bristol Knee Score ${ }^{73}$. Next disease specific scores exist such as the Western Ontario and McMaster Universities Index for Osteoarthritis (WOMAC) ${ }^{10}$ and the Oxford knee score ${ }^{19}$. Furthermore a generic Short Form 36 (SF 36) exists that is widely used for qualityof-life assessment in several circumstances or after various intervention ${ }^{87} \mathrm{~s}$.

Regarding those evaluating methods numerous papers have been appeared 
discussing their clinimetric properties. In a nearly classic paper by Lingard et a $\left.\right|^{54}$ the validity and responsiveness of KSS, WOMAC and SF 36 are investigated. Validity reflects the extent to which the instrument measures what it is purported to measure. They found poor correlation among the items of the knee score, but the knee score had good convergent construct validity with the WOMAC pain score and was a responsive outcome measure for patients undergoing total knee arthroplasty.

There was also poor correlation among the items of the Knee Society function score, but the function score had good convergent construct validity with the SF-36 physical functioning score. It was less responsive than the WOMAC function or SF-36 physical functioning scores for measuring functional outcomes following total knee arthroplasty.

As the Knee Society Score is calculated with use of a clinical scoring algorithm that includes both positively and negatively scored items, it is inappropriate to test for internal consistency of these scores. In comparison, the WOMAC and SF-36 scores are easier to interpret because there is high internal consistency and strong correlations among items. Therefore, a patient with a WOMAC pain score of 50 points can be assumed to have, on average, moderate pain with activities. Also a patient with an SF-36 physical functioning score of 50 points can be assumed to have, on average, little limitation with most activities.

Convergent construct validity is demonstrated if the correlation between the scores of two different instruments measuring the same health dimensions is positive and appreciably greater than zero. The convergent construct validity of the Knee Society pain and function scores was established by the finding that they had modest correlations with the analogous domains of the WOMAC and SF-36 scales.

The correlation between the Knee Society function and SF-36 physical functioning scores $(r=0.63$ preoperatively and $r=0.72)$ was stronger than that between the Knee Society function and WOMAC function scores $(r=0.46$ preoperatively and $r=0.58$ ) at both assessment times. One reason for this finding may be the items selected for these scores. The questions on the Knee Society function scale ask only about walking distance, stair climbing ability, and use of a walking aid. Half of the items on the SF-36 physical functioning score are devoted to walking distance and stair-climbing ability, whereas the WOMAC function score has more varied items.

It was found that the Knee Society knee score and the WOMAC pain score were more sensitive for detecting change over time than was the SF-36 bodily pain score. The lack of responsiveness of the SF-36 bodily pain score may be 
attributed to the fact that it is too generic to be sensitive enough to detect change due to total knee arthroplasty.

Kreibich et al. ${ }^{51}$, found in their study of different measures of outcome after total knee arthroplasty that the WOMAC and Knee Society scores were more responsive with regard to detecting change in patient status at three and twelve months than were the SF-36 scores and simple functional tests such as the six-minute walk and thirty-second stair climb. Responsiveness was also assessed in terms of patient satisfaction and perceived improvement in quality of life and change in general health status. Correlations between changes in the scores of the different systems and these items allowed us to ascertain which scales best capture patient-centered measures of improvement. The WOMAC pain and function and SF-36 physical functioning scores were significantly more responsive than the Knee Society scores in terms of patient satisfaction and perceived improvement in quality of life; this finding indicated that these scores better reflect changes that are most important to patients.

Next to self-report and doctor related measurements, or classic scores, there is the availability of objective measures. This is mainly categorized as gait analyses and performance based measurements. Highly sophisticated gait analysis systems ${ }^{42,98}$ performance based measurements ${ }^{1,92}$, or simple gait tests $^{51,76}$ are available. Self-report and performance based measurements are deemed complementary as they cover a different aspect of recovery ${ }^{48}$. Gait analyses required specialized laboratories, are time consuming and frequently space remains a limitation. With specialized ambulatory devices it becomes possible to assess subjects in their own environment or at least have them tested in limited space. Such a system becomes useful when it is not only complementary but also its reliability and validity are proven. In addition it should be able to discriminate healthy persons from patients. In this thesis such a system, The Dynaport ${ }^{\circledR}$ Knee Test was utilized ${ }^{92}$. Its clinimetric properties are well established. The content validity is likely to be good. It has been shown able to discriminate between patients and controls, on different parameters, such as accelerations, angles, durations, step number, step frequencies, relative speed and asymmetry. These parameters have been shown to be efficient and useful for the evaluation of function in TKR patients ${ }^{14}$.

The reproducibility and construct validity was concluded to be $\operatorname{good}^{66}$. Intraclass Correlation Coefficients (ICCs) for inter-observer and intra-observer reliability were very good; 0.90 (0.83-0.94) and 0.95 (0.83-0.98), respectively ${ }^{66}$. Construct validity was confirmed by expected correlations, expressed as 
Pearson's correlation coefficients (r), with the Western Ontario and McMaster University Osteoarthritis Index (WOMAC) physical functioning ( $r=0.55)$, Medical Outcomes Study Short Form-36 Health Survey ( $r=$ SF-36) physical functioning $(r=0.62)$ and KSS function $(r=0.64)$. As for assessing construct validity, the results were supported in a study that compared the results of the test to the 'silver-standard' of the eye of a physical therapist and was observed to have strong correlations ${ }^{67}$.

\section{Advances in adult reconstructive knee surgery}

Although the long-term success of knee replacement has been well established, the orthopaedic surgeon, related scientists and also society still warrant improvement of quality and longevity. Shifting standard toward 'the millennium patient' in terms of high demand function to maintain expectations of modern society. This indicates that interventions are performed earlier in life and warrant better performance to meet standard that go with specific ages, but also should provide long term guarantee with use of better materials and methods. Currently there are various issues concerning adult reconstructive knee surgery that receive much attention. In general knee arthroplasy should restore normal knee kinematics, but this goal remains very difficult. Therefore, prosthetic design is continuously developing to improve knee function ${ }^{9}$.

High flexion and patella tracking are frequently discussed topics ${ }^{3,4,6,7}$. The main functions of the patella are to improve the efficiency of the extensor forces, to centralize the forces of the different muscles attached to it and to provide a smooth sliding mechanism with little friction ${ }^{38}$. It is also believed to contribute to global stability. Because of very high mechanical stresses to which the patello-femoral joint is subjected ${ }^{38}$, it possesses the thickest articular cartilage $^{11}$. At the same time is of the greatest frequency of degenerative changes. These properties have motivated numerous studies to understand the cause of patellar degeneracies ${ }^{86}$ and subsequent treatments ${ }^{88}$. These studies have delineated a number of fundamental topics such as patellar kinematics, extensor forces, patello-femoral contact pressure and stresses in the patella ${ }^{38}$. Assessing these various aspects of patellar biomechanics becomes relevant when facing the problem of evaluating surgical procedures in terms of standard knee functionality such as knee replacement. Even more it is especially relevant in assessing the role of resurfacing the patella in total knee arthroplasty ${ }^{69}$. The strategy of retention or replacing the damaged cartilage with a polyethylene backing has been investigated in such biomechanical studies ${ }^{61}$. Several issues are of importance in the design of the implant to have optimal biomechanics. 
The congruency between the prosthetic femoral trochlea and the new or native patella will play a role in the force distribution and transmission. It is found that a patella design with an anatomical shape is stable and provokes the lowest compressive forces ${ }^{38}$.

Hence a femoral component with anatomical trochlea shapes ${ }^{9}$ is advocated to accommodate either the natural patella or a replacement for surgical versatility, stability and durability, provided that femoral component rotation is adequate ${ }^{95}$. Patellar tracking is accommodated by the valgus position of the femoral component. Patellar thickness is of influence on patellar contact forces and this has been investigated in various studies.

Numerous clinical studies have been conducted with these technical aspects as basic knowledge to clinically prove the superiority of one option above the other. These studies have evaluated patients using knee scoring systems both with short term follow up and long term follow up. As these trials are combined in two excellent meta analyses ${ }^{74,75}$, commonly considered as the highest level of evidence, it can be concluded that patella resurfacing reduces the risk of anterior knee pain in long term follow up and reduces the risk of reoperation. Reoperation, meaning secondary patellar resurfacing, should be avoided as it is believed to have inferior or even deteriorating results ${ }^{70}$. If secondary resurfacing is considered in the case of retention then it is advised to perform such in the early post operative follow up. However, looking at high quality trials that were included in these two meta analyses, it remains undecided which option is to prefer ${ }^{74,75}$.

Computer assisted surgery is well implemented in order to optimize implantation and alignment, but show only improved consistency in alignment ${ }^{59}$ rather than better performances of patients compared to conventional operative technique s8,94. $^{\text {. }}$

Surgical techniques are altered to minimize soft tissue damage ${ }^{40}$. A pain free knee joint after arthroplasty is no longer the only objective of reconstructive knee surgery. Early mobilization and rehabilitation are now as relevant ${ }^{91}$. The surgeon may contribute to this process by altering implants and surgical techniques. Rehabilitation programs are well established to enhance rehabilitation and reduce in hospital stay ${ }^{16}$. In the era of less or minimal invasive surgery ${ }^{89}$ muscle sparing techniques are pursued. Early recovery after various surgical techniques are subject to research ${ }^{22,57}$. It is of importance to elucidate the true functional recovery compared to standard techniques and to provide basic scientific rationale for such alterations. The importance of this was highlighted by Lonner et al. ${ }^{56}$. They stated that most current scoring systems are poor determinants of early functional outcome (and may not capture early benefits of minimal invasive approaches). 
In view of these advances several issues are now relevant, especially with the knowledge that outcome is dependent upon clinimetric aspects of employed measurement tools.

Unicompartmental knee replacement has been claimed to result in faster recovery than compared to total knee replacement ${ }^{84,99}$. As various measurement tools measuring outcome in knee replacement are shown to have different construct validity and responsiveness it was deemed that various tools would show different outcomes. In this view it can be questioned whether the used measurement tools reflect the actual recovery ${ }^{37,64}$, it can be postulated whether they are actually better or whether it is due to the better preoperative status.

Reduction of in hospital stay is pursued in order to reduce costs ${ }^{77,82}$. The feasibility of faster recovery is dependent upon intensive rehabilitation. Joint care programs are established to enhance this. In this view patients are informed about the course of hospitalization, type and duration of surgery but also on the longevity of recovery arthroplasty. It is believed that unicompartmental knee replacement is superior over total knee replacement ${ }^{84,99}$, not only in range of motion $^{82}$, but also in terms of postoperative recovery ${ }^{77}$. As different outcome measurement tools provide different insight in recovery it is of interest to establish true functional recovery after unicompartmental knee replacement.

Despite the long term success of arthroplasty, an osteotomy around the knee as a joint preserving procedure remains an excellent surgical option ${ }^{18}$. The type of osteotomy (open wedge versus closed wedge) does not seem to have an influence on clinical outcome ${ }^{12}$. However it has been reported in a randomized trial that a lateral closing wedge is more precise and ensures a shorter time of bone healing. This trial ${ }^{12}$ was performed with a non angle stable plate, whereas Lobenhoffer et $a f^{55}$ demonstrated that success of a medial opening wedge depends on stability. In earlier literature, a medial opening wedge proved more precise in achieving correction than does a lateral closing wedge ${ }^{39}$. As medial opening wedge is being favored, since a fibular osteotomy and possible related peroneal nerve injuries could be abandoned, this brings a next issue in this procedure.

Primary bone healing requires direct and compressive bone contact that can be observed after compressive plating of a fracture ${ }^{63}$. Secondary bone healing involves responses in the periosteum and external soft tissues ${ }^{63}$. Vascular ingrowth requires a calcified matrix as observed during hard callus formation during fracture healing, but is disturbed in unstable situations. Thus for successful healing of a medial opening wedge osteotomy a matrix seems required for both osteoinductive and conductive circumstances. This is 
traditionally offered through autologous or allogenic bone grafts. Ceramic implants are attributed to have the same properties ${ }^{24}$. Thus it is of interest whether these implants are feasible.

Based on the above mentioned issues, the following research questions were formulated:

1. Are functional differences between unicompartmental knee replacement and total knee replacement dependent upon the method of assessment employed?

2a. Can bone healing after open wedge high tibial osteotomy be reliably documented?

2b. How is the feasibility of ceramic implants in open wedge high tibial osteotomy?

3a. Is it possible to elucidate the true longevity of recovery after unicompartmental knee replacement?

$3 \mathrm{~b}$. is it possible to establish differences across WOMAC, SF36, KSS and Dynaport ${ }^{\circledR}$ Knee test with the knowledge that function could also be reflected in the ability to perform activities of daily living and this seems rather important and may be less related to range of motion64 or reported function scores ${ }^{37}$ ?

4a. Is faster postoperative recovery dependent upon a traditional approach to the knee joint when compared to an alternate muscle sparing technique?

$4 \mathrm{~b}$. Is it of interest to provide anatomic evidence for presented claims as a part of valuing own measurements?

5. Could the indecisiveness about patellar resurfacing be attributed to the insufficient responsiveness of used measurement parameters in past trials, rather than assuming that no difference exists? 
Chapter 1 


\section{LITERATURE}

1. The Gait Treadmill.

2. (2009) The Swedish Knee Arthroplasty Register 1.0

3. Anglin C, Brimacombe JM, Hodgson AJ, Masri BA, Greidanus NV, Tonetti J, Wilson DR (2008) Determinants of patellar tracking in total knee arthroplasty. Clin Biomech (Bristol, Avon) 23:900-910

4. Anglin C, Brimacombe JM, Wilson DR, Masri BA, Greidanus NV, Tonetti J, Hodgson AJ (2008) Intraoperative vs. weightbearing patellar kinematics in total knee arthroplasty: a cadaveric study. Clin Biomech (Bristol, Avon) 23:60-70

5. Arden N, Nevitt MC (2006) Osteoarthritis: epidemiology. Best Pract Res Clin Rheumatol 20:3-25

6. Argenson JN, Komistek RD, Mahfouz M, Walker SA, Aubaniac JM, Dennis DA (2004) A high flexion total knee arthroplasty design replicates healthy knee motion. Clin Orthop Relat Res:174-179

7. Asano T, Akagi M, Koike K, Nakamura T (2003) In vivo three-dimensional patellar tracking on the femur. Clin Orthop Relat Res:222-232

8. Ayers DC (1997) Polyethylene wear and osteolysis following total knee replacement. Instr Course Lect 46:205-213

9. Barink M, Van de Groes S, Verdonschot N, De Waal Malefijt M (2006) The difference in trochlear orientation between the natural knee and current prosthetic knee designs; towards a truly physiological prosthetic groove orientation. J Biomech 39:1708-1715

10. Bellamy N, Buchanan WW, Goldsmith CH, Campbell J, Stitt LW (1988) Validation study of WOMAC: a health status instrument for measuring clinically important patient relevant outcomes to antirheumatic drug therapy in patients with osteoarthritis of the hip or knee. J Rheumatol 15:1833-1840

11. Bellemans J (2003) Biomechanics of anterior knee pain. Knee 10:123-126

12. Brouwer RW, Bierma-Zeinstra SM, van Raaij TM, Verhaar JA (2006) Osteotomy for medial compartment arthritis of the knee using a closing wedge or an opening wedge controlled by a Puddu plate. A one-year randomised, controlled study. J Bone Joint Surg Br 88:1454-1459

13. Bryan RS, Peterson LF (1973) Polycentric total knee arthroplasty. Orthop Clin North Am 4:575-584

14. Chao EY, Laughman RK, Stauffer RN (1980) Biomechanical gait evaluation of pre and postoperative total knee replacement patients. Arch Orthop Trauma Surg 97:309-317

15. Charnley J (1972) The long-term results of low-friction arthroplasty of the hip performed as a primary intervention. J Bone Joint Surg Br 54:61-76 


\section{Chapter 1}

16. Cook JR, Warren M, Ganley KJ, Prefontaine P, Wylie JW (2008) A comprehensive joint replacement program for total knee arthroplasty: a descriptive study. BMC Musculoskelet Disord 9:154

17. Coventry MB (1965) Osteotomy of the Upper Portion of the Tibia for Degenerative Arthritis of the Knee. a Preliminary Report. J Bone Joint Surg Am 47:984-990

18. Coventry MB, Ilstrup DM, Wallrichs SL (1993) Proximal tibial osteotomy. A critical long-term study of eighty-seven cases. J Bone Joint Surg Am 75:196-201

19. Dawson J, Fitzpatrick R, Murray D, Carr A (1998) Questionnaire on the perceptions of patients about total knee replacement. J Bone Joint Surg Br 80:63-69

20. de Vet HC, Terwee CB, Bouter LM (2003) Current challenges in clinimetrics. J Clin Epidemiol 56:1137-1141

21. Drake BG, Callahan CM, Dittus RS, Wright JG (1994) Global rating systems used in assessing knee arthroplasty outcomes. J Arthroplasty 9:409-417

22. Dutton AQ, Yeo SJ, Yang KY, Lo NN, Chia KU, Chong HC (2008) Computer-assisted minimally invasive total knee arthroplasty compared with standard total knee arthroplasty. A prospective, randomized study. J Bone Joint Surg Am 90:2-9

23. Eftekhar NS (1983) Total knee-replacement arthroplasty. Results with the intramedullary adjustable total knee prosthesis. J Bone Joint Surg Am 65:293-309

24. Erbe EM, Marx JG, Clineff TD, Bellincampi LD (2001) Potential of an ultraporous betatricalcium phosphate synthetic cancellous bone void filler and bone marrow aspirate composite graft. Eur Spine J 10 Suppl 2:S141-146

25. Feinstein A (1987) Clinimetrics. Yale University Press New Haven, CT

26. Feinstein AR (1983) An additional basic science for clinical medicine: III. The challenges of comparison and measurement. Ann Intern Med 99:705-712

27. Feinstein AR (1983) An additional basic science for clinical medicine: IV. The development of clinimetrics. Ann Intern Med 99:843-848

28. Felson DT, Zhang Y, Anthony JM, Naimark A, Anderson JJ (1992) Weight loss reduces the risk for symptomatic knee osteoarthritis in women. The Framingham Study. Ann Intern Med 116:535-539

29. Ferruzzi A, Buda R, Faldini C, Vannini F, Di Caprio F, Luciani D, Giannini S (2008) Autologous chondrocyte implantation in the knee joint: open compared with arthroscopic technique. Comparison at a minimum follow-up of five years. J Bone Joint Surg Am 90 Suppl 4:90-101

30. Font-Rodriguez DE, Scuderi GR, Insall JN (1997) Survivorship of cemented total knee arthroplasty. Clin Orthop Relat Res:79-86

31. Gaasbeek RD, Groen BE, Hampsink B, van Heerwaarden RJ, Duysens J (2007) Valgus bracing in patients with medial compartment osteoarthritis of the knee. A gait analysis study of a new brace. Gait Posture 26:3-10 
32. Goodfellow J, O'Connor J (1978) The mechanics of the knee and prosthesis design. J Bone Joint Surg Br 60-B:358-369

33. Goodfellow J, O'Connor J (1992) The anterior cruciate ligament in knee arthroplasty. A risk-factor with unconstrained meniscal prostheses. Clin Orthop Relat Res:245-252

34. Gunston FH (1971) Polycentric knee arthroplasty. Prosthetic simulation of normal knee movement. J Bone Joint Surg Br 53:272-277

35. Guyatt GH, Kirshner B, Jaeschke R (1992) A methodologic framework for health status measures: clarity or oversimplification? J Clin Epidemiol 45:1353-1355

36. Hangody L, Rathonyi GK, Duska Z, Vasarhelyi G, Fules P, Modis L (2004) Autologous osteochondral mosaicplasty. Surgical technique. J Bone Joint Surg Am 86-A Suppl 1:65-72

37. Hassaballa MA, Porteous AJ, Newman JH (2004) Observed kneeling ability after total, unicompartmental and patellofemoral knee arthroplasty: perception versus reality. Knee Surg Sports Traumatol Arthrosc 12:136-139

38. Heegaard J, Leyvraz PF, Curnier A, Rakotomanana L, Huiskes R (1995) The biomechanics of the human patella during passive knee flexion. J Biomech 28:12651279

39. Hernigou P, Medevielle D, Debeyre J, Goutallier D (1987) Proximal tibial osteotomy for osteoarthritis with varus deformity. A ten to thirteen-year follow-up study. J Bone Joint Surg Am 69:332-354

40. Huang HT, Su JY, Chang JK, Chen CH, Wang GJ (2007) The early clinical outcome of minimally invasive quadriceps-sparing total knee arthroplasty: report of a 2-year followup. J Arthroplasty 22:1007-1012

41. Husted JA, Cook RJ, Farewell VT, Gladman DD (2000) Methods for assessing responsiveness: a critical review and recommendations. J Clin Epidemiol 53:459-468

42. Inc AD The Ariel Performance Analysis System (APAS).

43. Insall J, Ranawat CS, Scott WN, Walker P (1976) Total condylar knee replacment: preliminary report. Clin Orthop Relat Res:149-154

44. Insall JN, Dorr LD, Scott RD, Scott WN (1989) Rationale of the Knee Society clinical rating system. Clin Orthop Relat Res:13-14

45. Jacobs JJ, Shanbhag A, Glant TT, Black J, Galante JO (1994) Wear Debris in Total Joint Replacements. J Am Acad Orthop Surg 2:212-220

46. Jacobs W, Anderson P, Limbeek J, Wymenga A (2004) Mobile bearing vs fixed bearing prostheses for total knee arthroplasty for post-operative functional status in patients with osteoarthritis and rheumatoid arthritis. Cochrane Database Syst Rev:CD003130

47. Judet J, Judet R, et al. (1947) Essais de prosthese ostéo-articulaire. Presse Med 55:302

48. Kennedy D, Stratford PW, Pagura SM, Walsh M, Woodhouse LJ (2002) Comparison of gender and group differences in self-report and physical performance measures in total hip and knee arthroplasty candidates. J Arthroplasty 17:70-77 


\section{Chapter 1}

49. Kessler MW, Ackerman G, Dines JS, Grande D (2008) Emerging technologies and fourth generation issues in cartilage repair. Sports Med Arthrosc 16:246-254

50. Kettelkamp DB, Thompson C (1975) Development of a knee scoring scale. Clin Orthop Relat Res:93-99

51. Kreibich DN, Vaz M, Bourne RB, Rorabeck CH, Kim P, Hardie R, Kramer J, Kirkley A (1996) What is the best way of assessing outcome after total knee replacement? Clin Orthop Relat Res:221-225

52. Kurtz SM, Muratoglu OK, Evans M, Edidin AA (1999) Advances in the processing, sterilization, and crosslinking of ultra-high molecular weight polyethylene for total joint arthroplasty. Biomaterials 20:1659-1688

53. Li S, Burstein AH (1994) Ultra-high molecular weight polyethylene. The material and its use in total joint implants. J Bone Joint Surg Am 76:1080-1090

54. Lingard EA, Katz JN, Wright RJ, Wright EA, Sledge CB (2001) Validity and responsiveness of the Knee Society Clinical Rating System in comparison with the SF36 and WOMAC. J Bone Joint Surg Am 83-A:1856-1864

55. Lobenhoffer P, Agneskirchner JD (2003) Improvements in surgical technique of valgus high tibial osteotomy. Knee Surg Sports Traumatol Arthrosc 11:132-138

56. Lonner J, Deirmengian C (2007) Specialty update. What's new in adult reconstructive knee surgery. J Bone Joint Surg Am 89:2828-2837

57. Luring C, Beckmann J, Haibock P, Perlick L, Grifka J, Tingart M (2008) Minimal invasive and computer assisted total knee replacement compared with the conventional technique: a prospective, randomised trial. Knee Surg Sports Traumatol Arthrosc 16:928-934

58. Luring C, Oczipka F, Perlick L, Tingart M, Grifka J, Bathis H (2009) Two year follow-up comparing computer assisted versus freehand TKR on joint stability, muscular function and patients satisfaction. Knee Surg Sports Traumatol Arthrosc 17:228-232

59. Lutzner J, Krummenauer F, Wolf C, Gunther KP, Kirschner S (2008) Computer-assisted and conventional total knee replacement: a comparative, prospective, randomised study with radiological and CT evaluation. J Bone Joint Surg Br 90:1039-1044

60. Marmor L (1973) The modular knee. Clin Orthop Relat Res:242-248

61. Mayman D, Bourne RB, Rorabeck CH, Vaz M, Kramer J (2003) Resurfacing versus not resurfacing the patella in total knee arthroplasty: 8- to 10-year results. J Arthroplasty 18:541-545

62. McKee GK, Watson-Farrar J (1966) Replacement of arthritic hips by the McKee-Farrar prosthesis. J Bone Joint Surg Br 48:245-259

63. McKibbin B (1978) The biology of fracture healing in long bones. J Bone Joint Surg Br 60-B:150-162 
64. Miner AL, Lingard EA, Wright EA, Sledge CB, Katz JN (2003) Knee range of motion after total knee arthroplasty: how important is this as an outcome measure? J Arthroplasty 18:286-294

65. Mithoefer K, Williams RJ, 3rd, Warren RF, Potter HG, Spock CR, Jones EC, Wickiewicz TL, Marx RG (2005) The microfracture technique for the treatment of articular cartilage lesions in the knee. A prospective cohort study. J Bone Joint Surg Am 87:1911-1920

66. Mokkink LB, Terwee CB, van der Slikke RM, van Lummel RC, Benink RJ, Bouter LM, de Vet HC (2005) Reproducibility and validity of the DynaPort KneeTest. Arthritis Rheum 53:357-363

67. Mokkink LB, Terwee CB, van Lummel RC, de Witte SJ, Wetzels L, Bouter LM, de Vet HC (2005) Construct validity of the DynaPort KneeTest: a comparison with observations of physical therapists. Osteoarthritis Cartilage 13:738-743

68. Moran CG, Pinder IM, Lees TA, Midwinter MJ (1991) Survivorship analysis of the uncemented porous-coated anatomic knee replacement. J Bone Joint Surg Am 73:848857

69. Muller W, Wirz D (2001) The patella in total knee replacement: does it matter? 750 LCS total knee replacements without resurfacing of the patella. Knee Surg Sports Traumatol Arthrosc 9 Suppl 1:S24-26

70. Muoneke HE, Khan AM, Giannikas KA, Hagglund E, Dunningham TH (2003) Secondary resurfacing of the patella for persistent anterior knee pain after primary knee arthroplasty. J Bone Joint Surg Br 85:675-678

71. Murray DW, Goodfellow JW, O'Connor JJ (1998) The Oxford medial unicompartmental arthroplasty: a ten-year survival study. J Bone Joint Surg Br 80:983-989

72. Naudie D, Bourne RB, Rorabeck CH, Bourne TJ (1999) The Install Award. Survivorship of the high tibial valgus osteotomy. A 10- to -22-year followup study. Clin Orthop Relat Res:18-27

73. Newman J, Pydisetty RV, Ackroyd C (2009) Unicompartmental or total knee replacement: the 15-year results of a prospective randomised controlled trial. J Bone Joint Surg Br 91:52-57

74. Nizard RS, Biau D, Porcher R, Ravaud P, Bizot P, Hannouche D, Sedel L (2005) A metaanalysis of patellar replacement in total knee arthroplasty. Clin Orthop Relat Res:196203

75. Pakos EE, Ntzani EE, Trikalinos TA (2005) Patellar resurfacing in total knee arthroplasty. A meta-analysis. J Bone Joint Surg Am 87:1438-1445

76. Parent E, Moffet H (2002) Comparative responsiveness of locomotor tests and questionnaires used to follow early recovery after total knee arthroplasty. Arch Phys Med Rehabil 83:70-80 


\section{Chapter 1}

77. Price AJ, Waite JC, Svard U (2005) Long-term clinical results of the medial Oxford unicompartmental knee arthroplasty. Clin Orthop Relat Res:171-180

78. Prismant (2005) Yearbook for the hospital. Utrecht

79. Rand J, Neyret P (2005) Isakos meeting on the management of osteoarthritis of the knee prior to knee arthroplasty. ISAKOS

80. Riley LH, Jr. (1976) The evolution of total knee arthroplasty. Clin Orthop Relat Res:7-10

81. Ritter MA, Campbell E, Faris PM, Keating EM (1989) Long-term survival analysis of the posterior cruciate condylar total knee arthroplasty. A 10-year evaluation. J Arthroplasty 4:293-296

82. Robertsson O, Borgquist L, Knutson K, Lewold S, Lidgren L (1999) Use of unicompartmental instead of tricompartmental prostheses for unicompartmental arthrosis in the knee is a cost-effective alternative. 15,437 primary tricompartmental prostheses were compared with 10,624 primary medial or lateral unicompartmental prostheses. Acta Orthop Scand 70:170-175

83. Rodriguez JA, Bhende H, Ranawat CS (2001) Total condylar knee replacement: a 20year followup study. Clin Orthop Relat Res:10-17

84. Rougraff BT, Heck DA, Gibson AE (1991) A comparison of tricompartmental and unicompartmental arthroplasty for the treatment of gonarthrosis. Clin Orthop Relat Res:157-164

85. Shields RK, Enloe LJ, Evans RE, Smith KB, Steckel SD (1995) Reliability, validity, and responsiveness of functional tests in patients with total joint replacement. Phys Ther 75:169-176; discussion 176-169

86. Shih HN, Shih LY, Wong YC, Hsu RW (2004) Long-term changes of the nonresurfaced patella after total knee arthroplasty. J Bone Joint Surg Am 86-A:935-939

87. Stewart AL, Hays RD, Ware JE, Jr. (1988) The MOS short-form general health survey. Reliability and validity in a patient population. Med Care 26:724-735

88. Stiehl JB (2005) A clinical overview patellofemoral joint and application to total knee arthroplasty. J Biomech 38:209-214

89. Tenholder M, Clarke HD, Scuderi GR (2005) Minimal-incision total knee arthroplasty: the early clinical experience. Clin Orthop Relat Res 440:67-76

90. Terwee CB, Dekker FW, Wiersinga WM, Prummel MF, Bossuyt PM (2003) On assessing responsiveness of health-related quality of life instruments: guidelines for instrument evaluation. Qual Life Res 12:349-362

91. van den Akker-Scheek I (2007) Recovery after short-stay total hip and knee arthroplasty. Evaluation of a support program and outcome determination. Orthopaedic Surgery. Groningen 
92. van den Dikkenberg N, Meijer OG, van der Slikke RM, van Lummel RC, van Dieen JH, Pijls B, Benink RJ, Wuisman PI (2002) Measuring functional abilities of patients with knee problems: rationale and construction of the DynaPort knee test. Knee Surg Sports Traumatol Arthrosc 10:204-212

93. van Saase JL, Vandenbroucke JP, van Romunde LK, Valkenburg HA (1988) Osteoarthritis and obesity in the general population. A relationship calling for an explanation. J Rheumatol 15:1152-1158

94. van Strien T, van der Linden-van der Zwaag E, Kaptein B, van Erkel A, Valstar E, Nelissen $\mathrm{R}$ (2008) Computer assisted versus conventional cemented total knee prostheses alignment accuracy and micromotion of the tibial component. Int Orthop

95. Walker PS (2001) Biomechanics of the patella in total knee replacement. Knee Surg Sports Traumatol Arthrosc 9 Suppl 1:S3-7

96. Walldius B (1957) Arthroplasty of the knee with an endoprosthesis. Acta Chir Scand 113:445-446

97. White SH, Ludkowski PF, Goodfellow JW (1991) Anteromedial osteoarthritis of the knee. J Bone Joint Surg Br 73:582-586

98. www.c-motion.com Visual3D Professional ${ }^{\mathrm{TM}}$ and Visual3D Basic/RT ${ }^{\mathrm{TM}}$

99. Yang KY, Wang MC, Yeo SJ, Lo NN (2003) Minimally invasive unicondylar versus total condylar knee arthroplasty--early results of a matched-pair comparison. Singapore Med J 44:559-562 


\section{ChAPTER 2}

\section{Functional outcome after knee arthroplasty is dependent upon evaluation method employed}

Wouter L.W. van Hemert, Lucas L.A Kleijn, Will G.H. Meyers, Ide C. Heyligers,

Bernd Grimm

Eur J orthop surg traumatol (2009) 19: 415-422 


\section{Abstract}

It is becoming increasingly important to evaluate surgical procedures beyond pain relief and implant survival. Patient satisfaction and objective functional assessment is now as relevant.

The aim of this study was to establish the functional differences and patient perceptions between unicompartmental (UKR) and total knee replacement (TKR).

In a prospective study 52 TKR patients were compared to 24 UKR (at preoperative, 3 months, 6 months and 1 year postoperative). The disease specific KSS and Womac (pain and function subscores), the generic SF36 (pain, function and patient perception subscores) and the Dynaport ${ }^{\circledR}$ Knee Test, a validated performance-based knee test using accelerometers to score function during activities of daily living, was utilized.

Preoperative UKR patients had significantly higher KSS function and the Dynaport ${ }^{\circledR}$ Knee Test $(p<0.05)$, but despite being younger, with different indication, they were not different to TKR with regards to function and pain subscores of Womac and SF36. Regarding preoperative perception, UKR patients reported better physical and social function but subjectively felt worse than TKR patients regarding health, emotion and mental status (n.s.). At one year, postoperative perception scores for both groups increased significantly, with UKR retaining functional lead and UKR patients also felt superior regarding health, emotion and mental status (n.s.). Postoperative recovery regarding KSS, Womac, and SF36-pain was steep only during the first 3 months with near equal values for both TKR and UKR. It was found that SF36-Function recovery was not significant, but UKR also scored higher than TKR. Only functional scores by the Dynaport ${ }^{\circledR}$ Knee Test showed continued improvement and maintained the functional advantage of UKR patients throughout recovery.

UKR and TKR patients have different age demographics, indications and perceptions, but clinical outcome scores do not equally capture these differences, especially with regards to function. Postoperative functional benefits of UKR seem to be due mainly to the superior preoperative conditions. Appreciation of recovery with generic, disease specific and functional measurements appears invaluable. 


\section{INTRODUCTION}

Traditionally, the success of (knee) arthroplasty is reported by studying the longevity of the prosthesis with revision as an end point. However, such a technical success from the surgeon's point of view may not necessarily implicate a similar outcome to the patient's standpoint, so from the patient's perspective the outcome could be deemed a failure. This can be reflected in the method that is utilized to study the outcome, and these can be divided as patient related measurements, joint related parameters, functional tests, disease specific scores and generic scores (Figure 1).

Outcome studies enhance the surgeon's appreciation of the value of joint replacement from the patient's perspective. Patients can provide reliable and valid judgements of health status and the benefits of treatment. The use of patient questionnaires enables the patient to answer standard questions and to score pain (for example) without the interpretation of an assessor and its bias. The functional outcome as measured by performance-based tests can be influenced only marginally by either the doctor or the patient. It therefore can be considered as a valuable addition to existing assessment tools as indicated by Barr et a $\beta^{3}$.

Although many surgeons utilize functional scoring systems such as the American based Knee Society Score (KSS) ${ }^{7}$ to evaluate outcome, it is likely that the criteria for a successful knee arthroplasty differ between the patient and the surgeon. This was evident in a report by Bullens et al. ${ }^{5}$, who concluded that surgeons are more satisfied with the results of total knee arthroplasty than are their patients. In addition to concerns about long-term functional outcome, Trousdale et al..$^{22}$ showed that patients' major concerns were postoperative pain and the time required for recovery. Still there are patients who remain unsatisfied with the results of surgery, despite technical successes. Of patients with a Knee Society Score of $>90$ points after total knee arthroplasty, only 35\% of patients stated that they had no limitations, suggesting a certain unreliability as reported by Konig et $a l^{8}$. This was highlighted in a study by Dickstein et $a l .{ }^{6}$, who found that one-third of the elderly patients who underwent knee replacement were unhappy with the outcome at six and twelve months postoperatively.

It would be expected that outcome measurements of two different procedures with different indications and patient characteristics produce different findings. But clearly the success of a knee replacement procedure can be appreciated in different manners. In this view, it is of interest to highlight the acclaimed differences between unicompartmental and total knee replacement using both subjective and objective tools. 

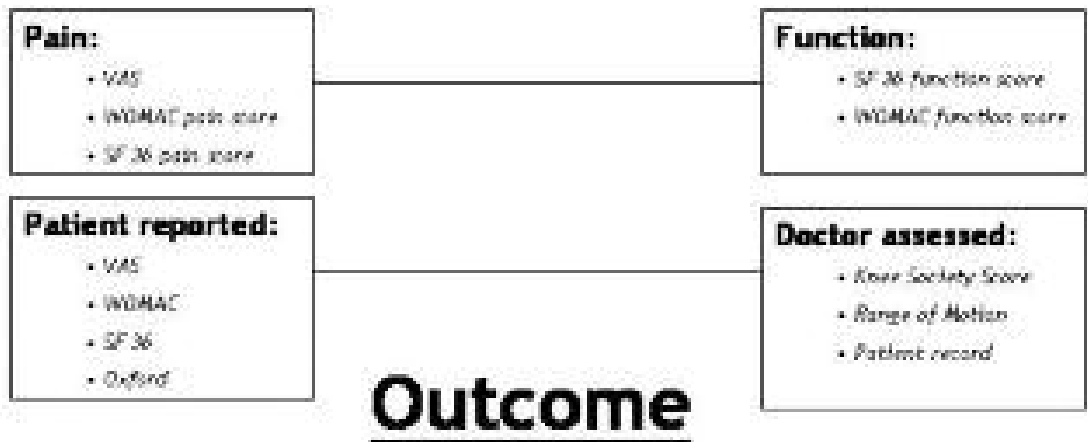

\section{Outcome}

\section{Generic scare:}

- 353 mmost hearoh

- SF 36 Socio! foretiwing
Disease specific:

- vochatseiforas

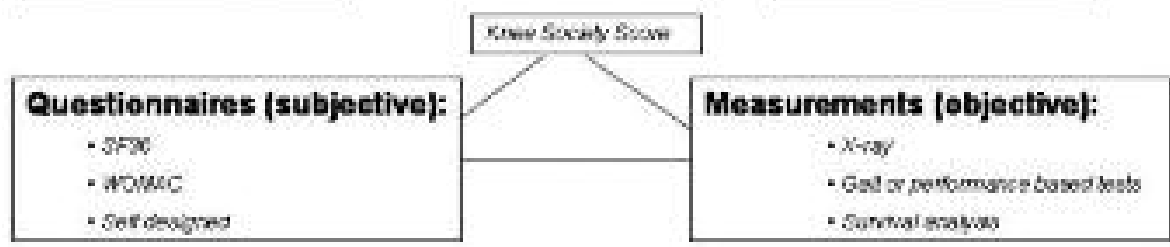

Figure 1: Outcome measurements

A limited number of studies in the literature have addressed the clinical outcome and recovery of unicompartmental and total knee replacement in a comparison ${ }^{10,16,20,25}$. Newman et al. ${ }^{16}$ presented a randomized study comparing unicompartmental replacement to total knee replacement, showing a greater range of motion following unicompartmental replacement. Weale et al. ${ }^{25}$ suggested a superior result in rehabilitation and cost, beneficial to unicompartmental knee replacement. This difference was not shown to be statistically significant however. Weale et al. ${ }^{25}$ report on superior functional recovery after unicompartmental knee replacement over total knee replacement. Kort $^{9}$ describes superior recovery and knee function, beneficial to unicompartmental knee replacement.

It was the goal of this study to assess surgical outcome on two different knee arthroplasty procedures and investigate if claimed outcome differences between patient and procedure can be measured using various assessment tools. It is hypothesized that outcome of knee arthroplasty is dependent upon the evaluation method employed. 


\section{MATERIALS AND METHODS}

For this study a retrospective analysis of a prospective studied cohort of 52 total knee replacements, Anatomic Graduated Component (AGC) (Biomet, Dordrecht, The Netherlands), and 24 meniscal bearing unicompartmental replacements, Oxford Knee (Biomet, Dordrecht, The Netherlands) was performed. Of both total knee replacement as well as unicompartmental knee replacement long term follow up is well established ${ }^{18,27}$. Standard time points for measurements were set on preoperative and on 3, 6 and 12 months postoperative and data were acquired in a prospective design. Preoperative measurements were acquired within two weeks prior to surgery. Post operative rehabilitation program was equal for both groups and was followed outpatient in most cases. All operations were performed by the senior author (WM) or under his supervision.

\section{Indications for Total Knee Replacement}

All patients with bicompartmental or tricompartmental osteoarthritis of the knee received total knee replacement. All procedures were performed through a medial parapatellar approach. The monoblock tibial component was used in a cruciate retaining version and patella resurfacing was performed in all cases after routine denervation with cautery and removal of osteophytes.

\section{Indications for Unicompartmental Replacement}

Patients with medial osteoarthritis of the knee were offered unicompartmental replacement and were younger of age than has been reported previously ${ }^{18}$. In all patients, the varus deformity was passively correctable to neutral. The anterior cruciate ligament was observed to be intact intraoperatively and the cartilage of the lateral compartment was considered normal for this age group. The surgical procedure was performed according to the Oxford unicompartmental knee replacement guidelines.

\section{Outcome parameters}

The patient demographics of age, sex and Body Mass Index (BMI) were recorded.

Clinical outcome after knee replacement was assessed by the clinician-based American Knee Society Score (KSS). The disease specific Western Ontario and McMaster Universities Index for Osteoarthritis (WOMAC) ${ }^{4}$, consisting of subscores pain, function and stiffness, and the generic quality-of-life Short Form 36 (SF 36), which contains subscores of pain, function and satisfaction, were used as selfreported questionnaires. Both were in a validated Dutch-translated version ${ }^{1,19}$ and 
answers were in a 5-point Likert-scale. The scores of WOMAC were transformed into a 100 point scale (highest is best) as frequently used in literature.

In addition to these classic assessment methods, the Dynaport ${ }^{\circledR}$ Knee Test, an accelerometer based system with small movement sensors that are fixed to the patient, was used as a performance based knee test. It assesses functional abilities objectively in a standardized set of tasks, closely related to activities of daily living (ADL). An algorithm programmed by the manufacturer was used to calculate one Dynaport ${ }^{\circledR}$ Knee Score that ranges from 0 to 100 (best). The rationale of the system has been explained ${ }^{24,26}$ and the reliability and construct validity was studied ${ }^{14,15}$.

Improvement was calculated between two time points of each score. Period A was set between preoperative and 3 months, and Period B was between 3 and 6 months. Period C was set between 6 and 12 months, whereas period D was considered the improvement between preoperative and one year (Figure 2).

Figure 2: division of time periods

Statistical analysis

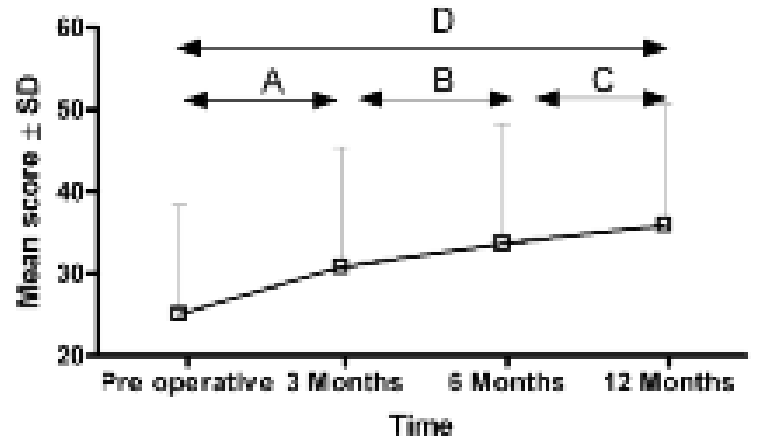

Data analysis was performed using Statistical Package for the Social Science (SPSS) 12.0 (Chicago, Illinois, USA). Reported values are mean \pm standard deviation (SD). For each time period the differences in means of improvement of all scores were analyzed with a two-sided Student's t-test in the event of normal data distribution, otherwise a Mann-Whitney test was used for comparison.

Differences in the WOMAC and SF 36 scores among measured time points in each patient group were compared using repeated measures ANOVA. Posthoc comparisons were checked using the Tukey-Kramer Multiple Comparisons Test. Maxwell and Delaney explained that for proper use of repeated measures analysis of variance (ANOVA), the number of observations should be larger than $n+10$, where $n$ is the number of level of repeated measures. This study was comprised over three scenarios and there were 24 patients in the smallest 
group. When employing t-tests and the sample size is between 16 and 40, a tdistribution can be applied if the sampling distribution is moderately skewed, unimodal, without outliers, which was the case in this study. Therefore the validity and applicability of the used tests were considered acceptable ${ }^{13}$. Level of significance was set at $\mathrm{p}<0.05$.

\section{Results}

The patients in the unicompartmental knee replacement group were significantly younger and the majority of the patients were female in both groups (Table 1). BMI was higher in the total knee group, but not significantly so (Table 1).

Preoperatively, the KSS was better for the unicompartmental knee replacement than for the total knee replacement (Figure 3a) and pain and function scores of Womac (Figure 3c and 3e) and SF36 (Figure 3d and 3f) are similar. The total knee replacement group was slightly better in SF36 health, emotion and mental health, whereas the unicompartmental knee replacement was better in physical and social functioning. These differences did not reach significant levels (Student t-test, $p$ values ranging from 0.343 to 0.935 ). The Dynaport ${ }^{\circledR}$ Knee Test was significantly higher preoperatively in the unicompartmental knee replacement group (Figure 3b).

Comparing the steepness of KSS improvement between both groups postoperatively it revealed no significant difference during the one year follow up (Mann-Whitney test, $\mathrm{p}$ value ranging from 0.159 to 0.289 ). Only period C (6-12 months) showed a decrease in the KSS for unicompartmental knee replacement, while the total knee replacement group continued to improve resulting in a significant difference in recovery rate between both groups (Mann-Whitney test, $\mathrm{p}=0.04)$.

\begin{tabular}{lccc} 
& TKR $( \pm$ SD $)$ & UKR $( \pm$ SD $)$ & P value \\
\hline Age & $70.6(8.6)$ & $61.5(8.4)$ & $0.001^{*}$ \\
BMI & $30.0(5.3)$ & $28.6(4.6)$ & 0.232 \\
\hline
\end{tabular}

The mark ${ }^{\prime * \prime}$ is significant

Table 1: Mean age and body mass index of patients after total knee replacement (TKR) and unicompartmental knee replacement (UKR) 
Figure 3a: Knee Bockly Bcore

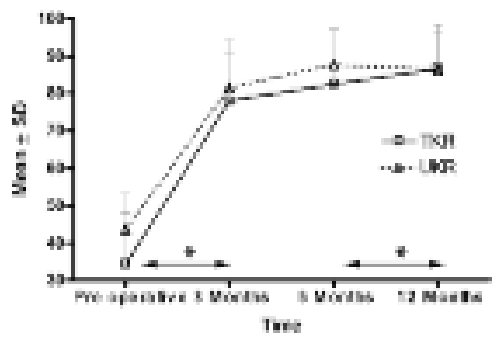

Figure 3c. WCMAC Function Beore

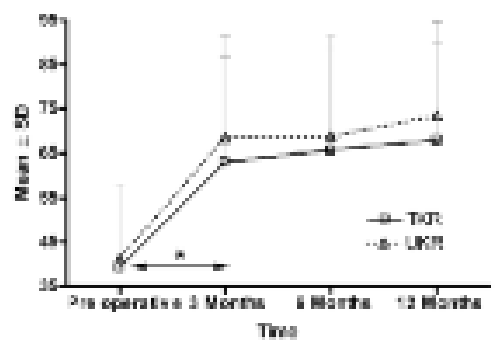

Figure 3s: WOMAC Pain 8eare

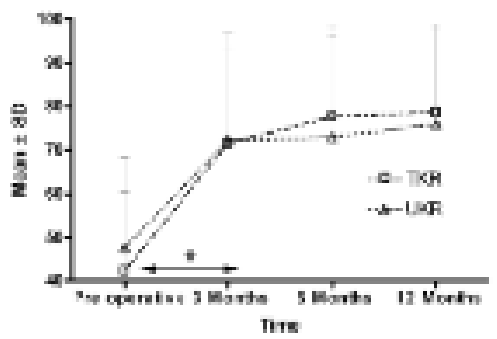

Figure Jb: Dyrapart \% Kraes Scura

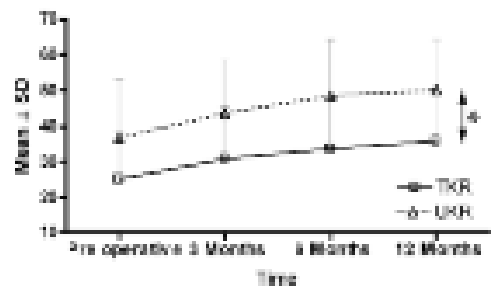

Figure 3d. SF 36 Function 8core

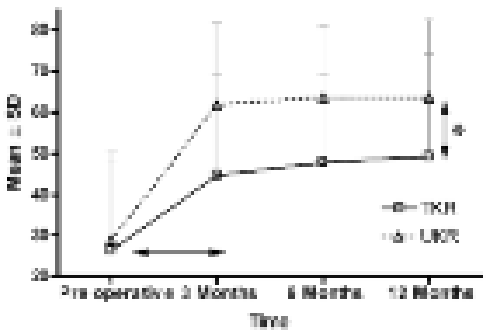

Figure 3f: SF 36 Pain Seare

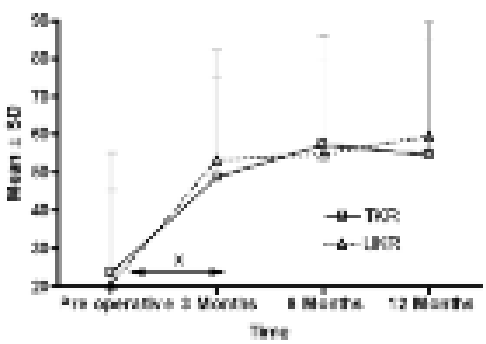

Figure 3: Function and pain scores of total knee replacement (TKR ) (Solid Line) and unicompartmental knee replacement (UKR) (Dashed Line). Significant differences are marked Asterisk 
The WOMAC pain and function scores (Figure $3 c$ and $3 e$ ) were not significantly different during follow up (Student t-test, $p$ values ranging from 0.328 to 0.872 ). Both the unicompartmental knee replacement group and the total knee group showed a significant improvement in the WOMAC scores up to three months postoperative (Repeated measures ANOVA, $\mathrm{p}$ values ranging from 0.035 to 0.047), but ceased to improve thereafter (Repeated measures ANOVA, $p>0.05$ ). The comparison between groups in WOMAC stiffness, WOMAC pain score and WOMAC functioning revealed no significant differences at all time periods post operative (Student t-test, $\mathrm{p}$ values ranging from 0.075 to 0.982 ).

SF 36 (Figure 3d) showed a similar function score preoperatively (Student ttest, $p=0.675$ ). The comparison between groups in steepness of improvement was in favour of the unicompartmental knee replacement, mainly due to period $\mathrm{A}$ (Student t-test, $\mathrm{p}=0.040$, significant improvement) and Period C (Student T-test, $\mathrm{p}$ $=0.069$ ). However, the SF 36 pain score (Figure 3e and 3f) showed no significant difference during follow up (Student t-test, $p$ value ranging from 0.540 to 0.794 ).

Regarding the SF 36 perception scores (Figure 4), both groups reported improvement between preoperative and one year. The subscore emotion was statistically significant (Repeated measures ANOVA, $p=0.041$ ), whereas physical functioning, social functioning, health, mental health, improved at nonsignificant levels (Repeated measures ANOVA $p>0.05$ ). In all postoperative perception measures the patients after unilateral knee replacement scored higher than those after total knee replacement although their preoperative values for general health, mental health and emotion were lower (Student t-test, $p>0.05$ ).

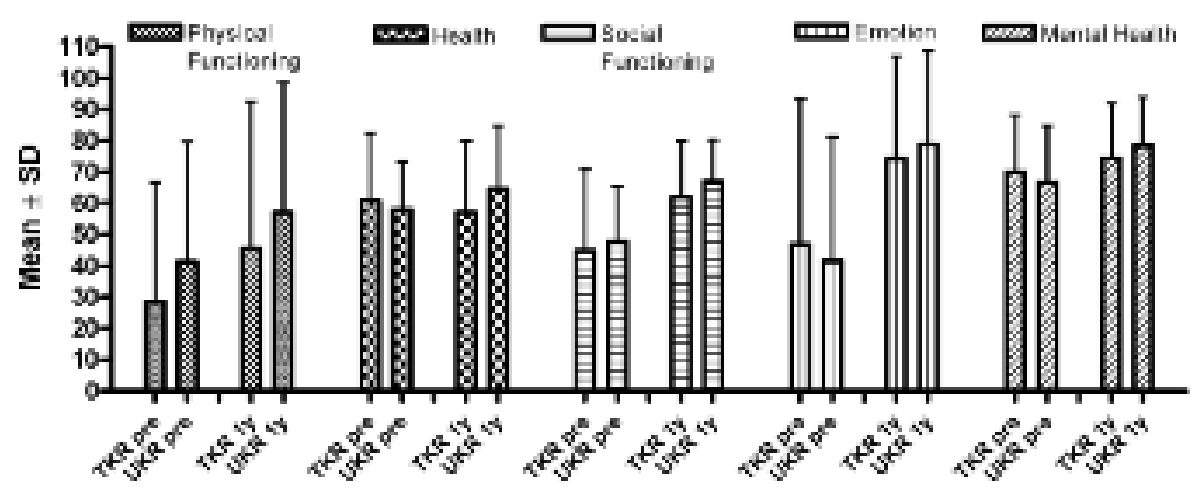

Figure: 4 Patient perceptions 
Regarding the performance-based functional measurements with the Dynaport ${ }^{\circledR}$ Knee Test, the preoperative functional advantage of patients, indicated for unilateral knee replacement, remained during recovery as both groups improved at equal rates (Student t-test, $p$ values ranging from 0.195 to 0.979 ). While other scores levelled off at 3 months or 6 months, the Dynaport ${ }^{\circledR}$ Knee score in period C improved.

\section{Discussion}

This paper is addresses the recovery after unicompartmental knee replacement in relation to total knee replacement and uses both a knee score, self reported questionnaires and a performance based knee test. It is recognized that both surgical procedures are conducted based on different preoperative indications. However, similar efforts were found in the literature $e^{10,20,25,28}$. As it has been established unicompartmental knee replacement has become a solution in itself ${ }^{9}$ and not merely a delay for total knee replacement, a true comparison would involve only patients with medial knee involvement. However, when the surgical recovery profiles, and the methodology of outcome measurements, rather than the indications of both procedures are compared, the results are worth discussing.

Based upon the measurements that assess function, patients preoperatively indicated for unicompartmental knee replacement objectively perform better than total knee replacement prior to surgery. Since unicompartmental knee replacement is performed in patients with less extensive arthritis and at a younger age, it could be expected that the unicompartmental knee replacement group would have better preoperative functional status than the total knee arthroplasty group.

This was true in the present study, where it was found that all functionrelated measurements with objective elements (KSS, The Dynaport ${ }^{\circledR}$ Knee Test) were in favour of unicompartmental knee replacement, although preoperative differences in subjective function scores of WOMAC and SF 36 questionnaires were not significant. Therefore the magnitude of difference is dependent upon the used evaluation method employed.

However, using the KSS, the unicompartmental knee replacement and total knee replacement level out at the same point. Obviously, a patient that starts with a lower value has a larger range for improvement. The fact that both groups level out after surgery indicates that the KSS does not appear to be responsive enough to detect further differences. This can be illustrated by the maximum value for knee flexion in the KSS, which is set on 120 degrees, whereas patients 
after unicompartmental knee replacement are in most cases able to reach beyond this ceiling.

In contrast the Dynaport ${ }^{\circledR}$ Knee Test shows a difference between unicompartmental knee replacement and total knee replacement preoperatively and continues to show this difference throughout the postoperative improvement process. It indicates that this test is more responsive to changes due to surgery. Therefore higher preoperative starting values and thus the related joint and patient condition, rather than the type of prosthesis can be considered responsible for a better performance.

A close study of the functional results, postoperatively, was expected to show a more rapid recovery of the unicompartmental group. However, the improvements between both groups in the studied time periods were not significantly different. Since unicompartmental knee replacement is performed less invasive it could be expected that these patients would show a higher magnitude of functional recovery due to better soft tissue condition such as preserved quadriceps muscles.

Comparing functional recovery between groups using the WOMAC and SF36 function score pre-operative values were almost equal with both assessment tools. A much steeper improvement up to 3 months was measured with SF36 function in favour of the unicompartmental knee replacement. This resulted in a functional benefit for unicompartmental knee replacement in comparison to total knee replacement that WOMAC did not capture.

In direct contrast, Parent and Moffet ${ }^{17}$ found, using a methodological comparison, that SF 36 was least responsive between pre operative and 3 months. WOMAC proved to be the most responsive outcome. Angst et a ${ }^{2}$ also confirmed that functional improvement was better detected by WOMAC over SF36. The value of SF36 in this report may not reflect true functional gain, and WOMAC is still the more trustworthy test, indicating that improvement is essentially similar. It appears that the more reliable test produces a similarity in results where a difference was hypothesized and the less responsive test result in the acclaimed difference. It is worth noting that the questions in WOMAC which cover the functional aspects appear to have a larger array than SF36. WOMAC is a disease specific questionnaire, whereas SF36 is regarded as more generic. This would indicate that WOMAC should have picked up changes, if any, but may not be responsive enough and functional differences exists. As Sodermann and Malchau ${ }^{21}$ demonstrated high validity and reproducibility of WOMAC, it clearly provokes uncertainties as to which score is superior, and it indicates that using only one score may not reflect true outcome. 
Given the indication and age demographics in the two patient groups, it is remarkable that expected and objective functional differences are only marginally reflected in the result of the patient questionnaires. The differences in assessing knee function both before and after surgery show that knee function can be reflected differently. This is especially important for the physician in the evaluation of a procedure and it should be considered in the design of a study.

The perceptions of studied patients showed that those preoperatively indicated for unicompartmental knee replacement, with less advanced stage of arthritis and objective function at a higher level, show that they consider themselves better in both physical and social functioning, but scored lower in health, mental health and emotion compared to those indicated for total knee replacement. Thus a less advanced condition could result in more mental deprivation, probably because they still aim for higher activity levels and they are not yet as adapted as those patients in more advanced stages. Postoperatively, patients after unicompartmental knee replacement objectively have not functionally improved in comparison to those having undergone total knee replacement, while they do report so regarding SF 36 function score. Furthermore, they report higher scores in health, mental health and emotion as well as social and physical functioning was better than in the total knee replacement group. Expectations after total knee replacement are likely to be lowered as age increases and the level of activity, although it has been reported these patients are still unhappy with the result of the surgery ${ }^{6}$. Younger patients and those with less advanced stages of arthritis may therefore subjectively benefit more from surgery than objectively can be detected.

Marx et $a^{12}$ have recently demonstrated that WOMAC and SF 36 are responsive and therefore these self-report measures can be considered to likely reflect the patients' perception after total joint surgery. Maly et $\mathrm{al}^{11}$ indicated that self-report measures are strongly related to pain, whereas physical performance measures are strongly related to self-efficacy. The patient has primary concerns in terms of pain relief and longevity of rehabilitation ${ }^{22}$. Both the improvement in WOMAC and SF36 pain scores in this study were comparable between both groups. This indicates that patients tend to report rather their pain relief and its forthcoming satisfaction in preference to the gain of function. However, looking at the results at the measured time points, SF36 pain score favours unicompartmental knee replacement in contrast to WOMAC pain score, which favours the opposite. It can be discussed whether this difference is the influence of the specific questions in SF36 compared to WOMAC, or that the patients reflect their pain differently with the two questionnaires. In this view, where the 
unicompartmental group is significantly better in objective measurements, it confirms that patients report their pain relief rather than functional gain and it shows that both surgical procedures provide adequate and similar pain relief.

It would be of interest to investigate cases with medial osteoarthritis of the knee receiving both unicompartmental knee replacement and total knee replacement. Only then it can be stated that the treated condition rather than the type of prosthesis is the reason for better performance. However in our opinion it is virtually impossible to perform such in a randomised trial. Random allocation of patients with different indications for surgery and meet different criteria seems rather unethical. When this is pursued a power analysis is necessary, but in this study we have not done so. Therefore the significances could be an item of discussion and subject to a type II error due to potential low power. However, since methods instead of population are compared, we feel this is less of an issue.

Considering the acknowledged differences, this paper was set up to document the expected functional and perceptional differences between unicompartmental and total knee replacement. In this view it can be concluded that patients after unicompartmental knee replacement using performancebased tests are functionally better objectively, which is likely to be due to the favourable preoperative situation.

However, both patient groups show that the objective functional difference are not reflected in the employed questionnaires relating to function, patient perception and the development of postoperative improvement. Knee replacement is appreciated differently by the treating surgeon (KSS), the patient (WOMAC and SF36) and any objective tests (Dynaport). This study raises the impression that patients with different indications show remarkable similarities. It can be concluded that different outcome measurements produce different results, suggesting different capabilities of the tests. In agreement with van den Akker-Scheek et a ${ }^{23}$ it is recommend to utilise generic, disease-specific and performance-based measurements to fully appreciate recovery after knee replacement.

\section{Acknowledgement}

The authors like to thank Mr. Glenn Ward, PhD, for editorial comments on the manuscript.

\section{Disclosure}

All authors have not received and will not receive neither accept any benefit from any third party or industry directly or indirectly related to the outcome of this study. 
Chapter 2 


\section{Outcome dependent upon measurement employed}

\section{LITERATURE}

1. Aaronson NK, Muller M, Cohen PD, Essink-Bot ML, Fekkes M, Sanderman R, Sprangers MA, te Velde A, Verrips E (1998) Translation, validation, and norming of the Dutch language version of the SF-36 Health Survey in community and chronic disease populations. J Clin Epidemiol 51:1055-1068

2. Angst F, Aeschlimann A, Steiner W, Stucki G (2001) Responsiveness of the WOMAC osteoarthritis index as compared with the SF-36 in patients with osteoarthritis of the legs undergoing a comprehensive rehabilitation intervention. Ann Rheum Dis 60:834-840

3. Barr S, Bellamy N, Buchanan WW, Chalmers A, Ford PM, Kean WF, Kraag GR, GereczSimon E, Campbell J (1994) A comparative study of signal versus aggregate methods of outcome measurement based on the WOMAC Osteoarthritis Index. Western Ontario and McMaster Universities Osteoarthritis Index. J Rheumatol 21:2106-2112

4. Bellamy N, Buchanan WW, Goldsmith CH, Campbell J, Stitt LW (1988) Validation study of WOMAC: a health status instrument for measuring clinically important patient relevant outcomes to antirheumatic drug therapy in patients with osteoarthritis of the hip or knee. J Rheumatol 15:1833-1840

5. Bullens PH, van Loon CJ, de Waal Malefijt MC, Laan RF, Veth RP (2001) Patient satisfaction after total knee arthroplasty: a comparison between subjective and objective outcome assessments. J Arthroplasty 16:740-747

6. Dickstein R, Heffes Y, Shabtai El, Markowitz E (1998) Total knee arthroplasty in the elderly: patients' self-appraisal 6 and 12 months postoperatively. Gerontology 44:204-210

7. Insall JN, Dorr LD, Scott RD, Scott WN (1989) Rationale of the Knee Society clinical rating system. Clin Orthop Relat Res:13-14

8. Konig A, Scheidler M, Rader C, Eulert J (1997) The need for a dual rating system in total knee arthroplasty. Clin Orthop Relat Res:161-167

9. Kort N (2007) Unicompartmental Knee Arthroplasty. In, Groningen

10. Laurencin CT, Zelicof SB, Scott RD, Ewald FC (1991) Unicompartmental versus total knee arthroplasty in the same patient. A comparative study. Clin Orthop Relat Res:151-156

11. Maly MR, Costigan PA, Olney SJ (2006) Determinants of self-report outcome measures in people with knee osteoarthritis. Arch Phys Med Rehabil 87:96-104

12. Marx RG, Jones EC, Atwan NC, Closkey RF, Salvati EA, Sculco TP (2005) Measuring improvement following total hip and knee arthroplasty using patient-based measures of outcome. J Bone Joint Surg Am 87:1999-2005

13. Maxwell S, Delaney H (2003) Designing Experiments and Analyzing Data: A Model Comparison Perspective, Second Edition. Lawrence Erlbaum 


\section{Chapter 2}

14. Mokkink LB, Terwee CB, van der Slikke RM, van Lummel RC, Benink RJ, Bouter LM, de Vet HC (2005) Reproducibility and validity of the DynaPort KneeTest. Arthritis Rheum 53:357-363

15. Mokkink LB, Terwee CB, van Lummel RC, de Witte SJ, Wetzels L, Bouter LM, de Vet HC (2005) Construct validity of the DynaPort KneeTest: a comparison with observations of physical therapists. Osteoarthritis Cartilage 13:738-743

16. Newman JH, Ackroyd CE, Shah NA (1998) Unicompartmental or total knee replacement? Five-year results of a prospective, randomised trial of 102 osteoarthritic knees with unicompartmental arthritis. J Bone Joint Surg Br 80:862-865

17. Parent E, Moffet H (2002) Comparative responsiveness of locomotor tests and questionnaires used to follow early recovery after total knee arthroplasty. Arch Phys Med Rehabil 83:70-80

18. Price AJ, Waite JC, Svard U (2005) Long-term clinical results of the medial Oxford unicompartmental knee arthroplasty. Clin Orthop Relat Res:171-180

19. Roorda LD, Jones CA, Waltz M, Lankhorst GJ, Bouter LM, van der Eijken JW, Willems WJ, Heyligers IC, Voaklander DC, Kelly KD, Suarez-Almazor ME (2004) Satisfactory cross cultural equivalence of the Dutch WOMAC in patients with hip osteoarthritis waiting for arthroplasty. Ann Rheum Dis 63:36-42

20. Rougraff BT, Heck DA, Gibson AE (1991) A comparison of tricompartmental and unicom-partmental arthroplasty for the treatment of gonarthrosis. Clin Orthop Relat Res:157-164

21. Soderman P, Malchau H (2000) Validity and reliability of Swedish WOMAC osteoarthritis index: a self-administered disease-specific questionnaire (WOMAC) versus generic instruments (SF-36 and NHP). Acta Orthop Scand 71:39-46

22. Trousdale RT, McGrory BJ, Berry DJ, Becker MW, Harmsen WS (1999) Patients' concerns prior to undergoing total hip and total knee arthroplasty. Mayo Clin Proc 74:978-982

23. van den Akker-Scheek I (2007) Recovery after short-stay total hip and knee arthroplasty. Evaluation of a support program and outcome determination. In: Orthopaedic Surgery. Groningen

24. van den Dikkenberg N, Meijer OG, van der Slikke RM, van Lummel RC, van Dieen JH, Pijls B, Benink RJ, Wuisman PI (2002) Measuring functional abilities of patients with knee problems: rationale and construction of the DynaPort knee test. Knee Surg Sports Traumatol Arthrosc 10:204-212

25. Weale AE, Halabi OA, Jones PW, White SH (2001) Perceptions of outcomes after unicompartmental and total knee replacements. Clin Orthop Relat Res:143-153 


\section{Outcome dependent upon measurement employed}

26. Witvrouw E, Victor J, Bellemans J, Rock B, Van Lummel R, Van Der Slikke R, Verdonk R (2002) A correlation study of objective functionality and WOMAC in total knee arthroplasty. Knee Surg Sports Traumatol Arthrosc 10:347-351

27. Worland RL, Johnson GV, Alemparte J, Jessup DE, Keenan J, Norambuena N (2002) Ten to fourteen year survival and functional analysis of the AGC total knee replacement system. Knee 9:133-137

28. Yang KY, Wang MC, Yeo SJ, Lo NN (2003) Minimally invasive unicondylar versus total condylar knee arthroplasty--early results of a matched-pair comparison. Singapore Med J 44:559-562 


\section{ChaPTer 3}

Tricalcium phosphate granules or rigid wedge preforms in open wedge high tibial osteotomy:

\section{a radiological study with a new evaluation system}

Wouter L.W. van Hemert, Karel Willems, Patricia. G. Anderson, Ronald J. van Heerwaarden, Ate B. Wymenga

Knee. 2004 Dec;11(6):451-6 


\section{Abstract}

The capacity of two forms of porous beta-tricalcium phosphate bone substitutes (TCP) to promote bone healing in open wedge high tibial osteotomy (OWHTO) was studied. We reviewed the X-rays of 27 osteotomies, with either TCP-wedges or TCP-granules as filling material, to compare the bone healing rates and bone remodelling, at specific postoperative intervals. A new radiologic rating system for OWHTO was created and tested for clinical applicability. All osteotomies healed uneventfully and complete resorption of TCP was demonstrated at 1 year postoperative in $85 \%(n=23)$ of the procedures. In $44 \%(n=10)$ of these 23 procedures, the osteotomy site was no longer visible. No difference in bone healing rate and bone remodelling was found when comparing the use of granules to a wedge, and no adverse effects of TCP were observed. The good interobserver $(k=0.7)$ and intraobserver $(k=0.6)$ reliability of the new radiologic rating system enables clinical use.

Good bone healing was found in OWHTO with both wedges and granules of TCP. 


\section{INTRODUCTION}

Patients with medial compartment osteoarthritis and a varus leg axis can be successfully treated with a valgus high tibial osteotomy ${ }^{4,10}$. In recent years, the medial opening wedge technique has been favoured over the lateral closing wedge osteotomy to avoid co-morbidity associated with the fibular osteotomy from the latter procedure ${ }^{8}$. In the open wedge high tibial osteotomy (OWHTO), a medially based gap is created in the tibial metaphysis that many surgeons prefer to fill with bone or ceramic materials. Various arguments have been used such as decrease of local blood loss, increase of mechanical stability, or increase of bone healing.

The introduced filling material may cause specific changes in bone healing and bone remodelling. Fracture treatment of proximal tibial fractures has provided insight into bone healing ${ }^{7,16}$ and radiological phases of bone remodelling in the proximal tibia ${ }^{22}$. Bone healing in open wedge osteotomies differs from that in fractures because of the bone distraction in the opened wedge and introduced filling materials. Therefore a specific radiographic rating system is needed. As yet, no radiologic rating system to monitor bone healing in OWHTO is available.

Autologous bone is often used to fill bone defects. These graft materials however have become less popular due to co-morbidity at the donor site, increase of operation time and risks of disease transmission ${ }^{6,8,20}$. Hence, bone substitutes, e.g. acrylic bone cement ${ }^{9}$, hydroxyapatite ${ }^{11}$ and tricalciumphosphate ${ }^{18}$, have become more popular. In OWHTO these bone substitutes are used by surgeons who assume that they enhance initial mechanical stability and that they shorten bone-healing time, which enables early full weight bearing. This thereby shortens the time until fixation material removal.
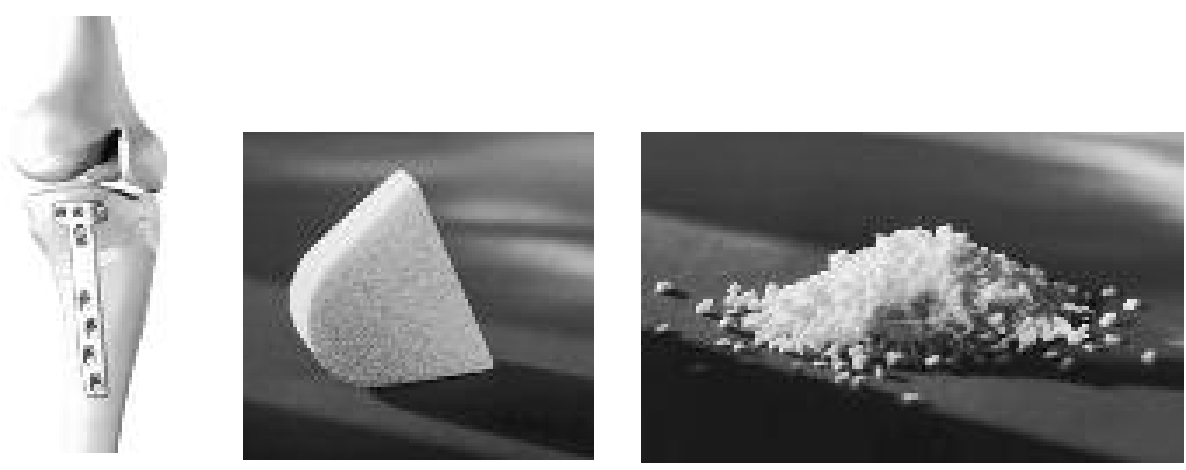

Figure 1. OWHTO with Tomofix ${ }^{\mathrm{TM}}$ (left), chronOS ${ }^{\mathrm{T} м}$ wedge (middle) and granules (right) 
Porous beta-tricalciumphosphate (TCP), when used as a bone substitute in orthopaedic surgery, has been shown to be osteoconductive and resorbable ${ }^{21}$. TCP granules and TCP wedges are available to fill the OWHTO bone gap (Figure 1). The granules cover a large area of cancellous bone in the open wedge gap and provide a loose matrix for bone ingrowth. The bone wedges might add some mechanical stability but cover only part of the bone gap. However by closing the wedge, they may prevent haematoma leakage, a mechanism proposed to enhance bone healing. Furthermore, bone ingrowth into the open porous, but densely structured wedges may be more difficult. Therefore, it remains uncertain whether bone healing and bone remodelling will be retarded if a rigid TCP wedge is used as OWHTO filling material instead of loose TCP granules.

The objective of this study was to compare bone healing and bone remodelling in OWHTO patients with bone gaps filled with TCP granules to that of patients treated with TCP wedges as well as to assess the clinical use of TCP in OWHTO. To monitor fracture healing a new radiological rating system was designed and tested for interobserver and intraobserver reliability to verify its clinical applicability.

\section{Patients AND methods}

The X-rays of 27 patients who underwent an open wedge high tibial osteotomy for medial osteoarthritis of the knee between January 2000 and May 2001 were reviewed. In all cases the open wedge gap was filled with TCP preforms (chronOS ${ }^{\mathrm{TM}}$ - Synthes): in 16 patients in granular form and in 11 patients with rigid wedges. The mean age at surgery was 43 years (SD of the mean 10.5). None of the patients suffered from diseases disturbing bone healing and only three patients were regular tobacco smokers at the time of operation.

All OWHTO's were performed by one surgeon (AW) using a medial plate fixation (TomoFix ${ }^{\mathrm{TM}}$ - Synthes) to stabilize the osteotomy. Pre-operative varus alignment ranged from 4 to 11 degrees and correction of leg axis was aimed at $3^{\circ}$ valgus in all patients. Immediately before plate fixation the opened wedge gap was filled with TCP. Both the granules and the rigid wedges were impregnated with patient's own blood before insertion. The surgeon was asked which of the two types of TCP was easier to handle during surgery. The postoperative rehabilitation protocol consisted of $10-15 \mathrm{~kg}$ weight bearing for 6 weeks after which full weight bearing was allowed as tolerated.

Conventional AP and lateral X-rays were acquired immediately after surgery 


\begin{tabular}{|c|c|c|c|}
\hline & Phase in article & McKibbin & Explanation \\
\hline 0 & Direct postoperative & Inflammation & Haematoma \\
\hline 1 & Vascular phase & Soft callus & $\begin{array}{l}\text { Osteopenic bone, rounded osteotomy sites, clear } \\
\text { distinction between TCP and bone }\end{array}$ \\
\hline 2 & Calcification phase & Soft and Hard callus & $\begin{array}{l}\text { Whitening of sites and blurred distinction between TCP } \\
\text { and bone }\end{array}$ \\
\hline 3 & Osteoblastic phase & Hard callus, remodelling & $\begin{array}{l}\text { Distinction between TCP and bone slightly visible, though } \\
\text { healed osteotomy }\end{array}$ \\
\hline 4 & Consolidation phase & Hard callus and remodelling & Full reformation, though osteotomy recognizable, no TCP \\
\hline 5 & Full reformation & Remodelling & No sign of osteotomy \\
\hline
\end{tabular}

Table 1: Phases of remodelling

and at 6 weeks, 3, 6, and 12 months, postoperatively. For each radiograph the bone remodelling phase was determined independently by two investigators using the new rating system (Table 1). Bone union was defined as grade 4 or above. Complete reformation is defined as the diminishing of the osteotomy gap with the full resorption of the TCP. The time to full remodelling was noted. A Chi-square analysis was used to evaluate differences in bone healing between the two different types of TCP implants at the various time intervals. Alpha was set at 0.05.

\section{Tricalciumphosphate}

Tricalciumphosphate (chronOSTM - Synthes, Switzerland) is a synthetic and phase pure porous beta-tricalciumphosphate ceramic. ß-TCP is resorbed in vivo by osteoclasts ${ }^{13}$. Its interconnecting pore structure with $70 \%$ total open porosity and a pore size ranging from $100-500 \mu \mathrm{m}$ is in a range which allows vascularisation ${ }^{15}$ and bone ingrowth ${ }^{3}$. The smaller pores in the range of 1-10 $\mu \mathrm{m}$ are more suitable for fluid flow and diffusion to improve the metabolic environment ${ }^{22}$.

\section{The radiologic rating system}

The rating system to monitor bone healing was modified from an existing fracture healing system described by McKibbin ${ }^{11}$. It consists of five stages (Table 1). The vascular phase typically has osteopenic bone and sharpened to rounded osteotomy sites, and with the bone filler used in this study the TCP can be easily differentiated from the bone (Figure 2). In the calcification phase callus formation and calcium deposition causes whitening of the edges of the osteotomy and the edges of the filling material become blurred as a first sign of resorption. Typical for the osteoblastic phase is the cloudy bone formation 


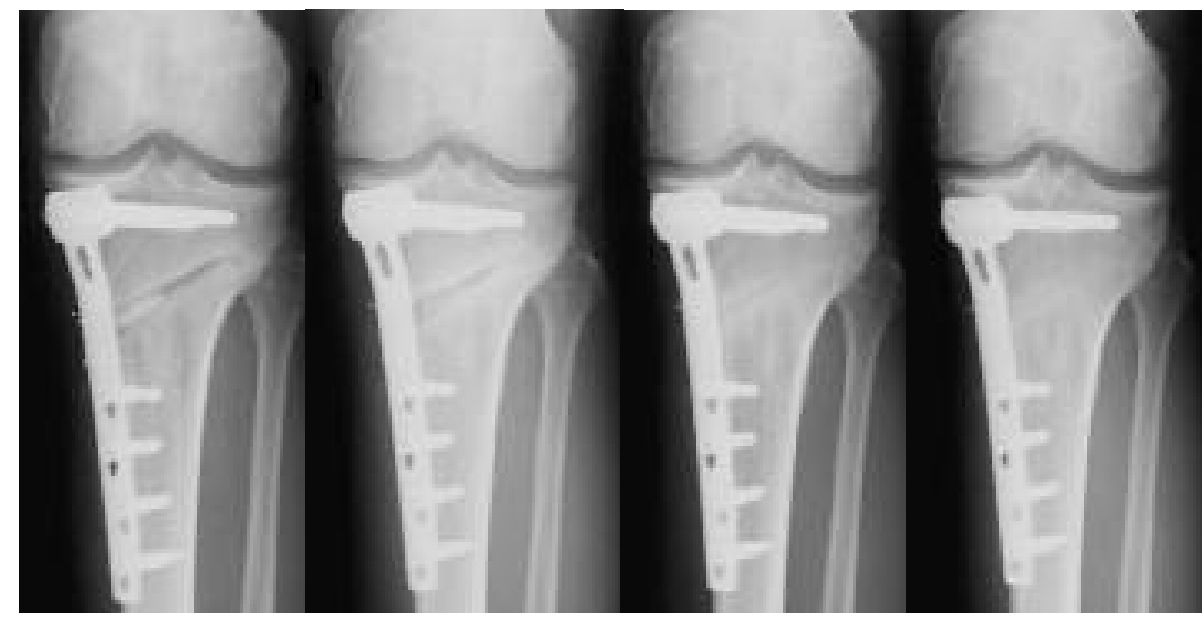

Figure 2: Radiologic follow-up of OWHTO with TCP at 6 weeks, 3, 6 and 12 months intervals.

above the whitened osteotomysites and the decrease of visibility of the TCP. In the consolidation phase the bone is healed; however, the osteotomy site is still recognizable as the TCP filling material has not yet full been resorbed. Full reformation is reached when the filling material is not visible anymore and the osteotomy is hardly visible as a sign of radiological full resorption.

\section{Reproducibility of the radiologic rating system}

The radiographs were classified by two investigators ( $\mathrm{WH}$ and $\mathrm{KW}$ ) at three different times. The first round was used to practice with the new rating system. During this round the sequence of the radiographs was known to the investigators. The second round was performed one month later and at that time each investigator was blinded to the patient's name as well as to the sequence of the radiographs. The same protocol was used for the third round which was held two weeks later. These scores for each radiograph provided the basis for inter- and intraobserver reliability. Interobserver reliability was determined for each follow-up interval of every patient as well as the agreement whether in a follow-up sequence the next radiograph showed a similar bone healing phase or advancement when compared to the previous.

Interobserver variability as well as the intraobserver variability during the first, second and third round was determined using Cohen's kappa. Interpretation of these values was according to the guidelines described by Landis and $\mathrm{Koch}^{12}$ : A Kappa value between 0.21 and 0.4 corresponds to a fair agreement.A value 
between 0.41 and 0.6 represents moderate agreement and values between 0.61 and 0.8 indicate substantial agreement. A value above 0.81 is considered to be almost perfect.

\begin{tabular}{ccccc} 
Group & Sex & Resorption of TCP & Mean age & Size of osteotomy \\
\hline $\begin{array}{c}\text { TCP solid wedge } \\
(n=11)\end{array}$ & $\begin{array}{c}\text { Male } 55 \%(n=6) \\
\text { Female } 45 \%(n=5)\end{array}$ & $82 \%$ & 43 & $91 \%>5 \mathrm{~mm}$ \\
\hline TCP granules & Male 69 $\%(n=11)$ & $87 \%$ & 42 & $87 \%>5 \mathrm{~mm}$ \\
$(n=16)$ & Female 31 \% $(n=5)$ & & & \\
\hline Overall & Male 63\% $(n=17)$ & $85.2 \%$ & 43 & $89 \%>5 \mathrm{~mm}$ \\
$(n=27)$ & Female 37\% $(n=10)$ & $(n=23)$ & & \\
\hline
\end{tabular}

Table 2: Specific properties of TCP groups

\section{Results}

The radiographs of 16 osteotomies using TCP granules as a bone substitute and those of 11 osteotomies using a TCP wedge could be evaluated. All 27 procedures were performed without any complications during or after the operation. The performing surgeon preferred a wedge type of TCP if he was able to choose, due to difficulties in properly positioning the granules in the gap created by the opened wedge. At clinical evaluation there were no wound healing problems, no non-unions, no loss of corrections, and no infections. Specific properties of the two groups are presented in Table 2; sex, age and size of the osteotomy are similar for the two groups.

During the first round of evaluations of all radiographs almost perfect agreement was reached $(\mathrm{k}=0.8)$ whereas the investigators, reached substantial agreement both during the second $(k=0.6)$ and third round $(k=0.7)$. The intraobserver reliability for the two investigators is presented in Table 3.

\begin{tabular}{lll} 
Rounds compared & $1^{\text {st }}$ investigator & $2^{\text {nd }}$ investigator \\
\hline First and second & 0.53 & 0.6 \\
First and third & 0.53 & 0.57 \\
Second and third & 0.62 & 0.59 \\
\hline
\end{tabular}

Table 3: Kappa scores for intra-observer reliability 
As shown in Table 4, after 12 months the TCP was no longer visible in $85 \%$ $(n=23)$ of the patients X-rays. In $44(n=10)$ of the 23 osteotomies, no sign of the osteotomy was visible (Figure 2). As shown in Figure 3 and Table 5, the bone union rate in both groups progressed gradually. Union of OWHTO's filled with TCP did not depend on sex, age or the size of the osteotomy. Also no retarded bone healing was found in the three patients who smoked. No significant difference in union between the osteotomies with wedges and the osteotomies with granules could be demonstrated $(p=0.164)$.

\begin{tabular}{lllll} 
& 6 weeks & 3 months & 6 months & 12 months \\
\hline Grade 1 & $48 \%(n=13)$ & none & none & none \\
Grade 2 & $52 \%(n=14)$ & $56 \%(n=15)$ & none & none \\
Grade 3 & none & $41 \%(n=11)$ & $52 \%(n=14)$ & $15 \%(n=4)$ \\
Grade 4 & none & $3 \%(n=1)$ & $44 \%(n=12)$ & $48 \%(n=13)$ \\
Grade 5 & none & none & $4 \%(n=1)$ & $37 \%(n=10)$
\end{tabular}

Table 4: Progress of union of TCP treated osteotomies

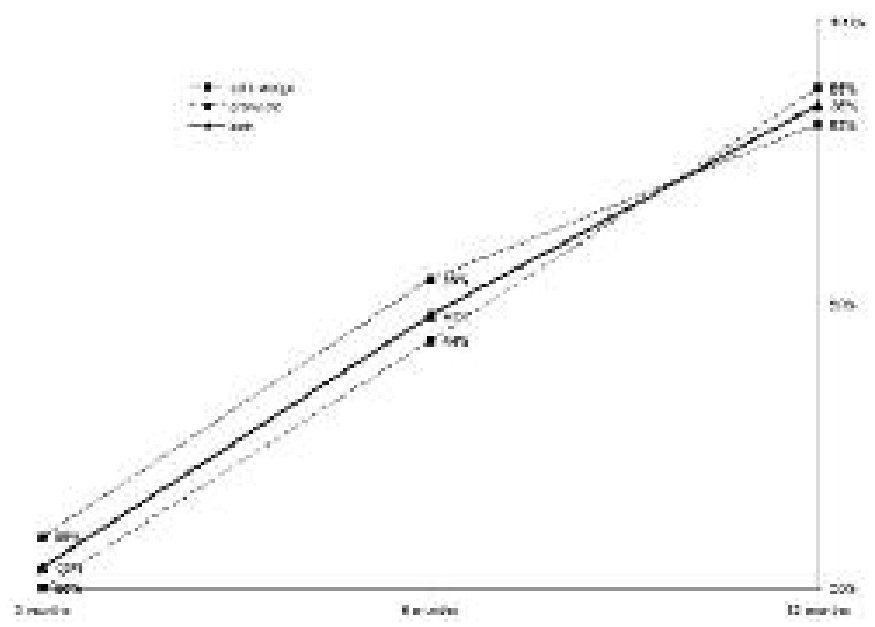

Figure 3: Difference of union rate between TCP granules and wedges. 


\begin{tabular}{lllllllll} 
& \multicolumn{2}{c}{$\begin{array}{c}\text { 6 weeks } \\
\text { granules wedge }\end{array}$} & $\begin{array}{c}3 \text { month } \\
\text { granules wedge }\end{array}$ & $\begin{array}{c}6 \text { months } \\
\text { granules wedge }\end{array}$ & \multicolumn{2}{c}{$\begin{array}{c}12 \text { months } \\
\text { granules wedge }\end{array}$} \\
\hline Grade 1 & $44 \%$ & $55 \%$ & & & & & & \\
& $(n=7)$ & $(n=6)$ & & & & & & \\
\hline Grade 2 & $56 \%$ & $45 \%$ & $56 \%$ & $55 \%$ & & & & \\
& $(n=9)$ & $(n=5)$ & $(n=9)$ & $(n=6)$ & & & & \\
\hline Grade 3 & & & $44 \%$ & $36 \%$ & $56 \%$ & $45 \%$ & $12 \%$ & $18 \%$ \\
& & & $(n=7)$ & $(n=4)$ & $(n=9)$ & $(n=5)$ & $(n=2)$ & $(n=2)$ \\
\hline Grade 4 & & & & $9 \%$ & $38 \%$ & $55 \%$ & $50 \%$ & $45 \%$ \\
& & & & $(n=1)$ & $(n=6)$ & $(n=6)$ & $(n=8)$ & $(n=5)$ \\
\hline Grade 5 & & & & & $6 \%$ & $38 \%$ & $36 \%$ \\
& & & & & $(n=1)$ & $(n=6)$ & $(n=4)$
\end{tabular}

Table 5: Progress in radiological bone healing phases in time (in percentage per group)

\section{Discussion}

All of the performed osteotomies with stable fixation and filling of the osteotomy gap with porous tricalciumphosphate healed without complications, (i.e., infection or non-union) within 12 months of the operation. In $85 \%$ of the osteotomies, the TCP preforms were not visible on the radiographs at 12 months. They could thus be considered to be remodelled. No difference in osteotomy healing or TCP remodelling was found between the group of granules and the group of solid wedges: however, pre-shaped wedges improved the ease of handling.

To our knowledge no radiologic rating system to monitor bone healing in open wedge osteomies has been reported. For this study such a system was developed for radiological evaluation of bone healing. The process of bone healing, which in fact is continuous, was divided into five phases according to the system used by McKibbin ${ }^{16}$ to enable postoperative monitoring at the intervals used in clinical practice. A rating system based on standard AP and lateral radiographs enables universal application and comparison between studies. However, the system is not designed to correlate specific phases to stability of bone union as this was found to be unreliable for fracture healing classification with AP and lateral radiographs ${ }^{7}$. The descriptions of the distinct phases which would be clear to both clinicians and radiologists was chosen to improve interobserver agreement.

Observer agreement of radiologic measurements may be unreliable which has been reported in different papers ${ }^{1,2,19}$. Whelan et al. ${ }^{22}$, however, measured 
substantial inter- and intraobserver agreement in a study on radiological assessment of the bone healing in tibial fractures. On two separate occasions eight weeks apart, they independently assessed the radiographs of 30 patients with tibial shaft fractures that had been treated by intramedullary fixation. The interobserver agreement was expressed by Cohens kappa, and ranged from 0.57 to 0.89 . Among the variables examined, the number of cortices bridged by bone appeared to be a reliable and easily measured radiological variable. For the radiologic rating of the osteotomy gaps created during OWHTO, rating in specific phases of bone healing proved to be clinically applicable according to guidelines described by Landis and $\mathrm{Koch}^{12}$. The results of inter- and intraobserver agreement found in the present study are satisfying, since the observers reached substantial agreement both during the second $(k=0.6)$ and third round $(k=0.7)$.

The good resorption and remodelling of the TCP that was used in the present study has been previously reported. In an in-vivo study in a non-human primate evaluating the safety and efficacy of a novel local bone harvesting technique in the spine, Steffen et al. ${ }^{21}$ demonstrated the complete integration of TCP cylinders with newly formed bone and resorption in $80 \%$ of the study population after 6 months. In a clinical study Muschik et al. ${ }^{17}$ used the same TCP granules as those inserted in the granules group of patients to achieve dorsal spondylodesis in adolescent idiopathic scoliosis and observed complete remodelling of TCP based on X-ray and CT measurements after 8 months. This is consistent with the results of the patients in the granules group (Figure 3). Resorption and remodelling of the TCP wedges has not been evaluated previously in a biomechanical or clinical study. In the present study no difference in resorption or remodelling capacity for the solid wedge preform was found as compared to the granules.

The resorption and remodelling properties are attributed to the chemical composition and the interconnecting pore structure and pore size of the TCP used in this study. In another study, significant bone formation was seen as early as 3 weeks and bone ingrowth paralleled tricalciumphosphate resorption ${ }^{5}$. The authors found that after one year, the new bone and the tricalciumphosphate were remodelled into a bone tissue that was indistinguishable from the normal bone on radiological and histological examination ${ }^{5}$. These results are confirmed in our study by the disappearance of $85 \%$ of the tricalciumphosphate, on studied radiographs from both implant groups after one year.

The use of different bone substitutes in OWHTO has been previously described. However these studies lack a standardized radiological follow-up as 
well as details regarding bone healing at different intervals. In a clinical study using acrylic bone cement as bone substitute, Hernigou et al. ${ }^{9}$ reported good results in a large series of 245 valgus producing osteotomies. A five-year survival of $94 \%$ of the performed OWHTO's is reported. A disadvantage of the use of the acrylic bone cement, which is mainly used to provide initial stability, is the exothermic setting reaction which might harm the living bone tissue and both the missing porosity and lack of resorption. Recently, Koshino et al. ${ }^{11}$ reported on the use of porous hydroxyapatite in OWHTO for 21 cases. The use of this non-resorbable ceramic bone substitute resulted in excellent 7-years follow-up results. At twelve to sixteen weeks trabecular continuity was observed at the osteotomy site on radiographs. We believe that the synthetic, osteoconductive and resorbable bone substitute used in this study provides an excellent alternative to other methods described above. Furthermore, the use of autologous bone graft from the iliac crest which is often accompanied with serious co-morbidity issues involving pain and risk of infection ${ }^{6,8,20}$ is prevented.

It is important to note that tricalciumphosphate, whether using granules or a wedge is not intended for load bearing and therefore an OWHTO should always be supported by an internal or external fixation method. For optimal results an implant with angle stable screws, should be used to bridge the osteotomy gap ${ }^{14}$. TCP must be used in a mechanically stable environment otherwise it cannot remodel into bone.

Lobenhoffer et al. ${ }^{14}$ used in their study no filling material and radiographic full consolidation was also observed in corrections up to 12 degrees. This raises the question whether a bone substitute is necessary. Prospective randomized studies should be preformed to compare the use of TCP and leaving the gap open. The maximum wedge-size that can heal with TCP is not yet defined. As the used TCP wedges are currently only available for up to $13^{\circ}$, we use bone grafts for corrections exceeding this amount.

In conclusion, TCP implants such as the chronOS ${ }^{\mathrm{TM}}$ wedges and granules can be successfully used as bone substitutes in open wedge high tibial osteotomies with a plate with angle stable screws. Our hypothesis that TCP granules offer a larger contact area for newly formed bone and could stimulate a faster vascularisation, remodelling and consolidating of the osteotomy, was not confirmed by our results. There was no significant difference in healing time between the TCP granules or wedge preforms. The new classification for healing of the open wedge osteotomies of the tibia was reliable for comparison of the results of the two bone substitutes. 
Chapter 3

\section{Acknowledgement}

The authors would like to thank Thierry Stoll, Synthes Biomaterials in Bettlach, Switzerland, for the development and preparation of the ceramic implants and the support of the study. 


\section{LITERATURE}

1. Andersen, D. J.; Blair, W. F.; Steyers, C. M., Jr.; Adams, B. D.; el-Khouri, G. Y.; and Brandser, E. A.: Classification of distal radius fractures: an analysis of interobserver reliability and intraobserver reproducibility. J Hand Surg [Am], 21(4): 574-82, 1996.

2. Bhandari, M.; Guyatt, G. H.; Swiontkowski, M. F.; Tornetta, P., 3rd; Sprague, S.; and Schemitsch, E. H.: A lack of consensus in the assessment of fracture healing among orthopaedic surgeons. J Orthop Trauma, 16(8): 562-6, 2002.

3. Chang, B. S.; Lee, C. K.; Hong, K. S.; Youn, H. J.; Ryu, H. S.; Chung, S. S.; and Park, K. W.: Osteoconduction at porous hydroxyapatite with various pore configurations. Biomaterials, 21(12): 1291-8, 2000.

4. Choi, H. R.; Hasegawa, Y.; Kondo, S.; Shimizu, T.; Ida, K.; and Iwata, H.: High tibial osteotomy for varus gonarthrosis: a 10- to 24-year follow-up study. J Orthop Sci, 6(6): 493-7, 2001.

5. Erbe, E. M.; Marx, J. G.; Clineff, T. D.; and Bellincampi, L. D.: Potential of an ultraporous beta-tricalcium phosphate synthetic cancellous bone void filler and bone marrow aspirate composite graft. Eur Spine J, 10 Suppl 2: S141-6, 2001.

6. Goulet, J. A.; Senunas, L. E.; DeSilva, G. L.; and Greenfield, M. L.: Autogenous iliac crest bone graft. Complications and functional assessment. Clin Orthop, (339): 76-81, 1997.

7. Hammer, R. R.; Hammerby, S.; and Lindholm, B.: Accuracy of radiologic assessment of tibial shaft fracture union in humans. Clin Orthop, (199): 233-8, 1985.

8. Heary, R. F.; Schlenk, R. P.; Sacchieri, T. A.; Barone, D.; and Brotea, C.: Persistent iliac crest donor site pain: independent outcome assessment. Neurosurgery, 50(3): 510-6; discussion 516-7, 2002.

9. Hernigou, P., and Ma, W.: Open wedge tibial osteotomy with acrylic bone cement as bone substitute. Knee, 8(2): 103-10, 2001.

10. Hernigou, P.; Medevielle, D.; Debeyre, J.; and Goutallier, D.: Proximal tibial osteotomy for osteoarthritis with varus deformity. A ten to thirteen-year follow-up study. J Bone Joint Surg Am, 69(3): 332-54, 1987.

11. Koshino, T.; Murase, T.; and Saito, T.: Medial opening-wedge high tibial osteotomy with use of porous hydroxyapatite to treat medial compartment osteoarthritis of the knee. J Bone Joint Surg Am, 85-A(1): 78-85, 2003.

12. Landis, J. R., and Koch, G. G.: The measurement of observer agreement for categorical data. Biometrics, 33(1): 159-74, 1977.

13. LeGeros, R. Z.; Parsons, J. R.; Daculsi, G.; Driessens, F.; Lee, D.; Liu, S. T.; Metsger, S.; Peterson, D.; and Walker, M.: Significance of the porosity and physical chemistry of calcium phosphate ceramics. Biodegradation-bioresorption. Ann N Y Acad Sci, 523: 268-71, 1988. 


\section{Chapter 3}

14. Lobenhoffer, P., and Agneskirchner, J. D.: Improvements in surgical technique of valgus high tibial osteotomy. Knee Surg Sports Traumatol Arthrosc, 11(3): 132-8, 2003.

15. Lu, J. X.: Role of interconnections in porous bioceramics on bone recolonization in vitro and in vivo. J. of Materials science: materials in medicine, 10: 111-120, 1999.

16. McKibbin, B.: The biology of fracture healing in long bones. J Bone Joint Surg Br, 60B(2): 150-62, 1978.

17. Muschik M.; Ludwig R.; Halbhübner S.; Bursche K.; Stoll T.; beta tricalcium phosphate as a bone substitute for dorsal spinal fusion in adolescent idiopathic scoliosis; preliminary results of a prospective clinical study. Eur Spine J, 10:S178-S184, 2001.

18. Rejda, B. V.; Peelen, J. G.; and de Groot, K.: Tri-calcium phosphate as a bone substitute. J Bioeng, 1(2): 93-7, 1977.

19. Sidor, M. L.; Zuckerman, J. D.; Lyon, T.; Koval, K.; Cuomo, F.; and Schoenberg, N.: The Neer classification system for proximal humeral fractures. An assessment of interobserver reliability and intraobserver reproducibility. J Bone Joint Surg Am, 75(12): 1745-50, 1993.

20. Silber, J. S.; Anderson, D. G.; Daffner, S. D.; Brislin, B. T.; Leland, J. M.; Hilibrand, A. S.; Vaccaro, A. R.; and Albert, T. J.: Donor site morbidity after anterior iliac crest bone harvest for single-level anterior cervical discectomy and fusion. Spine, 28(2): 134-9, 2003.

21. Steffen, T.; Stoll, T.; Arvinte, T.; and Schenk, R. K.: Porous tricalcium phosphate and transforming growth factor used for anterior spine surgery. Eur Spine J, 10 Suppl 2: S132-40, 2001.

22. Whelan, D. B.; Bhandari, M.; McKee, M. D.; Guyatt, G. H.; Kreder, H. J.; Stephen, D.; and Schemitsch, E. H.: Interobserver and intraobserver variation in the assessment of the healing of tibial fractures after intramedullary fixation. J Bone Joint Surg Br, 84(1): 15-8, 2002.

23. Yokozeki, H. H., T. et.al.: Influence of surface microstructure on the reaction of the active ceramics in vivo. J Mater Scien: Mat in Med, 9: 381ff, 1998. 


\section{ChaPTer 4}

\section{Functional improvement after}

unicompartmental knee replacement: a follow-up study with a performance based knee test

Lucas L.A. Kleijn, Wouter L.W. van Hemert, Will G.H. Meijers, Arnold D.M.Kester, Lukas Lisowski, MD, Bernd Grimm, Ide C. Heyligers 


\section{Abstract}

In a prospective study on 38 patients with a mean age of 62.2 years functional improvement after unilateral knee replacement in the treatment of medial osteoarthritis of the knee was measured using Knee Society Score (KSS) and the Dynaport ${ }^{\circledR}$ Knee Test. This is an accelerometer-based system that objectively measures functional aspects of gait during various tasks of daily life. It is easy to operate and results in a score ranging from 0 to 100. Preoperative, three and six months, one year and two years after surgery the KSS and the Dynaport ${ }^{\mathbb{R}}$ Knee Test score were acquired.

The mean KSS of all patients preoperative was 44.0 and 81.7 at three months, a significant improvement $(p<0.05)$. The patients reviewed at six months scored 87.4. No significant differences were noted after six months.

Significant differences could be found in the Dynaport ${ }^{\circledR}$ Knee Test score among the measured time points $(p<0.05)$. The mean preoperative Dynaport ${ }^{\circledR}$ Knee Test score was 35.8 and at three months $43.6(p<0.05), 48.6$ at six months $(p<0.05)$ and 50.5 at one year. At two years follow up the studied patients scored 52.3, which was not a significant improvement compared to one year $(p=0.46)$, however it was a significant improvement compared to six months $(\mathrm{p}<0.05)$.

The four subscores that the Dynaport ${ }^{\circledR}$ Knee Test score consists of show significant improvements up to two years after surgery. The low demanding tasks, Lift and Move and Locomotion, cease to improve beyond six months, whereas the high demanding tasks, Rise and Descend and Transfers, show improvements even after one year after surgery. This study has found that functional recovery continues beyond six months and even up to two years. Thus more attention should be paid to this extended recovery period and the use of objective measurement methods are advocated next to the clinician based scores and self reported questionnaires. 


\section{INTRODUCTION}

Various surgical options are available for treating medial unicompartmental osteoarthritis of the knee and vary from high tibial osteotomy, unicompartmental knee replacement to total knee arthroplasty. Unicompartmental knee replacement can be favored over total knee replacement because it preserves bone stock and cruciate ligaments and it is performed less invasive. Therefore it is said to result in faster recovery and approaches the physiologic movements of the knee better than total knee arthroplasty ${ }^{1}$. In young patients, unicompartmental knee replacement for medial osteoarthritis has proven to be successful both on short term as on long term follow-up ${ }^{8}$ and it has been reported to be more costeffective over total knee replacement in the same kind of patients ${ }^{14}$.

Clinical outcome after knee replacement is commonly assessed by function scores such as the clinician-based American Knee Society Score (KSS) ${ }^{2}$. These methods are accepted, routinely used and proven valid ${ }^{4}$. As unicompartmental knee replacement tends to be performed at a younger age functional aspects of knee replacement deserve more attention. Next to such knee scores, outcome and function can be measured using more objective methods or devices. Concerning gait-analysis after unicompartmental knee replacement few reports are available. Webster et al. ${ }^{19}$ report on 13 patients between 12.2 and 33.3 months after surgery operated on for medial osteoarthritis with a cementless unicompartmental knee system. The authors performed a one-time measurement using a 3-dimensional motion analysis system and electronic walkway and all but one patient showed a gait pattern not significantly differing from healthy controls.

Mattsson et al. ${ }^{6}$ studied 20 patients before and one year after knee replacement with a cemented unicompartmental prosthesis and provided data on walking speeds. They found that patients could increase their walking speed by $28 \%$ after surgery compared to preoperative.

Weidenhielm et al. ${ }^{20}$ reported kinematic data after unicompartmental knee replacement using electrogoniometers. In 26 of 36 patients they found improvement in stance knee flexion-extension patterns, although this improvement has not been supported by range of motion measurements. Pre- and postoperative comparisons between stance and swing phases were not significantly different. No information on the course of recovery within two years is available.

Current objective measurement systems such as electromyography, force platforms, optokinematic systems and 3-dimensional motion analysis are available and considered as the gold standard, but are time consuming and require sophisticated laboratories. In view of this problem an accelerometer 
based, user-friendly system was developed, the Dynaport ${ }^{\circledR}$ Knee Test. It objectively assesses functional abilities in a standardized set of tasks, closely related to activities of daily living (ADL). The rationale of the system has been explained indicating the potential value in evaluating patients' functional abilities in knee-related clinical practice and research ${ }^{17,21}$.

Reports on follow up of unicompartmental knee replacement, using such performance based knee tests on multiple time points, are, to our best knowledge, lacking in literature. Using both KSS and Dynaport ${ }^{\circledR}$ Knee Test, this paper is intended to objectify functional recovery after unicompartmental knee replacement during repetitive measurements in two years.

\section{Materials ANd Methods}

\section{Study design}

Between February 2000 and August 200140 patients (41 knees) were operated for medial osteoarthritis of the knee. When eligible according to the Oxford guidelines, a primary Phase 3 Oxford $^{\mathrm{TM}}$ Unicompartimental Knee System (Biomet, Dordrecht, the Netherlands) was placed ${ }^{1}$.

All patients were operated in a joint care program. When screened eligible for surgery informed consent was acquired and preoperative knee flexion, KSS and Dynaport ${ }^{\mathbb{B}}$ Knee Test scores were measured within two weeks before surgery. The surgical procedure was performed according to the Oxford guidelines. After surgery a standard rehabilitation program was followed supervised by a physical therapist, allowing mobilization and active knee exercises the first day after surgery. Patients were discharged from the hospital within one week. The majority followed a rehabilitation program outpatient during three months.

Three and six months, one year and two years after surgery the patients visited the outpatient clinic where they were examined by two orthopedic surgeons who scored KSS and knee function. A physical therapist operated the Dynaport ${ }^{\circledR}$ Knee Test.

\section{Instruments of measurement}

The KSS score is subdivided into a Knee score that scores the knee joint only and a Function score that rates pain, patient's ability to walk and climb stairs and the need for a support device ${ }^{2}$. It has been proven reliable as described by Kreibich et al. ${ }^{4}$.

During the Dynaport ${ }^{\mathbb{}}$ Knee Test patients perform various tests related to Activities of Daily Living (ADL), such as walking, stair climbing, getting up and 
moving objects ${ }^{17}$. The test lasts approximately 20-30 minutes and is supervised e.g. by a physical therapist. Patients are instructed to perform the test items at their own pace and items can be skipped if considered too difficult, resulting in 0 points.

The Dynaport ${ }^{\circledR}$ Knee Test consists of six small movement sensors that are fixed to the patient's thorax, pelvis, the left thigh and beneath both knees. These sensors measure the accelerations related to the orientation and movement patterns of the body and the trunk. Data is captured by a portable recorder worn around the waist as the patient performs a set of 29 test items, such as walking up and down stairs and sitting down. An algorithm programmed by the manufacturer calculates 4 cluster scores, Locomotion, Transfer, Lift and Move, Rise and Descend. These are weighed and combined into one overall Dynaport ${ }^{\mathbb{R}}$ Knee Test score that ranges form 0 to 100 .

Mokkink et al. ${ }^{7}$ investigated the reproducibility and validity of the Dynaport ${ }^{\circledR}$ Knee Test on 92 total knee arthroplasty patients who performed the test twice on the same day and 94 "healthy" controls performed the Knee Test once. The inter- and intra-observer reliability was found to be 0.90 and 0.95 respectively. Construct validity was studied by correlations with the WOMAC physical functioning (0.55), SF-36 physical functioning (0.62) and Knee Society Score (KSS) function (0.64).

\section{Statistics}

Data analysis was performed using Statistical Package for the Social Science (SPSS) 12.0 (Chicago, Illinois, USA).

Differences in KSS, The Dynaport ${ }^{\circledR}$ Knee Test score and the subscores were compared using repeated measures ANOVA for non-parametric data, the Friedman test. Level of significance was set on $p<0.05$. Post hoc comparisons were checked using Wilcoxon Signed Ranks test and considered significant if $p<0.05$. Non-parametric tests were used because of non-normality of the scores in the tested population.

\section{RESULTS}

Two patients (three knees) were excluded from data analysis. One patient had both knees operated on at two different time points, but measurements were recorded for both knees at the same time. Another patient had incomplete scores and was considered a loss to follow-up and therefore excluded from data analysis. One group of the remaining 38 patients (38 knees) was followed up 
and included in data analysis. We can report on 23 patients with a two-year record and 15 patients with a one-year record. Eight males and 30 females were analyzed in the study, with a mean age at time of surgery of 62.2 years (range 41 - 78, SD 9.5). The mean Body Mass Index was 28.5 (range 23 - 39, SD 3.6).

\section{KSS and knee flexion}

Significant differences could be found in KSS among the measured time points (Friedman test, $\mathrm{p}<0.05$ ). The mean KSS of all patients preoperative was 44.0 and 81.7 at three months follow-up. Post hoc comparisons showed that this is a steep improvement and an expected significant difference $(p<0.05)$. The patients seen at six months scored 87.4, less steep but a significant improvement compared to three months follow-up $(\mathrm{p}<0.05)$. The mean KSS decreased slightly to 86.1 $(p=0.55)$ at one year and leveled at 86.3 at two year follow-up $(p=0.83)$. Also the improvement from six months to two years was not found to be significant $(p=0.90)$. The time course of the KSS is displayed in figure 1 .

Considering knee flexion, significant differences were found in among the measured time points (Friedman test, $\mathrm{p}<0.05$ ). The mean flexion of all patients preoperative was 106.8 degrees. Post hoc comparisons showed that the improvement to 115.2 degrees at three months is significant $(p<0.05)$. Of all patients reviewed at six months the mean flexion was 119.6 degrees, again a mild and significant improvement $(p<0.05)$ compared to three months. The knee flexion leveled at one year at 120.5 and 119.1 at two years. No significant differences were noted after six months.

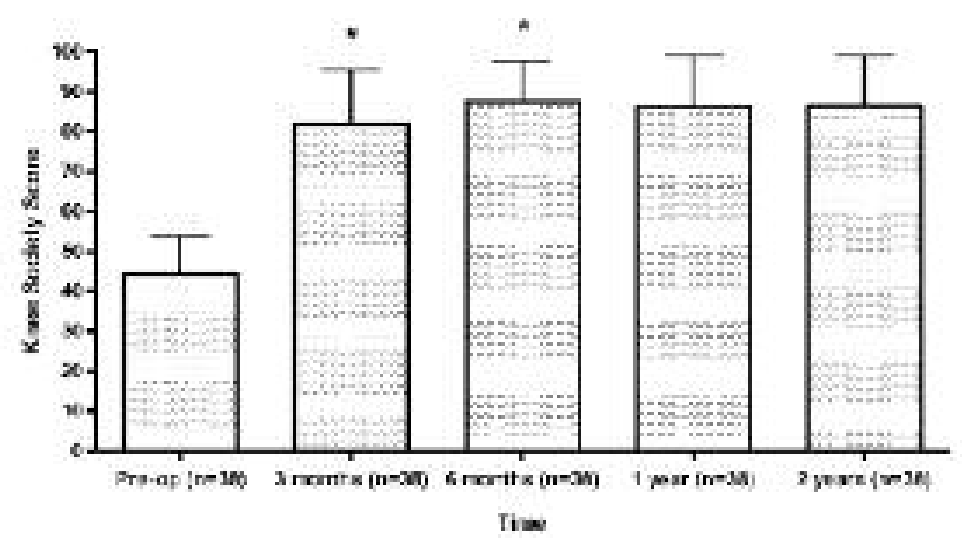

Figure 1: The Knee Society Score (Mean \pm SD) in time. The result that is marked

* is a significant improvement compared to the previous time point. 


\begin{tabular}{llll} 
Time point & $\begin{array}{l}\text { Knee flexion } \\
\text { (mean } \pm s d, \text { range) }\end{array}$ & $\begin{array}{l}\text { Knee score } \\
\text { (mean } \pm s d)\end{array}$ & $\begin{array}{l}\text { Function score } \\
\text { (mean } \pm s d)\end{array}$ \\
\hline Pre operative & $106.8^{\circ} \pm 14.3(90-135)$ & $41.7 \pm 10.5$ & $47.2 \pm 12.1$ \\
Three months & $115.2^{\circ} \pm 12.1(90-135)^{*}$ & $83.9 \pm 12.2^{*}$ & $79.1 \pm 16.2^{*}$ \\
Six months & $119.6^{\circ} \pm 11.1(100-135)$ & $86.8 \pm 10.1$ & $87.5 \pm 12.3$ \\
One year & $120.5^{\circ} \pm 11.7(100-140)$ & $83.3 \pm 11.7$ & $83.9 \pm 15.6$ \\
Two years & $119.1^{\circ} \pm 12.1(100-140)$ & $83.7 \pm 13.2$ & $88.1 \pm 14.0$
\end{tabular}

Table 1: Knee flexion and breakdown of KSS. Significant improvements compared to previous time points are marked*.

\section{The Dynaport ${ }^{\circledR}$ Knee Test}

Significant differences could be found in the Dynaport ${ }^{\circledR}$ Knee Test score among the measured time points (Friedman test, $\mathrm{p}<0.05$ ). The mean preoperative Dynaport ${ }^{\circledR}$ Knee Test score was 35.8. Patients reviewed at three months follow up scored a mean of 43.6, which was a significant improvement compared to preoperative $(p<0.05)$. It continued to improve to 48.6 significantly $(p<0.05)$ at six months. The Dynaport ${ }^{\circledR}$ Knee Test score at one year reached to 50.5, which was not a significant improvement $(p=0.69)$. At two year follow up the studied patients scored 52.3, which was not a significant improvement compared to one year $(p=0.46)$, however it was a significant improvement compared to six months $(p<0.05)$. The results and time course of the Dynaport ${ }^{\circledR}$ Knee Test score are displayed in figure 2 .

Considering the cluster score Lift and Move, significant differences could be found among the measured time points (Friedman test, $\mathrm{p}<0.05$ ). The mean pre operative score was 37.4. Post hoc comparisons showed and significantly improvement to 45.9 at three months $(p<0.05)$. It improved significantly to 50.5 at six months $(p<0.05)$, at one year it improved not significantly to 53.0 $(p=0.11)$. It increased to 54.1 at two years, but not significantly so $(p=0.88)$. No significant differences were noted after six months.

Significant differences could be found in the cluster score Locomotion among the measured time points (Friedman test, $\mathrm{p}<0.05$ ). The mean score pre operative was 37.4. It improved significantly to 45.7 at three months $(p<0.05)$ and to 52.5 at six months $(p<0.05)$. Neither the score of 54.1 was a significant improvement at one year $(p=0.18)$, nor was the score of 55.1 at two years $(\mathrm{p}=0.87)$. No significant differences were noted after six months.

Significant differences could be found in the cluster score Rise and 
Descend among the measured time points (Friedman test, $\mathrm{p}<0.05$ ). The mean score pre operative was 32.3. Post hoc comparisons showed a significant improvement to 41.4 at three months $(p<0.05)$ and the score improved significantly to 48.8 at six months ( $p>0.05)$. The improvement to 50.6 at one year was not significant $(p=0.57)$, whereas the improvement from one year to two years was significant $(p<0.05)$.

Significant differences could be found in the cluster score Transfers among the measured time points (Friedman test, $\mathrm{p}<0.05$ ). The mean score pre operative was 28.9. It improved significantly to 37.7 at three months $(p<0.05)$ and to 42.7 at six ( $p>0.05)$. It improved to 45.1 at one year, but not significantly so $(p=0.24)$, whereas improvement from one year to 45.7 at two years was significant $(\mathrm{p}<0.05)$.

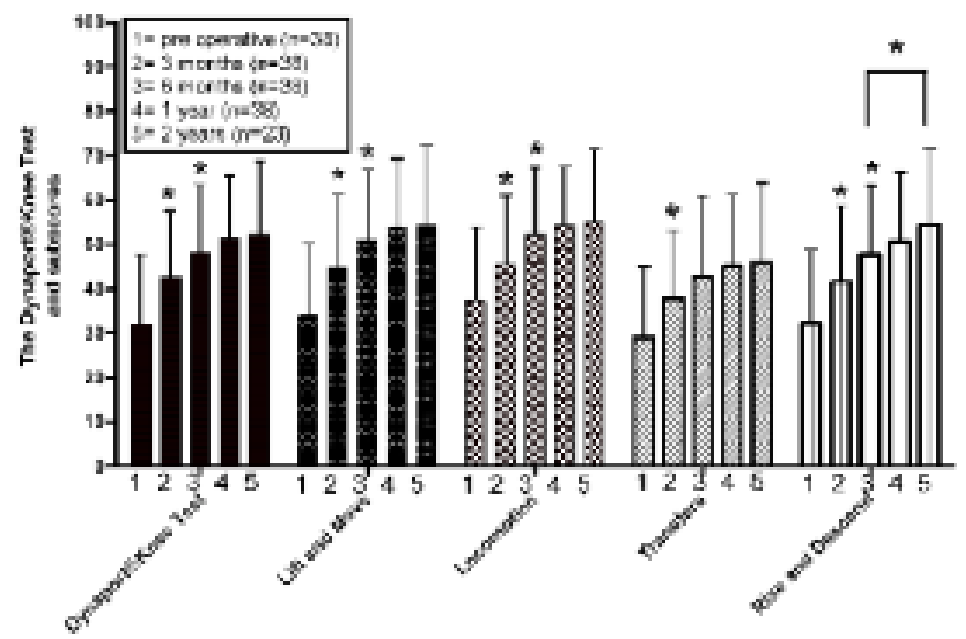

Figure 2: The Dynaport ${ }^{\circledR}$ Knee Test and its subscores in time (Mean \pm SD).

The result that is marked $*$ is a significant improvement compared to the previous time point.

\section{Discussion}

To our knowledge this is the first study to report on repetitive performance based knee test measurements during a two year follow up of patients after unicompartmental knee replacement. Also, it appears the first paper on measurements with the Dynaport ${ }^{\circledR}$ Knee Test measured together with KSS after unicompartmental knee replacement. In our study the pre and post operative 
KSS was similar to the KSS of patients described in literature ${ }^{3,9,13}$. Therefore it can be expected that the study was conducted on a representative group of patients and thus the acquired data with The Dynaport ${ }^{\circledR}$ Knee Test can be considered representative.

The KSS showed its typical, very steep, improvement in patients after unicompartmental knee replacement as in total knee arthroplasty patients ${ }^{3,9,13}$, but stopped to improve after six months and even decreased slightly beyond. Also the knee flexion, being a part of the KSS, was found to improve significantly up to six months. However, the measured differences between three and six months are rather small and therefore the clinical relevance of this finding can de debated.

Incoherence with KSS the Dynaport ${ }^{\circledR}$ Knee Test improved significantly up to six months. However we were able to measure further improvement beyond six months according to the Dynaport ${ }^{\circledR}$ Knee Test. Looking closely at the subscores it can be seen that this improvement was less in the considered low demanding tasks, but more substantial in the considered high demanding tasks. Locomotion, which resembles walking several distances, does level at six months. Walking on equal surfaces can be considered as a low demanding task and can be expected to recover quickly after surgery. Lift and Move combines scores that are acquired during lifting certain objects from different heights while moving it elsewhere. This is expected to be a more demanding task, since bending in order to reach objects is also done from the hip and spine. The cluster score Rise and Descend can be considered as the most difficult task. It resembles climbing stairs of different levels and requires the knee to bend considerably and therefore generates larger intra-articular loading pressures. This is usually one the most difficult items during rehabilitation and the significant improvement from one year to confirms this. One could expect that recovery of the knee joint required more time in order to reach a ceiling in such a more difficult task than the aforementioned two cluster scores. The cluster score Transfers contain items such as getting up and down. Shortly after surgery the patient rather than the knee itself is influenced, therefore it can be expected that this task is completed with more effort. It can be considered a difficult task, since patients have a considerable influence of their body weight and impairment of other joints, which could explain the repeated lower scores compared to the other than three subscores. This indicates that it does not take a prolonged recovery for exercise but throughout the recovery period this task is more troublesome. Similar to Rise and Descend is requires more time to reach a plateau. 
Significant improvement beyond six months was encountered between six months and two years whereas the difference between one year and two years was not. It obviously requires a larger time interval to produce significant improvement than was accounted for between one year and two years. The Dynaport ${ }^{\mathbb{B}} \mathrm{Knee}$ Test scores can vary from 0 to 100 and usually only very active people such as athletes reach maximum values ${ }^{17}$. Whether presented results of our patients are the best reflection of their function could be discussed, since patients are instructed to perform only at their own pace. It can be questioned whether the results could even be more distinctive, if this test was designed more challenging and thus patients were encouraged to perform with maximum effort.

The younger, more active and demanding patient, sometimes referred to as the 'millennium patient', in modern orthopaedics, requires more than clinician based scores were developed for. Besides pain relief, he demands a high knee flexion and expects post operative improvements to be a long lasting. Modern types of prostheses, such as unicompartmental knee replacements, can provide such results. The patient indicated for unicompartmental knee replacement usually is more active, more demanding and values functional improvement. The patients studied in this paper had an average age of 62.2 years and belong to this more demanding patient group. The acquired results indicate that physiological changes in recovery and functional improvement still take place beyond a time point where KSS appears not sensitive enough to register it. Thus the continuing functional improvement with The Dynaport ${ }^{\circledR}$ Knee Test may be beneficial to these subjects. However the exact clinical relevance of these improvements can be debated. Nevertheless, the measured improvements beyond six months should trigger attention for possibly prolonged recovery programs and patient information.

A limitation of using KSS in our study in particular in this issue is that the maximum value for knee flexion in the KSS is set on 120 degrees. This creates a premature ceiling effect in the results curve, since patients in our study and other studies can individually reach knee flexion beyond this limit (Table 1). Thus in our study the KSS seems to underrate the performance of a large number of functionally well performing patients. However, even if a modified KSS score was adjusted to account for higher flexion, it would only have resulted in a higher ceiling in the curve, but not in an increased duration of recovery.

Maly et al. ${ }^{5}$ has shown that self-report measures are strongly related to pain, whereas physical performance measures were strongly related to selfefficacy. In view of this paper the continuing functional improvement as measured by The Dynaport ${ }^{\circledR}$ Knee Test but not by the KSS can be partially 
explained by the objectiveness vs. the clinician based scores. Furthermore, it can be explained by the different demands during The Dynaport ${ }^{\circledR}$ Knee Test and that it is not as pain related as KSS.

Several papers have appeared using different assessment scores in order to value recovery, but track outcome rather than short term post operative functional improvement. Pennington et al. ${ }^{10}$ report on functional aspect after unicompartmental knee replacement using The University of California at Los Angeles activity assessment score and evaluate long term survival after unilateral knee replacement. However they do not address any differences between activity levels in recovery, since a pre operative score lacked. To evaluate prosthetic knee replacement Weale et al. ${ }^{18}$ use the Oxford questionnaire, stating that this introduces more objectiveness, yet it still does not reflect true objectiveness, since potential bias of the clinician or patient can be of influence. Schai et al. ${ }^{16}$ report on follow up after unilateral knee replacement using Tegner and Lysholm score, but could not provide results within two years due to limited time points included. Many authors have tried to convey more responsiveness over clinician based scores, since knee scores are claimed to be exceedingly unreliable ${ }^{15}$. Whereas patient perceptions after knee replacement become increasingly important, self reported questionnaires still include certain subjectiveness. In agreement with Maly et al. ${ }^{5}$ and based on our findings we advocate the use of performance based tests next to clinician based scores and self reported questionnaires when evaluating functional recovery during follow up.

A limitation of our study is that we were not able to acquire the two-year follow-up scores of Dynaport ${ }^{\circledR}$ Knee Test of all patients, although these patients did visit the outpatient where KSS could be scored some considered the Dynaport ${ }^{\circledR}$ Knee Test still too time consuming.

Unicompartmental knee arthroplasty in the treatment of medial osteoarthritis of the knee is a successful technique with excellent long term results ${ }^{8,11,12}$. This study provides further insight in the course of functional recovery after UKA. It appears to continue beyond six months and even up to two years. Thus more attention should be paid to this extended recovery period and the use of objective measurement methods are advocated next to the clinician based scores and self reported questionnaires.

\section{Acknowledgement}

No financial benefits were received for this study. The authors thank Alita Hidding, $\mathrm{PhD}$ for assistance. 
Chapter 4 


\section{Literature}

1. Goodfellow J and O'Connor J (1978) The mechanics of the knee and prosthesis design. J Bone Joint Surg Br 60-B: 358-369.

2. Insall JN, Dorr LD, Scott RD and Scott WN (1989) Rationale of the Knee Society clinical rating system. Clin Orthop Relat Res 13-14.

3. Keys GW, Ul-Abiddin Z and Toh EM (2004) Analysis of first forty Oxford medial unicompartmental knee replacement from a small district hospital in UK. Knee 11: 375377.

4. Kreibich DN, et al. (1996) What is the best way of assessing outcome after total knee replacement? Clin Orthop Relat Res 221-225.

5. Maly MR, Costigan PA and Olney SJ (2006) Determinants of self-report outcome measures in people with knee osteoarthritis. Arch Phys Med Rehabil 87: 96-104.

6. Mattsson E, Olsson E and Brostrom LA (1990) Assessment of walking before and after unicompartmental knee arthroplasty. A comparison of different methods. Scand J Rehabil Med 22: 45-50.

7. Mokkink LB, et al. (2005) Reproducibility and validity of the DynaPort KneeTest. Arthritis Rheum 53: 357-363.

8. Murray DW, Goodfellow JW and O'Connor JJ (1998) The Oxford medial unicompartmental arthroplasty: a ten-year survival study. J Bone Joint Surg Br 80: 983-989.

9. Naudie D, Guerin J, Parker DA, Bourne RB and Rorabeck CH (2004) Medial unicompartmental knee arthroplasty with the Miller-Galante prosthesis. J Bone Joint Surg Am 86-A: 1931-1935.

10. Pennington DW, Swienckowski JJ, Lutes WB and Drake GN (2003) Unicompartmental knee arthroplasty in patients sixty years of age or younger. J Bone Joint Surg Am 85-A: 1968-1973.

11. Price AJ, Waite JC and Svard U (2005) Long-term clinical results of the medial Oxford unicompartmental knee arthroplasty. Clin Orthop Relat Res 171-180.

12. Rajasekhar C, Das S and Smith A (2004) Unicompartmental knee arthroplasty. 2- to 12 year results in a community hospital. J Bone Joint Surg Br 86: 983-985.

13. Rees JL, Price AJ, Beard DJ, Dodd CA and Murray DW (2004) Minimally invasive Oxford unicompartmental knee arthroplasty: functional results at 1 year and the effect of surgical inexperience. Knee 11: 363-367.

14. Robertsson O, Borgquist L, Knutson K, Lewold S and Lidgren L (1999) Use of unicompartmental instead of tricompartmental prostheses for unicompartmental arthrosis in the knee is a cost-effective alternative. 15,437 primary tricompartmental prostheses were compared with 10,624 primary medial or lateral unicompartmental prostheses. Acta Orthop Scand 70: 170-175. 


\section{Chapter 4}

15. Ryd L, Karrholm J and Ahlvin P (1997) Knee scoring systems in gonarthrosis. Evaluation of interobserver variability and the envelope of bias. Score Assessment Group. Acta Orthop Scand 68: 41-45.

16. Schai PA, Suh JT, Thornhill TS and Scott RD (1998) Unicompartmental knee arthroplasty in middle-aged patients: a 2- to 6-year follow-up evaluation. J Arthroplasty 13: 365-372.

17. van den Dikkenberg $N$, et al. (2002) Measuring functional abilities of patients with knee problems: rationale and construction of the DynaPort knee test. Knee Surg Sports Traumatol Arthrosc 10: 204-212.

18. Weale AE, Halabi OA, Jones PW and White SH (2001) Perceptions of outcomes after unicompartmental and total knee replacements. Clin Orthop Relat Res 143-153.

19. Webster KE, Wittwer JE and Feller JA (2003) Quantitative gait analysis after medial unicompartmental knee arthroplasty for osteoarthritis. J Arthroplasty 18: 751-759.

20. Weidenhielm L, Olsson E, Brostrom LA, Borjesson-Hederstrom M and Mattsson E (1993) Improvement in gait one year after surgery for knee osteoarthrosis: a comparison between high tibial osteotomy and prosthetic replacement in a prospective randomized study. Scand J Rehabil Med 25: 25-31.

21. Witvrouw E, et al. (2002) A correlation study of objective functionality and WOMAC in total knee arthroplasty. Knee Surg Sports Traumatol Arthrosc 10: 347-351.

22. van den Dikkenberg $\mathrm{N}$ et al (2002) Measuring functional abilities of patients with knee problems: rationale and construction of the Knee Surg Sports Traumatol Arthrosc DynaPort knee test. Knee Surg Sports Traumatol Arthrosc 10:204-212

23. Weale AE, Halabi OA, Jones PW, White SH (2001) Perceptions of outcomes after unicompartmental and total knee replacements. Clin Orthop Relat Res 382:143-153

24. Webster KE, Wittwer JE, Feller JA (2003) Quantitative gait analysis after medial unicompartmental knee arthroplasty for osteoarthritis. J Arthroplasty 18:751-759

25. Weidenhielm L, Olsson E, Brostrom LA, Borjesson-Hederstrom M, Mattsson E (1993) Improvement in gait one year after surgery for knee osteoarthrosis: a comparison between high tibial osteotomy and prosthetic replacement in a prospective randomized study. Scand J Rehabil Med 25:25-31

26. Witvrouw E et al (2002) A correlation study of objective functionality and WOMAC in total knee arthroplasty. Knee Surg Sports Traumatol Arthrosc 10:347-351 


\section{ChAPTER 5}

\section{Early functional outcome after subvastus or parapatellar approach in knee arthroplasty is comparable}

Wouter L.W. van Hemert, Rachel Senden, Bernd Grimm, Matthijs J.A. van de Linde, Arno Lataster, Ide C. Heyligers

Accepted Knee Surg Sports Traumatol Arthrosc 


\section{Abstract}

Postoperative recovery after total knee arthroplasty could become more advantageous when early mobilization is commenced. Tissue sparing techniques are considered more important as they may result in less pain and better function. In knee arthroplasty the parapatellar approach is most often used whereas the subvastus approach is a suitable alternative. Although the latter has been reported superior, it is unknown, according to true objective measurements, which of the two is most advantageous. In this prospective randomized double blind short-term trial both options were compared using both objective and subjective scores, hypothesizing that subvastus would not be beneficial over parapatellar approach.

Measurements (KSS, WOMAC, PDI, VAS, ability to perform) were obtained at day 1 , day 3 , one week, six weeks and three months. The subvastus group $(n=20)$ showed only significantly less extension lag direct post operative $(p=0.038)$ compared to the parapatellar group $(n=20)$. Other scores were not significantly different. The Dynaport ${ }^{\circledR}$ knee Test, an objective performance based tool could not demonstrate significant differences.

A blunt anatomical dissection was carried out and in both observational and histological examination a dense innervation of the distal vastus medialis was found. This is at risk employing the subvastus approach. Both approaches harm the suprapatellar bursa. The vastus medialis sheath must be detached distally to open the knee joint. No true separate vastus medialis obliquus could be identified.

Comparable to literature only mild advantage employing the subvastus approach was found, but only early postoperative and not objectively. As this approach is also not suitable in every case we will continue to use the parapatellar approach. 


\section{INTRODUCTION}

Optimizing rehabilitation after total knee replacement will likely provide better functioning of the knee joint but also avoids complications and reduces healthcare $\operatorname{costs}^{18}$. Postoperative recovery of knee function is dependent upon patient factors such as co-morbidity, Body Mass Index (BMI) and pre-operative functioning of the knee ${ }^{10}$. Also surgeon related influences matter, as prosthetic design continues to evolve $\mathrm{e}^{1,3}$ and tissue sparing techniques are pursued to minimize damage and increase preservation of normal physiology ${ }^{7}$.

Postoperative rehabilitation of knee function is also dependent upon the method of assessment employed ${ }^{9}$. Traditionally the recovery of function is reflected by the range of motion and is considered between 0 and 120 degrees, as a part of the Knee Society Score (KSS). Normally a knee flexion up to 90 degrees is reached at 3 to 6 weeks after the operation and it is common to have a temporary extension lag. However, knee flexion appears to be less important than patient related outcomes such as WOMAC functioning. This assessment was found to correlate more with patient satisfaction and pain ${ }^{22}$.

In this view it can be understood that clinical evaluation after total knee replacement needs to be measured with multiple items ${ }^{2}$. Assessment must include a pain score; appreciation of range of motion and function should be assessed separately. Patient dependent questionnaires cannot only establish function. An objective performance based measurement is also needed.

As described in various reports concerning minimal invasive knee replacement ${ }^{12}$, preservation of integrity of the quadriceps muscle group is essential to knee function of the quadriceps ${ }^{7,10,23}$. Regarding surgeon related influences on rehabilitation various surgical approaches are employed to achieve reduction of tissue damage. The parapatellar approach is commonly used to expose the knee joint. It is performed through the quadriceps tendon longitudinally, continues around the patella and parallels the patellar ligament. The knee joint is relatively reached easily, even in obese patients. Using the less frequent medial "subvastus" approach the knee joint is opened at the inferior medial side of the vastus medialis muscle and continues distally parapatellar. Using this approach the extensor mechanism is deemed to be preserved as patella tendon junction remains unharmed.

This was shown in the study of Weinrauch et $a /^{38}$. In a consecutive series patients that had undergone knee replacement through a parapatellar approach had a significant larger extension lag early postoperative than patients the subvastus group. However a randomized trial by Weinhardt et $a^{37}$ studying 
parapatellar approach versus subvastus approach showed similar results in terms of pain, operation time and complications. Patients after knee replacement via subvastus approach reached 90 degrees of flexion earlier but were similar at time of discharge.

In the study of Matsueda et $a^{20}$ a group of total knee arthroplasty (TKA) patients with parapatellar approach and subvastus approach where retrospectively compared at six months rehabilitation. The patient outcomes were based on clinical and radiographic measures, occurrence of intraoperative lateral retinacular release and incidence of postoperative patellar subluxation. There were no significant differences for range of motion, Knee Society Score (KSS), knee function scores and stair climbing ability. In the subvastus group there were significantly fewer knees requiring a lateral retinacular release. The authors concluded that the subvastus approach led to improvement of patellar tracking and stability but not to increased function compared to the parapatellar approach.

Therefore, it can be questioned whether existing functional differences, if any, only occur in earlier phases of recovery. Also common using knee scores may not capture yet existing differences equally. We have demonstrated this before as then KSS could not discriminate between patella resurfacing or retention, whereas objective measurements $\mathrm{did}^{35}$. Furthermore the subvastus approach might not result in better tissue sparing as it may harm viable structures ${ }^{6,24}$.

We conducted a trial to establish early postoperative differences between the parapatellar approach and the subvastus approach, using a performance based test to complement range of motion, pain measurements and patient questionnaires. It was hypothesized that a subvastus approach would not lead to a functional faster recovery in early postoperative phase. Furthermore, we also conducted an anatomical observational dissection study to explore the anteromedial anatomy of the knee in relation to these two surgical approaches. It was intended to find possible explanations why the subvastus approach would not possibly result in a better postoperative function ${ }^{20,37}$ and to describe in detail the anatomical structures at risk employing either of both techniques ${ }^{14}$.

\section{Patients and Methods}

\section{Clinical trial}

In this study 40 patients with symptomatic unilateral osteoarthritis of the knee and indicated for total knee arthroplasty (TKA) were enrolled in a double blind 
prospective randomised design. Patients were randomly divided in a group of 20 patients who underwent a parapatellar approach and 20 patients were operated on using the subvastus approach. Randomisation occurred by opening an envelope with either the text 'Subvastus' or 'Parapatellar' written on it, selected from a box containing envelopes, just prior to surgery. Approval was acquired from the local Medical Ethics Committee.

The uncemented Scorpio cruciate retaining (CR) total knee system (Stryker, Warsaw, IN, USA ) was implanted and the operation was performed by either of the two senior authors $(\mathrm{ML}$ or $\mathrm{IH})$. As the parapatellar approach is employed as the standard approach both surgeons performed five subvastus procedures prior to this study to minimise learning curve bias. The patella was left unresurfaced in all cases but was everted in the parapatellar approach group. Tibial resection was performed according to the implant thickness at $8 \mathrm{~mm}$ resection beneath the relatively normal part of the plateau. Distal femoral resection was performed at 7 degrees of valgus en rotation was referenced to epicondylar axis, Whiteside's line and if possible posterior condyles.

Patients with a previous contralateral knee implantation, a poor medical condition, cognitive or language problems to complete the questionnaires, age over 80 years and that were unable to perform a gait test prior to surgery and were not included.

Aftertreatment was similar for both groups and consisted of a joint-care program rehabilitation protocol. Full weight bearing and active exercises were commenced the first day after surgery as tolerated. Patients were discharged after five days standard and rehabilitated throughout the study outpatient, three times a week, by the same team of therapists. Exercises for active muscle strengthening and range of motion were similar for all.

Both patients and the investigators ( $\mathrm{WH}$ and $\mathrm{RS}$ ) were blinded to the type of approach. The skin incision was equal in both groups and access to the ORreport was only allowed after completed 3 months of follow up.

The measurements were performed within a few days before surgery and postoperative at 2 weeks, 6 weeks and three months. They consisted of Knee Society Score (KSS), where we continuously used it broken down in Knee and Function Score, Western Ontario and McMaster Universities Index of Osteoarthritis (WOMAC) (lowest is best), VAS for pain (lowest is best), Pain Disability Index (PDI) (lowest is best) and the Dynaport ${ }^{\circledR}$ Knee test. Furthermore the preoperative stage of osteoarthritis was classified according to Ahlback's scoring system. Implant position was verified on a 6 week post-operative standing AP and lateral radiograph and standing long leg radiograph. It was 
considered a failure if standard knee measurements deviated more than 5 degrees from normal position.

The DynaPort ${ }^{\circledR}$ knee test is a short (30 minutes) standardized test to assess the quality of movement or patients with a knee dysfunction. Current objective measurement systems such as electromyography, force platforms, optokinematic systems are available but are time consuming, costly and require sophisticated laboratories. In view of this problem an accelerometer based, user-friendly device, the DynaPort ${ }^{\circledR}$ system, has been developed. It objectively assesses functional abilities in a standardized set of tasks closely related to ADL (Activities of Daily Living). The rationale of the DynaPort ${ }^{\circledR}$ system has been explained by van den Dikkenberg et $a^{34}$ and validity has been proven ${ }^{26,27}$.

Test persons wear several belts around their trunk and legs, while performing 29 sets of tasks related to ADL, such as walking several distances, climbing different stair heights and picking an lifting objects and always in the same order. The belts contain accelerometers that are able to detect movements and their signals are stored in a recorder, embedded in one of the belts. A semiautomatic signal analysis can be carried out to generate the DynaPort ${ }^{\circledR}$ knee test sub-scores (Locomotion, Rise and Descend, Lift and Move, Transfers) and the overall score. An item too difficult can be skipped, but results in 0 points.

The Dynaport ${ }^{\circledR}$ knee test was measured at the $3^{\text {rd }}$ day postoperative with the intention to determine the ability to participate. Active extension deficit but passively correctable (extension lag) and passive extension deficit were examined manually with the aid of a goniometer. VAS was recorded at day 1 and day 3 as well.

Data analysis was performed using Statistical Package for the Social Science (SPSS) 12.0 (Chicago, Illinois, USA). Reported values are mean \pm standard deviation (SD). This study design involves patients that are considered equal both prior to the study and after one year of follow up $p^{20,37}$. Differences are expected in the first few months of recovery. Previous papers report standard deviations between 10 and 20 are reported in Dynaport employed scores $^{33-35}$. We considered one standard deviation of difference clinically relevant. Based on this an a priori power analysis ( error probability of 0.05 and a power of 0.8 ) produced a minimum sample size of 34 patients.

The between subject differences of mean at each time point were analyzed using a Student T test or a Mann Whitney test depending on the data distribution. The within subject differences of mean were analyzed in a Oneway repeated measures ANOVA model with the approach as a between 
subjects factor. Post-Hoc comparisons were checked using a paired-samples Ttest. For proper use of repeated measures analysis of variance (ANOVA), the number of observations should be larger than $n+10$, where $n$ is the number of level of repeated measures. This study was comprised over four scenarios and there were 24 patients in the smallest group. If the sample size is between 16 and 40, a t-distribution can be applied if the sampling distribution is moderately skewed, unimodal, without outliers. Therefore the validity and applicability of the used test were considered acceptable ${ }^{21}$.

We used the Ahlback scoring system in a cross table to classify the stage of osteoarthritis and used a Chi-square test to exclude differences preoperative. The difference in mean of early postoperative extension lag, the ability to mobilise the first day postoperative, to participate in the $3^{\text {rd }}$ day test and the 3 month implant position including existing patellar tilt on the patella sunrise view were analyzed as a proportion sample using Fisher's Exact test. Level of significance was set at $\mathrm{p}<0.05$.

\section{Anatomical study}

Two lower limb specimens (left and right) were harvested from two different formalin injected human cadavers to investigate the anterior region of the thigh through dissection. The left specimen was exarticulated in the hip joint and the right one amputated $25 \mathrm{~cm}$ proximally from the patellar base. Furthermore both specimens were amputated $20 \mathrm{~cm}$ distally from the tibial tuberosity. The blunt dissection technique was carried out as described previously by van Mameren et $a l^{36}$.

In the left specimen the cutis and subcutis were completely removed by sharp dissection. In the right one the cutis was removed by sharp dissection. To explore the subcutaneous course of the greater saphenous vein and the infrapatellar and main branch of the saphenous nerve a blunt dissection of fat and connective tissue was utilized (Figure 1). A small circular band of cutis and subcutis was left intact at the proximal and distal end of this specimen and the (para)patellar blood supply and infrapatellar nerve supply were investigated by dissecting layers of deep fascia ("fascia lata/cruris") around the patella sharply and fatty "gliding" tissue between these layers bluntly (Figure 2).

In both knees the sartorius, vastus medialis, rectus femoris and vastus lateralis compartments were opened in that order by longitudinal incisions of the deep fascia lying over it (Figure 3). In the same order muscle fibers of the quadriceps components were detached from the connective tissue by blunt dissection leaving the connective tissue and neurovascular structures intact 
(Figure 4). Paraffin embedded Haematoxylin and Eosin stained histological sections were produced to identify these neurovascular structures.

The vastus intermedius muscle was approached by a longitudinal incision of the deep aponeurotic sheet underneath the other quadriceps components at the level of the rectus femoris muscle and dissected as described for these components (Figure 5).

The dissection procedure was photographed step by step using a Digital SLR camera (Canon 400D, Canon Inc) mounted on a tripod with a standard 50 $\mathrm{mm}$ lens $\mathrm{f} 1.8$, in macro mode.

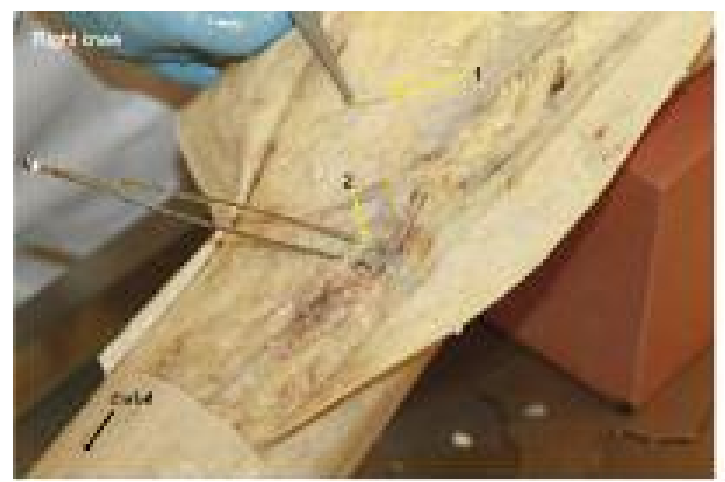

Figure 1. yellow arrow $1=$ infrapatellar branch of saphenous nerve yellow arrow 2 = main branch of saphenous nerve blue arrow $=$ superficial suncutaneous course of greater saphenous vein

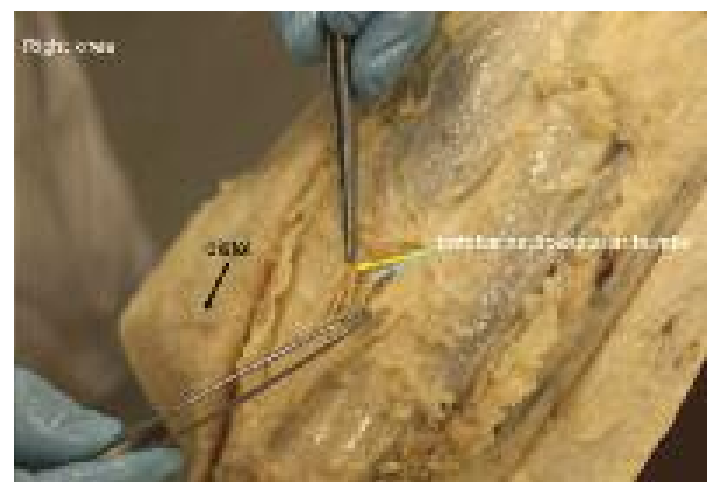

Figure 2 . 


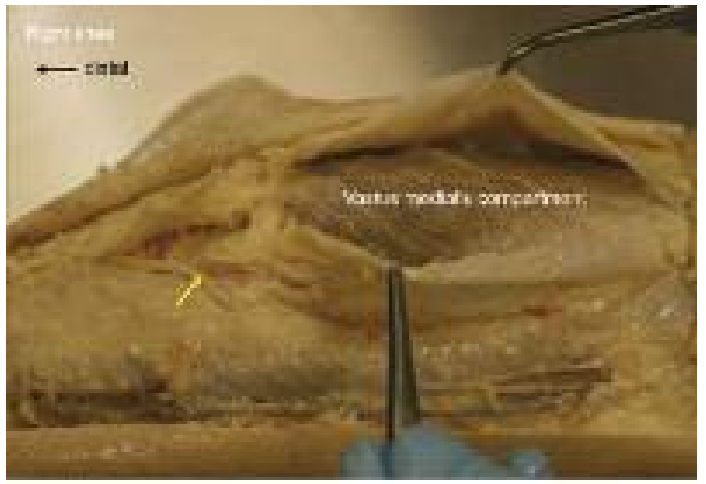

Figure 3. yellow arrow = infrapatellar branch of saphenous nerve

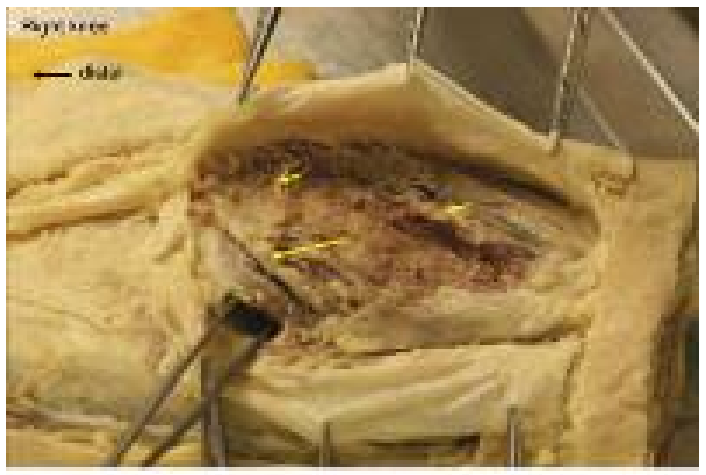

Figure 4. yellow arrows = neurovascular bundles

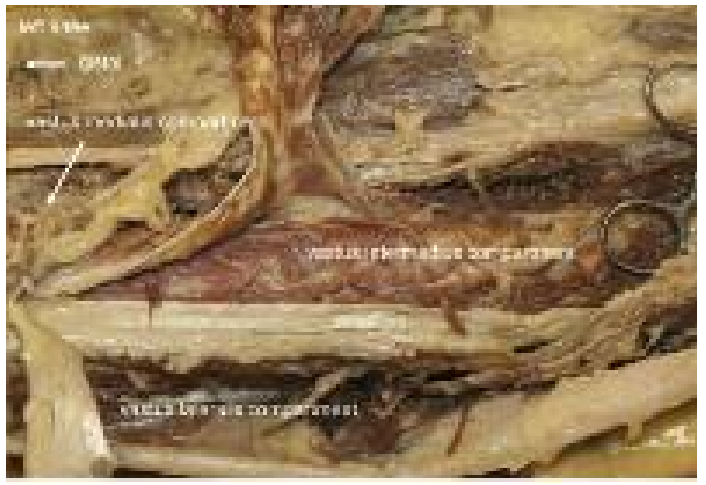

Figure 5. 


\section{Results}

All patients were available throughout the entire testing period. Preoperative demographic characteristics are presented in table 1. The mean peri-operative blood loss was recorded using the 24-hour drain production, as surgery was performed with a tourniquet.

\begin{tabular}{llll} 
& Parapatellar group $(\mathrm{n}=20)$ & Subvastus group $(\mathrm{n}=20)$ & $\mathrm{p}$ value \\
\hline Age & $70.9( \pm 7.1)$ & $70.3( \pm 11.8)$ & $\mathrm{p}=0.49$ \\
BMI & $30.3( \pm 5.9)$ & $29.2( \pm 5.5)$ & $\mathrm{p}=0.66$ \\
Sex & $13 \mathrm{~F} / 7 \mathrm{M}$ & $14 \mathrm{~F} / 6 \mathrm{M}$ & \\
Stage of osteoarthritis (Ahlback) & $1(n=10)$ & $1(n=11)$ & \\
& $2(n=6)$ & $2(n=5)$ & \\
& $3(n=4)$ & $3(n=4)$ & $p=0.34$ \\
Surgical time & $69( \pm 12.6)$ & $74.7( \pm 18.6)$ & $\mathrm{p}=0.81$ \\
Blood loss (24h drain production) & $672.7 \mathrm{ml} \pm 359.6$ & $574.6 \mathrm{ml} \pm 134.7$ &
\end{tabular}

Table 1: Demographic characteristics

The VAS score preoperative was 5.29 in the subvastus group and 5.97 in the parapatellar group $(p=0.30)$. At the first day postoperative the subvastus group scored a mean VAS of $5.06( \pm 2.5)$ which was lower than the VAS of 6.5 $( \pm 2.5)$ in the parapatellar group $(\mathrm{p}=0.09)$ and at the third day postoperative the subvastus group scored a mean VAS of $3.61( \pm 3.0)$ which was lower than the VAS of $4.67( \pm 2.8)$ in the parapatellar group, $(p=0.29)$ (Figure 6). Twelve patients of the subvastus group could mobilise the first day post-operative compared to 14 in the parapatellar group, whereas the remaining would follow the next day $(\mathrm{p}=0.71)$. At the third day nine patients in the parapatellar group showed an extension lag compared to three in the subvastus group ( $p=0.038$ ).

The proportion of patients that could pass the Dynaport ${ }^{\circledR}$ Knee test at the third day was not significantly different between groups ( $p$ values ranging from 0.73 to 1.00). Knee flexion is displayed in Figure 7.

At two weeks postoperative there were no significant differences between groups as indicated by Dynaport ${ }^{\circledR}$ Knee test and its subscores (Figure 8 ), as well as KSS (Figure 9), WOMAC pain, function and stiffness (Figure 10) (p values ranging from 0.23 to 0.96). PDI is presented in Figure 11. 
After six weeks and three months we did not discover any significant differences between groups as indicated by KSS (Figure 9), WOMAC pain and stiffness (Figure 10), PDI, as well as Dynaport ${ }^{\circledR}$ Knee test and its subscores (Figure 8 ). Only the function score of KSS (Figure 9) and WOMAC function (Figure 10) indicated significance in favour of the parapatellar approach ( $\mathrm{p}$ values ranging from 0.15 to 0.96 ).

The improvements within subject, determined using repeated measures model, were below significant levels. No post hoc test were obtained here.

Regarding the WOMAC function there was no significant difference between groups. Only at 3 months the parapatellar group reported a better function compared to the subvastus group $(p=0.031)$. The improvement of WOMAC function between pre operative and 2 weeks was positive for both but steeper for the subvastus $(\mathrm{p}=0.03)$ group whereas this was vice versa between 2 weeks and 6 weeks $(p=0.006)$ months.

Implant position was considered normal in all cases and patellar tilt was not found to be significantly different between groups ( $p=0.642$ )

One patient in the subvastus group sustained a deep infection, which resulted in extensive debriding surgery.

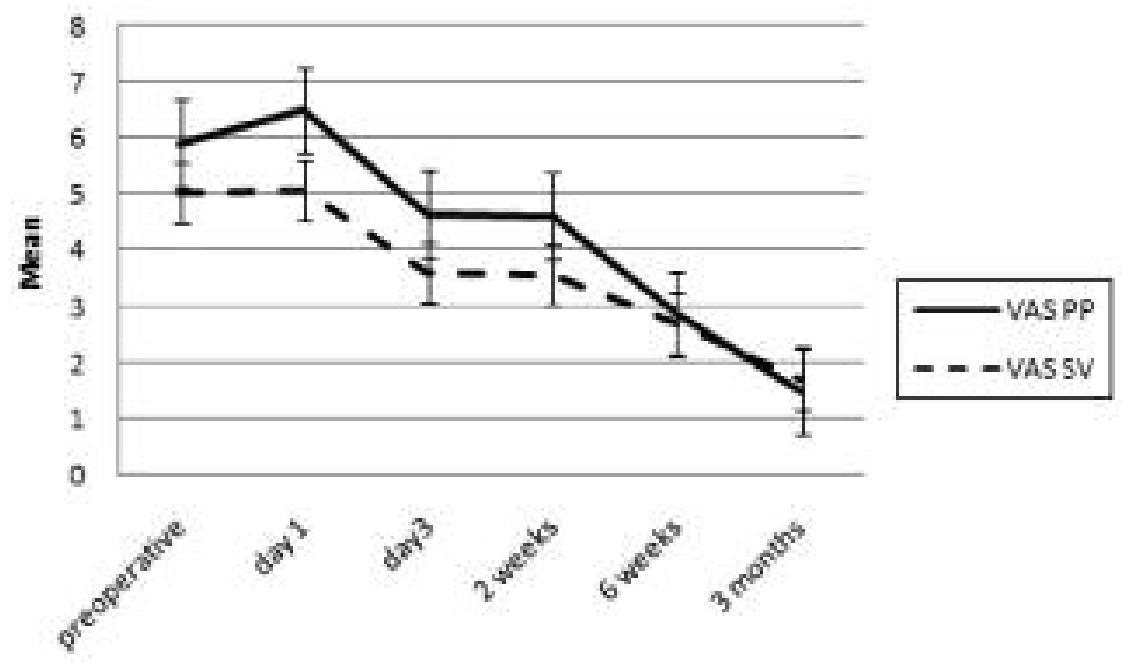

Figure 6. Mean Vas score in time 
Chapter 5

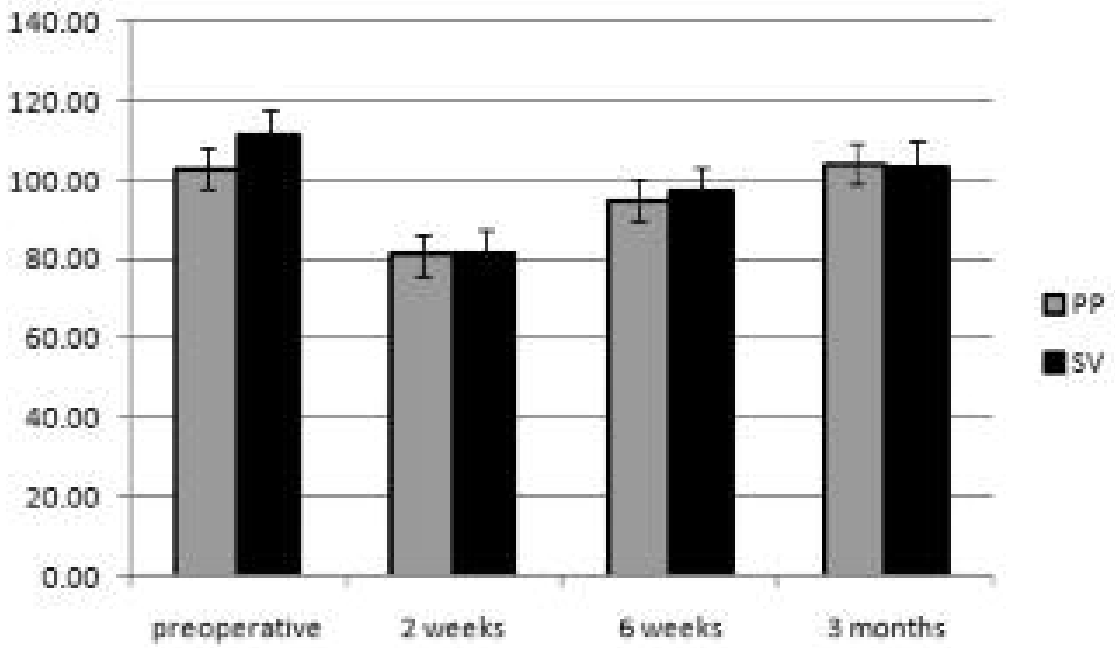

Figure 7. Knee flexion in time

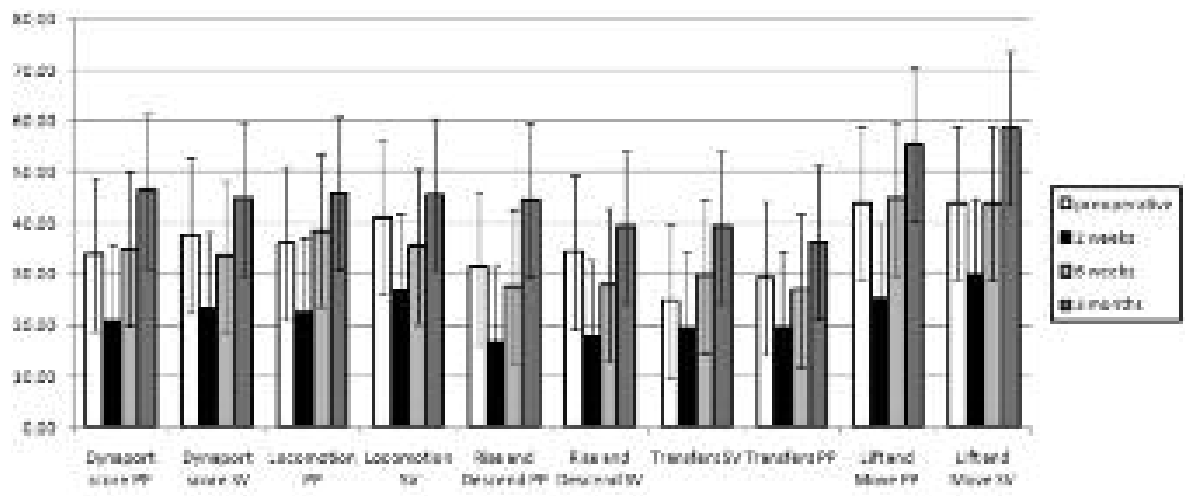

Figure 8. The Dynaport ${ }^{\circledR}$ Knee Test and subscores in time 


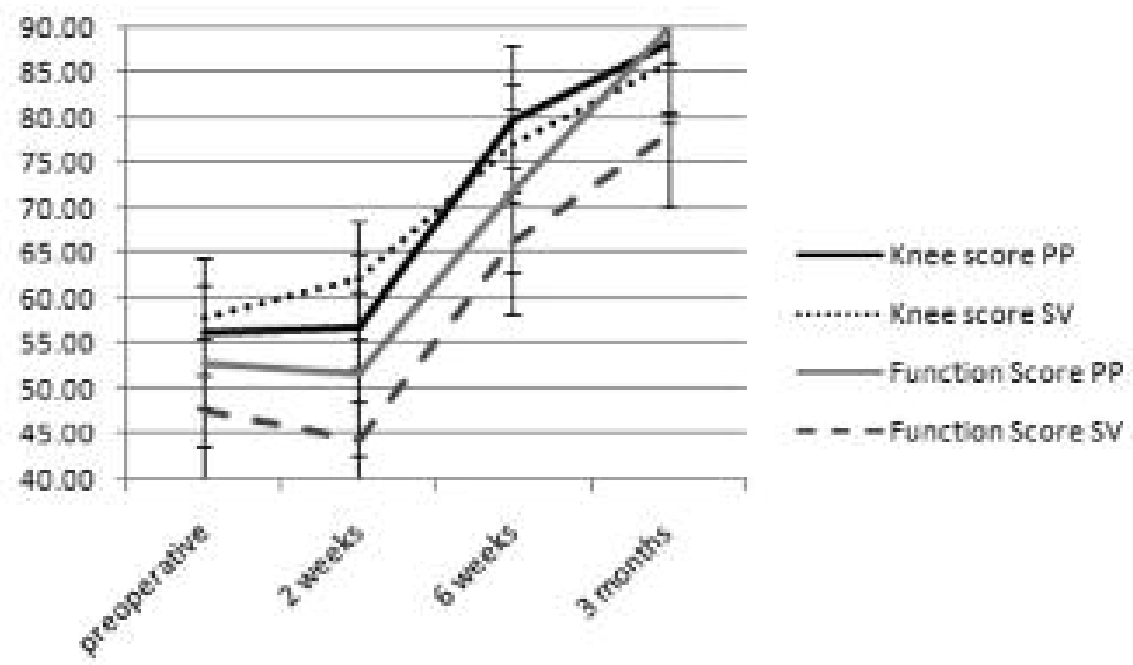

Figure 9. Breakdown of The Knee Society Score (KSS) in time

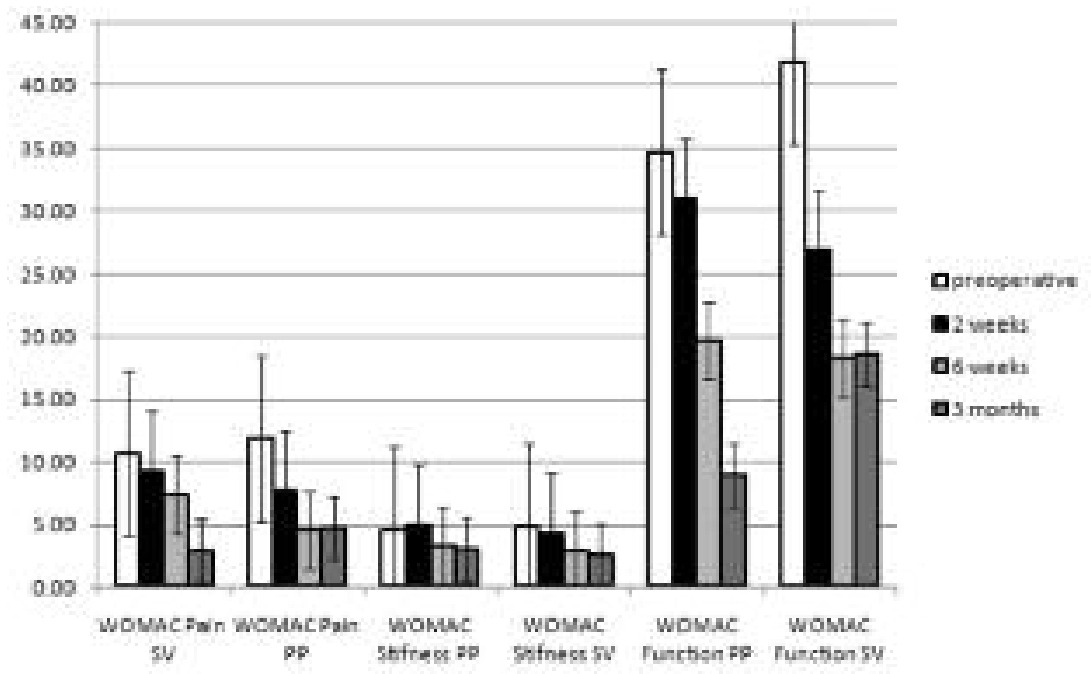

Figure 10. WOMAC score in time 


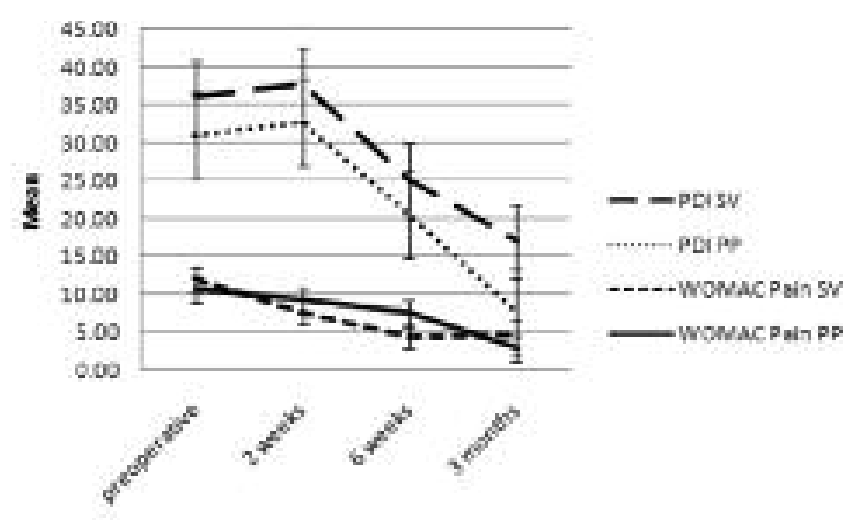

Figure 11. Pain Diability Index and WOMAC pain

\section{Anatomical dissection}

In both anatomical specimens the medial thigh compartment was opened longitudinally and fibers of the vastus medialis muscle were removed by bluntly detaching them from the dense connective tissue ('fascia lata'). The muscle bundles were separated from each other by loose connective tissue sheets attached to the dense connective tissue fascia surrounding the muscle compartment (Figure 12). A large number of neurovascular bundles between the oblique muscle bundles could be observed. The main branch originates through a double sheath of the deep fascia and runs until the distal end of the compartment (Figure 13). The most distal neurovascular bundle in the left specimen appeared at only a few millimeters from the distal border of the vastus medialis compartment, entering the compartment at $1 \mathrm{~cm}$ measured from the patellar base (Figure 14). More proximally further nerve vessel strands from 1.5 to $17 \mathrm{~cm}$ from the patellar base could be observed (Figures 15, 16). In the right specimen also a large number of neurovascular bundles could be observed piercing the oblique muscle bundles (Figure 4).

By separating the muscular and connective tissue in a blunt way two aponeurotic plates emerged, one at the distal (Figure 16) and one at the proximal side of the vastus medialis compartment (Figure 17). The distal aponeurosis was attached to the craniomedial and cranial side of the patella and the connective tissue at the medial side of the knee. In the right specimens a large aponeurotic plate consisting of dense connective tissue was found to lie parallel oriented with the superficial and deep fascia of the vastus medialis muscle and this was found to be continuous with the medial capsule of the knee (Figure 18). This plate has to be severed to open the knee joint. 
When blunt dissection was continued proximally, the orientation of the muscle fibers changed to more vertically. Exploration of the transition between the oblique and more vertically oriented muscle fibers revealed only branches macroscopically claimed as neurovascular bundles, while dense connective tissue was less present. No dense connective tissue sheath was present defining an exact border between a vastus medialis obliquus $(\mathrm{VMO})$ and vastus medialis rectus (VMR), as described by others ${ }^{11,32}$ (Figure 19).

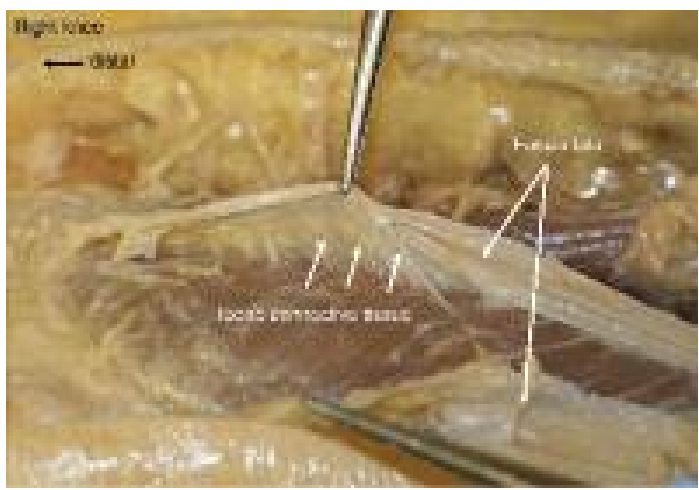

Figure 12.

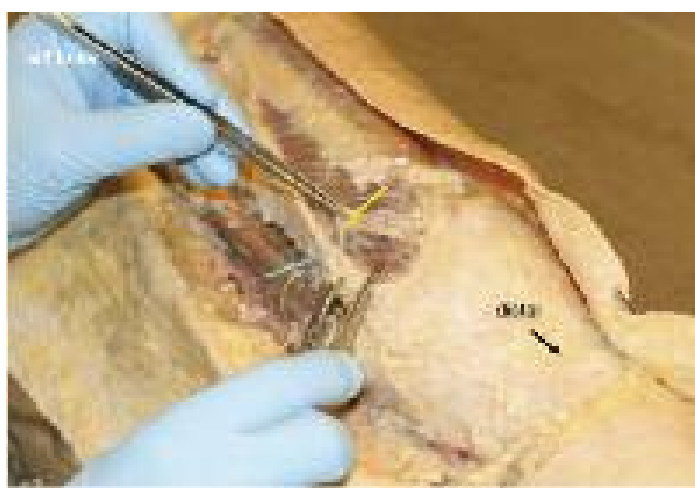

Figure 13. blue arrow = double sheet of fascia surrounding sartorius/vastus medialis muscles Yellow arrow $=$ neurovascular bundle 


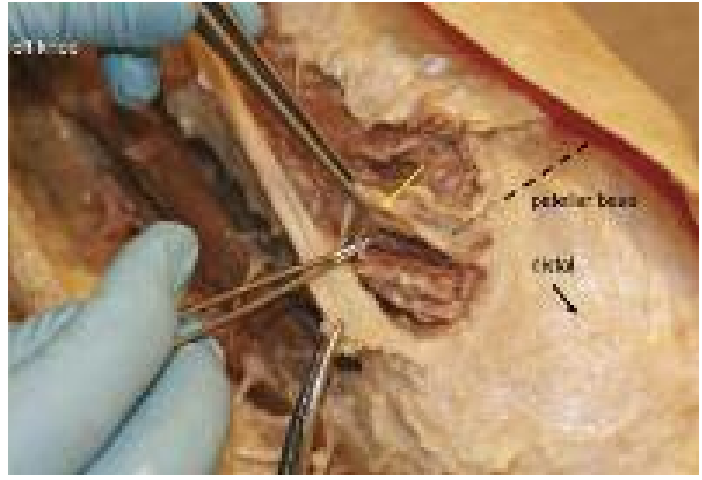

Figure 14. yellow arrow = neurovascular bundle

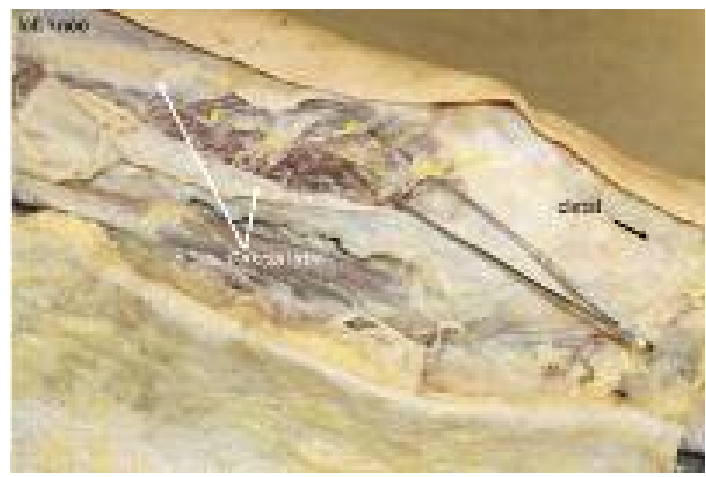

Figure 15. yellow arrows = neurovascular bundles

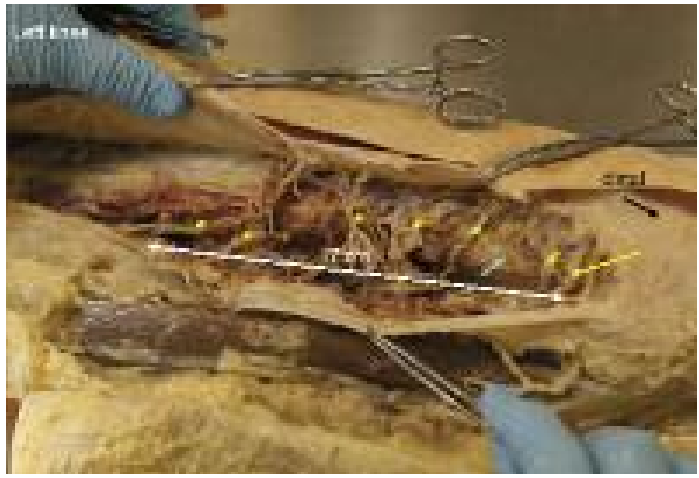

Figure 16. yellow arrows = neurovascular bundles

blue arrow $=$ distal aponeurotic vastus medialis plate 


\section{Subvastus vs parapetallair}

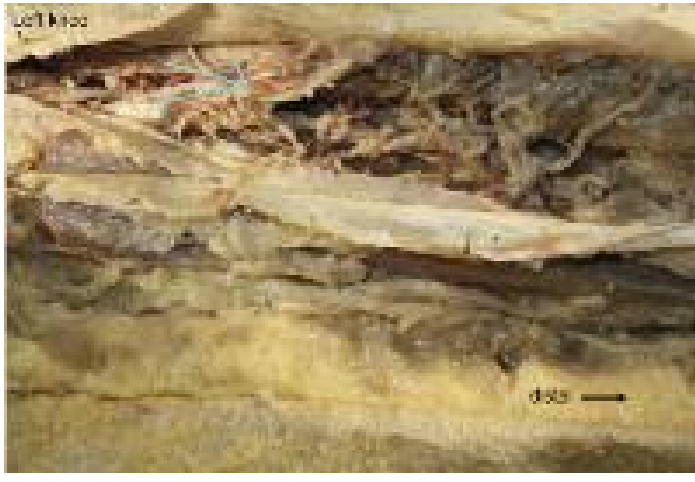

Figure 17. blue arrows = proximal aponeurotic vastus medialis plate

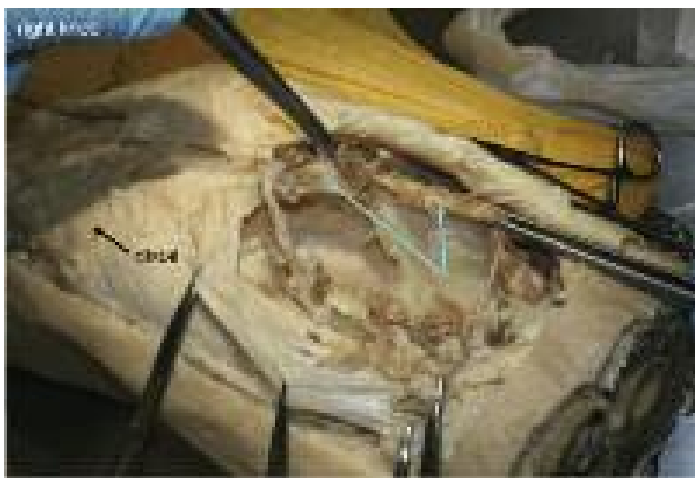

Figure 18. blue arrows $=$ distal aponeurotic vastus medialis plate

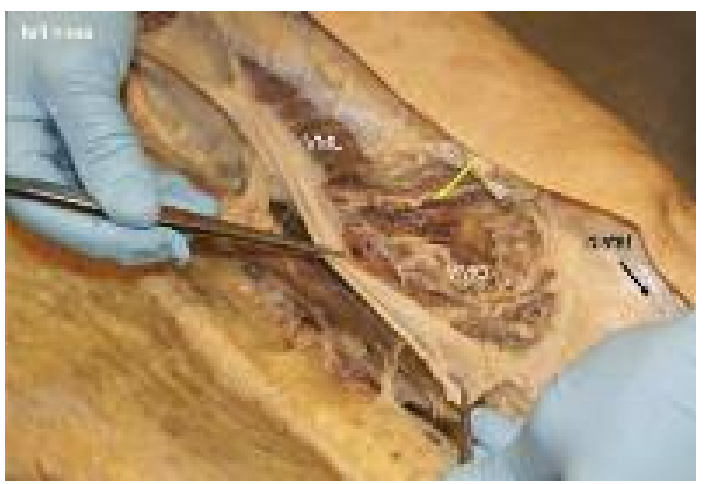

Figure 19. yellow arrow = neurovascular bundle between VMO and VMR 
In the vastus medialis compartment of the right specimen the $\mathrm{VMO}$ and VMR separating entity containing claimed neurovascular bundles was prepared for histology. In the histological sections neurovascular structures embedded in loose connective tissue indeed could be identified (Figures $20 \mathrm{~A}, \mathrm{~B}, \mathrm{C}$ )

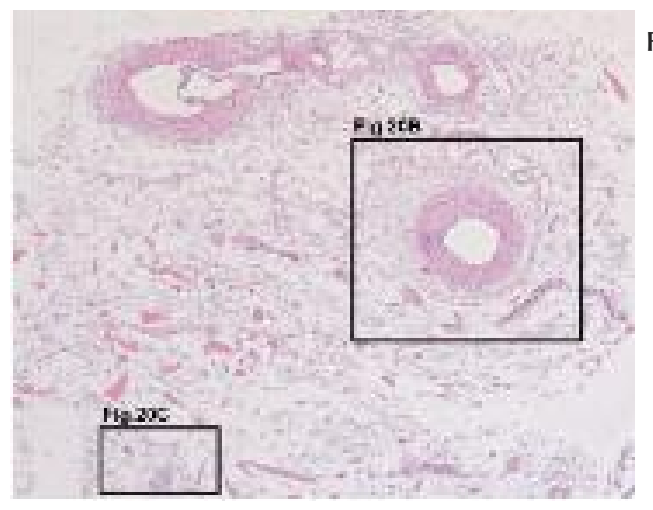

Figure 20A: H\&E $45 x$

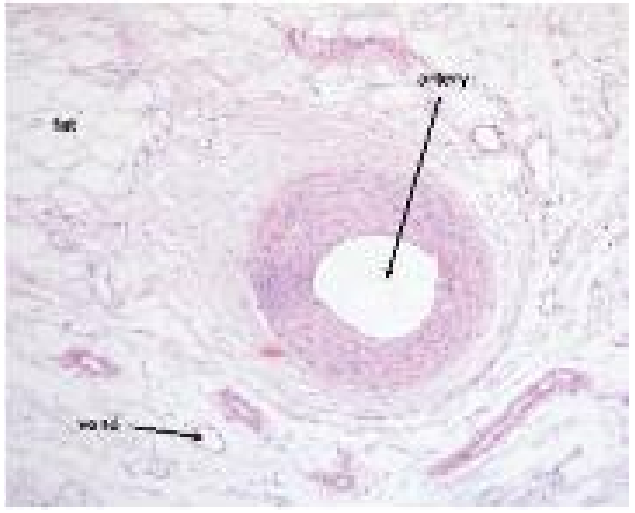

Figure 20B: H\&E100 x

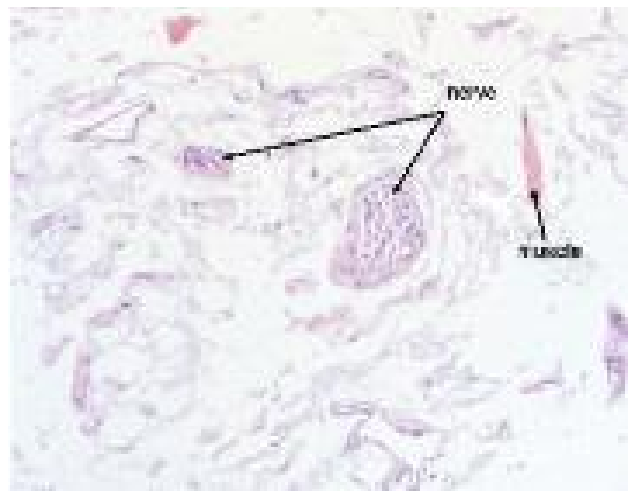

Figure 20C: H\&E $200 x$ 


\section{Discussion}

In this study we have compared the subvastus approach to the parapatellar approach in total knee arthroplasty (TKA). To our best knowledge this is the first paper to combine the disease specific Western Ontario and McMaster Universities Index for Osteoarthritis (WOMAC) ${ }^{4}$, Knee Society Score (KSS) and a objective performance based tool (Dynaport ${ }^{\circledR}$ knee test), as well as pain related score (VAS, PDI). We deliberately conducted a short-term clinical trial to focus on early recovery as this is deemed to be faster ${ }^{16}$ and both surgical procedures are considered to result in equal long term outcome ${ }^{7,20,37,39}$. Only early extension lag and reported WOMAC functioning was in favour of the subvastus group. We find this evidence insufficient to reject our hypothesis.

Current literature reports equal scores in terms of pain post operative, blood loss and need for substitution ${ }^{37}$. We found similar results. Pain was recorded using three different parameters, VAS, PDI as well as WOMAC. There is substantial pain relief compared to preoperative employing both approaches. No significant difference was found between groups. Since pain relief is the main reason for surgical intervention in knee osteoarthritis it should be considered as one of the key parameters.

We have appreciated function in this study in several scores. Function, as measured by manual flexion appreciation, seems to be advantageous for subvastus approach, in the first few postoperative days. First we distinguished those who were able to mobilise the first day postoperatively. Both group showed similar results where equal proportions of the patients in both group needed bed rest for one more day. Manual flexion measurements remained similar in both groups at the third day postoperative, contrary to the findings of Weinrauch et $a l^{11}$ and Weinhardt et $a l^{12}$, as they found better results for the subvastus approach compared to the parapatellar approach.

We have used the Dynaport ${ }^{\circledR}$ knee test in previous studies with success to demonstrate subtle differences in recovery issues after knee replacement. If we assume that the Dynaport ${ }^{\mathbb{B}} \mathrm{knee}$ test is rather sensitive in detecting small differences as we demonstrated before ${ }^{15,35}$, we conclude that in our study patients operated on using a subvastus approach are not functionally superior. Parent and Moffet $^{30}$ have demonstrated the usefulness of a gait test in early recovery. The Dynaport ${ }^{\circledR}$ Knee Test could therefore be more suitable for measurements in later time points in recovery after knee replacement.

Contrary to these findings we were able to detect significant functional advantages as measured by the WOMAC functioning score. Although the 
absolute values were not significantly different, employing the subvastus approach showed a significant steeper recovery after surgery compared to the parapatellar approach, but this finding was reverse between 6 weeks and three months. Kreibich et $a l^{17}$ and Parent et a ${ }^{\beta 0}$ studied the responsiveness of various parameters in relation to outcome after knee replacement independently and considered WOMAC (functioning) most responsive especially in early recovery phase.

Quadriceps strength as measured by lag deficiency ${ }^{38}$ showed mild short term superiority, which was confirmed by Cila et al ${ }^{8}$. We were able to show better performance of the subvastus group in the first few days since extension lag was significantly worse in the parapatellar group.

In relation to quadriceps functioning, in the report of Matsueda et al there has been great focus on the patellofemoral joint ${ }^{20}$. In his study the subvastus approach benefits patellar tracking. Although true patellar tracking should be considered a dynamic phenomenon this was recorded on a static 30 degrees patellar radiograph. Our patella tilt measurements showed no significant difference. Dynamic tests that challenge the patellofemoral function are reflected in the Rise and Descend subscore of the Dynaport ${ }^{\circledR}$ Knee test. In a previous paper we found this subscore discriminating in patellofemoral functioning ${ }^{35}$. However, the Rise and Descend subscore results also revealed no difference. It is uncertain by Matsueda et $a^{20}$ and Ozkoc et $a^{28}$ how patellar tilting correlates to clinical outcome.

Matsueda et $a 2^{20}$ also reports that fewer lateral retinacular releases have been performed in the subvastus group. This was said to be an advantage compared to the parapatellar approach. However, we consider a retinacular release a consequence of imbalance in the patello-femoral joint, mainly due to incorrect rotation of the femoral component.

The patella is vascularised through the extraosseus ring of the patella. Performing a lateral release may jeopardize the vascularity of the patella. In our dissection study (Figure 2), we found the medial part of this extraosseous ring to be located in the layered medial patellar retinaculum. We believe that these structures are severed in either of the two approaches as a medial incision of the retinaculum is performed in both approaches. Therefore the subvastus approach also does not preserve vascular integrity. Furthermore this retinaculum is trilaminar containing separate neurovascular structures and is medially a continuum of the distal vastus medialis muscle that effectively has to be severed in either of both approaches.

The vastus medialis obliquus (VMO) has been described as a separate 
entity of the vastus medialis muscle $e^{13,19,29,32}$. Panagiotopoulos et $a /^{29}$ emphasized the stabilising role of the medial patellofemoral ligament as being a part of the VMO. In this cadaveric biomechanical study, the contribution to the patellar stability was found to be around $50 \%$. Taskiran et a ${ }^{\beta 2}$ demonstrated that the $\mathrm{VMO}$ has its maximum contractility at early knee flexion as studied by integrated electromyography. However, employing our blunt dissection technique we have not encountered a VMO structure as a separate entity. This is an oblique or rather a more acute orientation of layered muscles fibres of the vastus medialis muscle. It is not separated by dense connective tissue resulting in a separate muscle unit. This has been supported by Hubbard et $a l^{13}$. We only found neurovascular structures at the level that is considered to be the anatomical border of the VMO. We therefore would propose to consider this a functional part of the vastus medialis muscle.

The vascularisation and innervation of the distal vastus medialis are located at immediate distal border of the vastus medialis fascia. During the subvastus approach these are at risk. Next to pain and joint effusion, this denervation could lead to loss of function due. This was also speculated by Kelly et al. ${ }^{14}$. Loss of quadriceps muscle strength seems rather a neurological deficit and failure of voluntary muscle activation than pain or savage of the tendon itself ${ }^{24,25}$.

The anterior and medial vastus medialis attachment to dense connective tissue layers of patellar insertion is preserved during subvastus approach. However, the posteromedial origo is severed (Figure 18). Here, a substantial part of the quadriceps attachment has to be released in order to perform the arthrotomy. This quadriceps attachment is considered as a major component in patellar stability, tracking and extensor mechanism ${ }^{31}$.

There is a limitation in this study. The relatively small sample size chosen based on the power analysis for the Dynaport ${ }^{\circledR}$ Knee test might result in type II error considering other parameters. Especially the outcome of VAS measurements, as they near significances, must therefore be interpreted with caution. When a bigger sample had been chosen, this could have resulted in significant differences. Preoperatively, the group already differ almost one point and therefore postoperative significances may be caused by existing differences. We think differences of al least more than one standard deviation is needed to add relevance.

Next to generic and disease specific scores, the use of objective or performance based instruments in studies on functional outcome is warranted. We have not encountered a report that describes the use of such in the 
comparison of parapatellar versus subvastus. Multiple reports have been published on different knee topics ${ }^{15,33,35}$. Pain is likely to influence the difference between self-reported questionnaires and objective tests.

Although we encountered mild very early advantages employing the subvastus approach early postoperative and vice versa later postoperative, evidence in functional gain seems rather weak to make a funded choice between both options. Employing a parapatellar arthrotomy has its advantages both in easiness and also of avoidance of muscle damage. We will continue to use the parapatellar approach.

\section{Acknowledgement}

We thank Maarten Werkman, Carola Munch, Tom Vanderhenst and Ghislain Geurts for assistance. 


\section{Subvastus vs parapetallair}

\section{LITERATURE}

1. Argenson JN, Scuderi GR, Komistek RD, Scott WN, Kelly MA, Aubaniac JM (2005) In vivo kinematic evaluation and design considerations related to high flexion in total knee arthroplasty. J Biomech 38:277-284

2. Bach CM, Nogler M, Steingruber IE, Ogon M, Wimmer C, Gobel G, Krismer M (2002) Scoring systems in total knee arthroplasty. Clin Orthop Relat Res:184-196

3. Barink M, Van de Groes S, Verdonschot N, De Waal Malefijt M (2006) The difference in trochlear orientation between the natural knee and current prosthetic knee designs; towards a truly physiological prosthetic groove orientation. J Biomech 39:1708-1715

4. Bellamy N, Buchanan WW, Goldsmith CH, Campbell J, Stitt LW (1988) Validation study of WOMAC: a health status instrument for measuring clinically important patient relevant outcomes to antirheumatic drug therapy in patients with osteoarthritis of the hip or knee. J Rheumatol 15:1833-1840

5. Berth A, Urbach D, Awiszus F (2002) Improvement of voluntary quadriceps muscle activation after total knee arthroplasty. Arch Phys Med Rehabil 83:1432-1436

6. Berth A, Urbach D, Neumann W, Awiszus F (2007) Strength and voluntary activation of quadriceps femoris muscle in total knee arthroplasty with midvastus and subvastus approaches. J Arthroplasty 22:83-88

7. Chen AF, Alan RK, Redziniak DE, Tria AJ, Jr. (2006) Quadriceps sparing total knee replacement. The initial experience with results at two to four years. J Bone Joint Surg Br 88:1448-1453

8. Cila E, Guzel V, Ozalay M, Tan J, Simsek SA, Kanatli U, Ozturk A (2002) Subvastus versus medial parapatellar approach in total knee arthroplasty. Arch Orthop Trauma Surg 122:65-68

9. Davies AP (2002) Rating systems for total knee replacement. Knee 9:261-266

10. Franklin PD, Li W, Ayers DC (2008) The Chitranjan Ranawat Award: functional outcome after total knee replacement varies with patient attributes. Clin Orthop Relat Res 466:2597-2604

11. Holt G, Nunn T, Allen RA, Forrester AW, Gregori A (2008) Variation of the vastus medialis obliquus insertion and its relevance to minimally invasive total knee arthroplasty. J Arthroplasty 23:600-604

12. Huang HT, Su JY, Chang JK, Chen CH, Wang GJ (2007) The early clinical outcome of minimally invasive quadriceps-sparing total knee arthroplasty: report of a 2-year followup. J Arthroplasty 22:1007-1012

13. Hubbard JK, Sampson HW, Elledge JR (1997) Prevalence and morphology of the vastus medialis oblique muscle in human cadavers. Anat Rec 249:135-142 


\section{Chapter 5}

14. Kelly MJ, Rumi MN, Kothari M, Parentis MA, Bailey KJ, Parrish WM, Pellegrini VD, Jr. (2006) Comparison of the vastus-splitting and median parapatellar approaches for primary total knee arthroplasty: a prospective, randomized study. J Bone Joint Surg Am 88:715-720

15. Kleijn LL, van Hemert WL, Meijers WG, Kester AD, Lisowski L, Grimm B, Heyligers IC (2007) Functional improvement after unicompartmental knee replacement: a follow-up study with a performance based knee test. Knee Surg Sports Traumatol Arthrosc

16. Kort N (2007) Unicompartmental Knee Arthroplasty. Groningen

17. Kreibich DN, Vaz M, Bourne RB, Rorabeck CH, Kim P, Hardie R, Kramer J, Kirkley A (1996) What is the best way of assessing outcome after total knee replacement? Clin Orthop Relat Res:221-225

18. Lavernia CJ, D'Apuzzo MR, Hernandez VH, Lee DJ, Rossi MD (2006) Postdischarge costs in arthroplasty surgery. J Arthroplasty 21:144-150

19. Lefebvre R, Leroux A, Poumarat G, Galtier B, Guillot M, Vanneuville G, Boucher JP (2006) Vastus medialis: anatomical and functional considerations and implications based upon human and cadaveric studies. J Manipulative Physiol Ther 29:139-144

20. Matsueda M, Gustilo RB (2000) Subvastus and medial parapatellar approaches in total knee arthroplasty. Clin Orthop Relat Res:161-168

21. Maxwell S, Delaney H (2003) Designing Experiments and Analyzing Data: A Model Comparison Perspective, Second Edition. Lawrence Erlbaum

22. Miner AL, Lingard EA, Wright EA, Sledge CB, Katz JN (2003) Knee range of motion after total knee arthroplasty: how important is this as an outcome measure? J Arthroplasty 18:286-294

23. Mizner RL, Petterson SC, Snyder-Mackler L (2005) Quadriceps strength and the time course of functional recovery after total knee arthroplasty. J Orthop Sports Phys Ther 35:424-436

24. Mizner RL, Petterson SC, Stevens JE, Vandenborne K, Snyder-Mackler L (2005) Early quadriceps strength loss after total knee arthroplasty. The contributions of muscle atrophy and failure of voluntary muscle activation. J Bone Joint Surg Am 87:1047-1053

25. Mizner RL, Stevens JE, Snyder-Mackler L (2003) Voluntary activation and decreased force production of the quadriceps femoris muscle after total knee arthroplasty. Phys Ther 83:359-365

26. Mokkink LB, Terwee CB, van der Slikke RM, van Lummel RC, Benink RJ, Bouter LM, de Vet HC (2005) Reproducibility and validity of the DynaPort KneeTest. Arthritis Rheum 53:357-363

27. Mokkink LB, Terwee CB, van Lummel RC, de Witte SJ, Wetzels L, Bouter LM, de Vet HC (2005) Construct validity of the DynaPort KneeTest: a comparison with observations of physical therapists. Osteoarthritis Cartilage 13:738-743 
28. Ozkoc G, Hersekli MA, Akpinar S, Ozalay M, Uysal M, Cesur N, Tandogan RN (2005) Time dependent changes in patellar tracking with medial parapatellar and midvastus approaches. Knee Surg Sports Traumatol Arthrosc 13:654-657

29. Panagiotopoulos E, Strzelczyk P, Herrmann M, Scuderi G (2006) Cadaveric study on static medial patellar stabilizers: the dynamizing role of the vastus medialis obliquus on medial patellofemoral ligament. Knee Surg Sports Traumatol Arthrosc 14:7-12

30. Parent E, Moffet H (2002) Comparative responsiveness of locomotor tests and questionnaires used to follow early recovery after total knee arthroplasty. Arch Phys Med Rehabil 83:70-80

31. Sakai N, Luo ZP, Rand JA, An KN (2000) The influence of weakness in the vastus medialis oblique muscle on the patellofemoral joint: an in vitro biomechanical study. Clin Biomech (Bristol, Avon) 15:335-339

32. Taskiran E, Dinedurga Z, Yagiz A, Uludag B, Ertekin C, Lok V (1998) Effect of the vastus medialis obliquus on the patellofemoral joint. Knee Surg Sports Traumatol Arthrosc 6:173-180

33. van den Akker-Scheek I (2007) Recovery after short-stay total hip and knee arthroplasty. Evaluation of a support program and outcome determination. Orthopaedic Surgery. Groningen

34. van den Dikkenberg N, Meijer OG, van der Slikke RM, van Lummel RC, van Dieen JH, Pijls B, Benink RJ, Wuisman PI (2002) Measuring functional abilities of patients with knee problems: rationale and construction of the DynaPort knee test. Knee Surg Sports Traumatol Arthrosc 10:204-212

35. van Hemert WL, Senden R, Grimm B, Kester AD, van der Linde MJ, Heyligers IC (2008) Patella retention versus replacement in total knee arthroplasty; functional and clinimetric aspects. Arch Orthop Trauma Surg

36. van Mameren H, Lataster A, Rensema H, Drukker J (1985) The use of modern imaging techniques (CT-scanning and NMR) in the study of the locomotor apparatus. Acta Morphol Neerl Scand 23:247-257

37. Weinhardt C, Barisic M, Bergmann EG, Heller KD (2004) Early results of subvastus versus medial parapatellar approach in primary total knee arthroplasty. Arch Orthop Trauma Surg 124:401-403

38. Weinrauch P, Myers N, Wilkinson M, Dodsworth J, Fitzpatrick P, Whitehouse S (2006) Comparison of early postoperative rehabilitation outcome following total knee arthroplasty using different surgical approaches and instrumentation. J Orthop Surg (Hong Kong) 14:47-52

39. White RE, Jr., Allman JK, Trauger JA, Dales BH (1999) Clinical comparison of the midvastus and medial parapatellar surgical approaches. Clin Orthop Relat Res:117-122 


\section{ChaPTER 6}

\section{Patella retention versus}

replacement in total knee arthroplasty;

\section{functional and clinimetric aspects}

Wouter L.W. van Hemert, Rachel Senden, Arnold D.M. Kester, Bernd Grimm, Matthijs J.A. van de Linde, Ide C. Heyligers

Arch Orthop Trauma Surg. 2009 Feb;129(2):259-65. 


\section{Abstract}

Whether to resurface the patella or not in total knee arthroplasty still remains undecided. Classical scores and questionnaires might not be responsive or demanding enough. This study used two accelerometer based systems to study the hypothesis whether performance based tests are able to detect a difference in patients with or without a resurfaced patella.

In this retrospective study 53 patients were included and divided into a resurfaced group $(n=31)$ and a non-resurfaced group $(n=22)$. Both groups were matched on age and longevity of follow up. Patients were clinically assessed using the Knee Society Score (KSS) at various time points. At final follow-up patients were also assessed once using the Dynaport ${ }^{\circledR}$ Knee Test and the Minimod $^{\circledR}$ Gait Test.

The Dynaport ${ }^{\circledR}$ Knee Test showed a significant functional advantage for patients with a resurfaced patella (44 vs. $39.7(p=0.042)$ ), whereas KSS and The Minimod ${ }^{\circledR}$ were not significant ( $p$ values ranging from $0.07-0.75$ ).

Similar to other reports in literature, using the KSS, it was not possible to identify significant difference between patella resurfacing or retaining in total knee arthroplasty, however using a performance based test it was possible to determine significant difference. The found advantage of patella resurfacing may be less due to pain relief but due to a functional benefit during demanding motion tasks. This finding indicates that current measurement tools may not be accurate or specific enough to detect this difference. Therefore we recommend complementing the classic evaluation tools with an objective functional test, when conducting a randomized trial to answer the indecision whether to resurface the patella or not. 


\section{INTRODUCTION}

Whether to resurface the patella in a total knee arthroplasty remains a frequently discussed issue in literature ${ }^{1,3,4,8,12,17,22,24,26,28,31,32}$. Since resurfacing the patella has been related to complications, there has been evident renewed interest in patellar retention ${ }^{2}$. Previous studies of patellofemoral problems after total knee arthroplasty have focused on the prevalence of prosthetic revision, patellar complications and functional results. However in a short term followup randomised clinical trial Waters et al. ${ }^{31}$ report on a higher incidence of anterior knee pain without resurfacing. Barrack et al.3 showed in a randomised clinical trial that outcome was similar between resurfaced and non resurfaced patellae, with 10 per cent requiring secondary resurfacing. Outcome was not related to the pre operative presence of anterior knee pain, obesity, or grade of chrondromalacia. In a randomised clinical trial Burnett et al. ${ }^{9}$ found no difference in outcome after ten years in revision rates, Knee Society Score (KSS), patient satisfaction, anterior knee pain and radiographic outcome.

There is a tendency for surgeons to resurface the patella in patients with inflammatory arthritis $3,13,32$. Furthermore, patellar resurfacing seems to be recommended in patients with case of a large, thick patella, a multiple operated knee, pre operative maltracking ${ }^{27}$ or patella pain ${ }^{17}$. Conversely patellar retention is advocated in case of small patella, patella baja/alta, the young aged patients, poor bone quality, well preserved articular cartilage, normal patella tracking and absence of patella pain ${ }^{6,17}$. Some papers report that patellar resurfacing improved pain relief and the ability to climb stairs ${ }^{32}$. Most mentioned indications are poorly evidence based, but merely expert opinions ${ }^{2,14}$. Although a tendency exists towards resurfacing the patella in total knee arthroplasty ${ }^{6}$, today no study can present results of resurfacing being superior to not resurfacing. A recent meta-analysis from 12 randomised clinical trials leans towards resurfacing, however still no definite conclusion can be drawn ${ }^{23}$.

A reason for the inconclusiveness may be that a substantial difference between both surgical options does not exist or that current methods of measuring clinical outcome are not sensitive enough to detect them. Performance based knee tests have been used to focus on functional differences and showed superior responsiveness to functional outcome to conventional questionnaires and scores.

Most studies, however, focus on classical function $\operatorname{scores}^{3,7,31}$, whereas few other papers use other, objective measurement tools, such as gait related 
tests. Pollo et $a^{25}$ gathered kinematic and kinetic parameters from 9 resurfaced and 9 not resurfaced patellae using a 5-camera Motion Analysis System and a force platform. They found no significant difference in the biomechanics of walking, stair climbing or chair rising between these patient groups, although this patient group may be too small for such a highly confounded study. Current objective measurement systems such as electromyography, force platforms, optokinematic systems are available, but are time consuming and require sophisticated laboratories. In view of this problem accelerometer based, userfriendly systems have become available such as the Dynaport ${ }^{\circledR}$ Knee Test[30] and the Minimod ${ }^{\circledR}$ gait test. The former objectively assesses functional abilities in a standardized set of tasks, closely related to activities of daily living, whereas the latter records basic parameters of human gait.

We conducted a study to determine the feasibility of aforementioned gait tools on patients after total knee replacement with and without resurfacing the patella. The hypothesis of this study was that, if any difference exists in clinical and functional outcome between patella resurfacing and retention, it could be detected using a performance based knee test and a gait test contrary to conventional scores.

\section{MATERIAL AND METHODS}

A cohort of 53 patients operated for osteoarthritis of the knee by two surgeons receiving unilateral total knee arthroplasty between 2002 and 2004 were included into this study. With one surgeon always resurfacing the patella and the other one routinely never resurfacing the patella, the patients were divided into a resurfaced group $(n=31)$ and a non-resurfaced group $(n=22)$. Patients were included for analysis when they were beyond 6 months after surgery, had unilateral involvement and were physically and mentally able to perform the gait test. Both groups were matched on age and longevity of follow up.

The Scorpio ${ }^{\circledR}$ Total Knee System (Stryker Nederland BV, Waardenburg, The Netherlands) was used in a cruciate retaining version. The design of the prosthesis includes a single radius femoral component and an increased patello-femoral lever arm to reduce the moment in this joint during flexionextension, possibly reducing patello-femoral pain risk. The surgical technique to treat the patella, regardless whether resurfaced or not, consisted of routine removal of patellar osteophytes, complete circular patella denervation with cautery and a lateral release in two cases (non-resurfacing group) for optimization of patellar tracking. 
Patients were clinically assessed using the Knee Society Score (KSS) pre operative, just before surgery and three months and test day (the duration depending on their individual time to follow up). Pre operative and three month values were available due to routine implant documentation and these were acquired retrospectively. At final follow-up patients were also assessed once using the Dynaport Knee Test (McRoberts BV, The Hague, Netherlands), Approval was acquired from the local Medical Ethics Committee.

\section{Clinician based rating scores}

The Knee Society Score was used as a clinical outcome and comparison. The KSS score is subdivided into a Knee score that scores the knee joint only and a Function score that rates pain, patient's ability to walk and climb stairs and the need for a support device ${ }^{15}$. It has been proven reliable as described by Kreibich et a $/^{19}$.

\section{The Dynaport ${ }^{\circledR K}$ Knee Test}

The Dynaport system consists of 5 accelerometers that the patient wears at various positions (Figure 1) while performing a set of motion tasks mimicking daily activities of various difficult levels such as walking, stair climbing or rising from a chair. The signal is recorded, analyzed and a score is calculated ranging from zero to 100 (best). The total Dynaport score is composed of four sub scores grouped by the nature of the motion tasks involved (Locomotion, Rise \& Descend, Transfers, Lift \& Move). The rationale and validation of the system has been reported ${ }^{30}$.

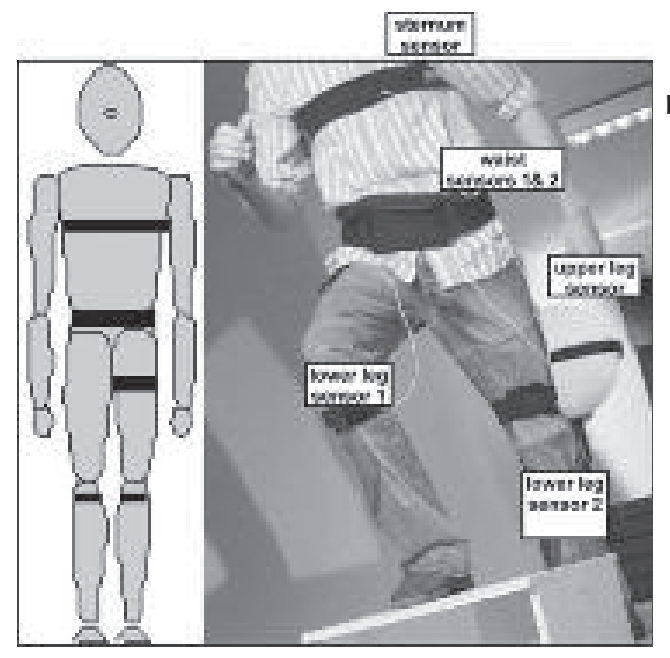

Figure 1: Dynaport Knee Test. 


\section{The Minimod $^{\circledR}$ Gait Test}

The second movement tool used in this study was the Minimod ${ }^{\circledR}$ system. This module contains three acceleration sensors measuring the walking direction, the vertical direction and the left-right direction. It is worn at the lower back while walking a set distance of twenty meters and records the tri-axial acceleration. After the measurement the data is analysed using proprietary software calculating various gait parameters and then the Minimod ${ }^{\circledR}$ Gait Test is divided into four categories: speed, asymmetry (differences between left and right), irregularity and inefficiency (inconsistency between successive steps). A validation study of this system has identified certain parameters to be more reproducible and sensitive than others ${ }^{18}$ and these have used to analyse patient groups: step frequency, step length walking speed, vertical displacement and asymmetry in step time, asymmetry in vertical displacement, asymmetry in forward acceleration and asymmetry moving up and down.

\section{Statistical analysis}

In order to test our hypothesis we compared the groups as measured by the KSS and The Dynaport ${ }^{\circledR}$ Knee Test. An expert in statistics was consulted to deal with pre study bias of selection in age, time of follow up and pre operative difference in KSS. Because of this preoperative difference in mean KSS between the groups, the analysis was stratified for high (above median) and low initial KSS. Since the follow-up KSS scores were not normally distributed, a stratified nonparametric Mann-Whitney rank-sum test (the Van Elteren test ${ }^{20}$ ) was used to test the difference in KSS between the two groups. The Dynaport ${ }^{\circledR}$ Knee Test scores were normally distributed; here we used a parametric linear regression analysis, with the stratification as a covariate, to test the difference between the study groups. The results of the Minimod ${ }^{\circledR}$ Test were analyzed either nonparametrically or parametrically as above, depending on normality of the data. All analyses were done using STATA statistical software (version 8.2, StataCorp, College Station, TX, USA). The level of significance was set at $p<0.05$.

\section{RESULTS}

The mean time of follow-up was 16.7 months (range 6-29 months) in the retained group and 17 months (range 6-27 months) in the resurfaced group and found not to be significantly different (Table 1). Patient characteristics as BMI and age were not significantly different. During follow up no complications were noted. All results are presented in Table 1. 


\begin{tabular}{|c|c|c|c|c|c|}
\hline & \multicolumn{2}{|c|}{ Patella resurfacing $(n=31)$} & \multicolumn{3}{|c|}{ Patella retention $(\mathrm{n}=22)$} \\
\hline & Mean & SD & Mean & SD & \\
\hline Age [years] & 72.5 & 8.8 & 71.0 & 7.7 & 0.526 \\
\hline BMI & 28.1 & 3.6 & 28.7 & 4.3 & 0.624 \\
\hline FU [months] & \multicolumn{2}{|c|}{$17(6-29)$} & \multicolumn{2}{|c|}{$17(6-27)$} & 0.889 \\
\hline KSS pre-op & 42.8 & 16.5 & 50.5 & 13.8 & 0.080 \\
\hline KSS at 3 month & 76.3 & 22.2 & 78.1 & 18.5 & 0.550 \\
\hline KSS at FU & 85.0 & 14.0 & 83.1 & 13.5 & 0.290 \\
\hline The Dynaport ${ }^{\circledR}$ Knee Test & 44.1 & 12.1 & 39.7 & 19.2 & $0.042^{*}$ \\
\hline Locomotion & 43.5 & 11.7 & 38.9 & 16.9 & 0.051 \\
\hline Rise \& Descend & 44.7 & 15.9 & 39.7 & 22.5 & $0.035^{*}$ \\
\hline Transfers & 37.3 & 13.1 & 34.4 & 19.2 & 0.057 \\
\hline Lift \& Move & 51.0 & 14.7 & 46.4 & 21.7 & 0.150 \\
\hline
\end{tabular}

Table 1: Patient characteristics, KSS and Dynaport ${ }^{\circledast}$ scores

The mean pre operative KSS in the resurfaced group was $42.7 \pm 16.5$ and was $50.5 \pm 13.8$ in the non resurfaced group which was not significantly different $(p=0.08)$. The mean post operative KSS at three months in the resurfaced group improved to $76.3 \pm 22.2$ and was $78.0 \pm 18.5$ in the non resurfaced group which was not significantly different $(p=0.55)$. The KSS continued to improve until the test day to $85.0 \pm 14.0$ in the non resurfaced group and was $83.1 \pm 13.5$ in the resurfaced group and no significant difference could be demonstrated $(p=0.29)$.

The mean Dynaport ${ }^{\circledR}$ Knee Test score in the resurfaced group was $44.1 \pm$ 12.1 which is a higher score than $39.7 \pm 19.2$ in the non resurfaced group and was significantly different $(\mathrm{p}=0.042)$ (Table 1 , Figure 2$)$. The mean sub score Locomotion in the resurfaced group was $43.5 \pm 11.9$ compared to $38.9 \pm 16.7$ in the non resurfaced group, but not significantly different $(p=0.051)$. The mean sub score Rise and Descend in the resurfaced group was $44.7 \pm 15.9$ which is a higher and significant score than $39.6 \pm 22.5$ in the non resurfaced group $(p=0.035)$. The mean sub score Lift and Move in the resurfaced group was 37.3 \pm 13.1 compared to $34.4 \pm 19.2$ in the non resurfaced group, but not significantly different $(\mathrm{p}=0.057)$. The mean sub score Transfers in the resurfaced group was $51.0 \pm 14.7$ compared to $46.4 \pm 21.7$ in the non resurfaced group, but not significantly different $(\mathrm{p}=0.15)$.

The values of the Minimod ${ }^{\circledR}$ gait test are listed in Table 2. Step frequency 
was $1.79 \pm 0.221 / \mathrm{s}$ in the resurfaced group and was significantly faster than the step frequency of $1.66 \pm 0.27 \mathrm{1} / \mathrm{s}$ in the retention group $(\mathrm{p}=0.020)$. The mean step length of the resurfacing group was $0.61 \pm 0.11 \mathrm{~m}$ and $0.58 \pm 0.13 \mathrm{~m}$ of the retention group, though not significant $(p=0.070)$. The mean walking speed was significantly faster $(p=0.030)$ in the resurfaced group than the retention group $(1.08 \pm 0.24 \mathrm{~m} / \mathrm{s}$ vs. $0.99 \pm 0.33 \mathrm{~m} / \mathrm{s})$. Other scores reached differences at non significant levels.

The Dynaport Knee Test

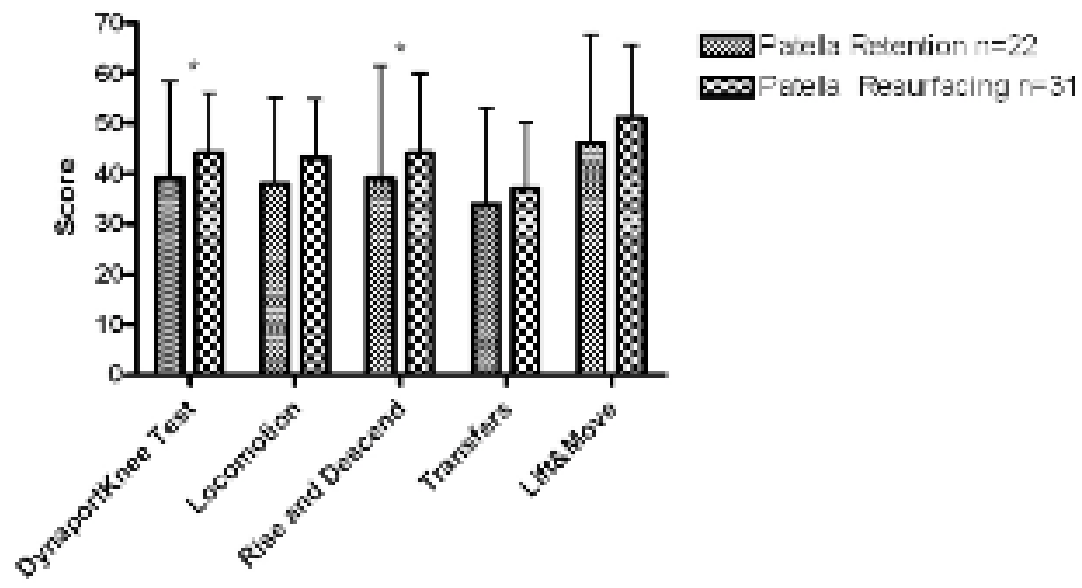

Figure 2: Dynaport scores (Mean $\pm \mathrm{SD}$ ) and significant differences ${ }^{*}$ ) in favor of resurfacing.

\begin{tabular}{lccccc} 
& \multicolumn{7}{c}{ Patella resurfacing $(\mathrm{n}=31)$} & \multicolumn{2}{c}{ Patella retention $(\mathrm{n}=22)$} & \\
& Mean & Sd. & Mean & Sd. & P value \\
\hline Step frequency $(1 / \mathrm{s})$ & 1.79 & 0.22 & 1.66 & 0.27 & $0.020^{*}$ \\
Step length $(\mathrm{m})$ & 0.61 & 0.11 & 0.58 & 0.13 & 0.070 \\
Walking speed $(\mathrm{m} / \mathrm{s})$ & 1.08 & 0.24 & 0.99 & 0.33 & $0.030^{*}$ \\
Vertical displacement $(\mathrm{m})$ & 0.06 & 0.05 & 0.05 & 0.01 & 0.824 \\
Asymmetry in step time & 0.07 & 0.06 & 0.07 & 0.05 & 0.732 \\
Asymmetry in vertical displacement & 0.15 & 0.09 & 0.13 & 0.09 & 0.565 \\
Asymmetry in forward acceleration & 0.23 & 0.18 & 0.17 & 0.13 & 0.487 \\
Asymmetry in up and down movement & 0.21 & 0.15 & 0.22 & 0.12 & 0.724 \\
\hline Significant differences ${ }^{*}$ ) & & & & &
\end{tabular}

Table 2: MiniMod Gait Test scores 


\section{Discussion}

In this study we have investigated whether a performance based test and a gait parameter test could distinguish whether a difference exists between patella resurfacing and retention in total knee arthroplasty. It was our goal to report on the feasibility rather than investigating the superiority of either option. In our study the pre and post operative KSS as well as the improvement that was achieved in the time postoperative was similar to the KSS of patients described in literature ${ }^{13}$. This indicates that The Dynaport ${ }^{\circledR}$ Knee Test was conducted on a representative group of patients and thus the acquired data with the movement analysis tests can be considered representative.

A number of studies where patellar resurfacing was performed randomly have demonstrated that the results are not superior in terms of pain relief. It can be questioned if we can't detect any significant differences due to unresponsive measurement tools or whether there's no difference at all. In our study, using the KSS we could not distinguish between pain, and functional related scores between patients with resurfaced patella and with patellar retention.

However, it has been stated that both the relative risk for re-operation is higher and the incidence of anterior is increased in case of patellar retention ${ }^{23}$. In relation to these favours we have demonstrated that a significant difference does exist and shows a trend towards resurfacing the patella. The Dynaport ${ }^{\circledR}$ Knee Test favours patella resurfacing and shows significances in both the overall score as well as the subscore Rise and Descend. The Rise and Descend score consists of walking up and down steps of certain levels, slope walking, stepping onto blocks of different heights and chair rising. It can be considered the most difficult part of the test, since the patellofemoral lever arm and quadriceps force is the highest. Active extension during stair climbing is dependent on both the amount on quadriceps contracture as the amount of knee flexion. At this point the patello-femoral contact forces are increased and the patello-femoral lever arm is the largest at 45 degrees of flexion, which typically occurs in the Rise and Descend task. The quadriceps muscles are already significantly weakened due to pre operative osteoarthritis, but needed substantially. In this study, it remains unclear however, what the pathophysiologic basis of this difference is. It can be hypothesized that a difference in patella femoral lever arm due to resurfacing or retention causes a relative insufficiency of the quadriceps muscle. We did not measure this. Barrack et $a \beta^{3}$ also suggest the patellofemoral joint as an important parameter in the evaluation after total knee arthroplasty and that stair climbing ability is the 
most specific activity to assess such function. Wood et $a l^{32}$ demonstrated that stair descent was better after patellar resurfacing: twenty-eight (33\%) of eightyfour patients managed so with a unilateral total knee arthroplasty that did not include patellar resurfacing, compared with eleven (19\%) of fifty-eight managed with patellar resurfacing, that descended stairs leading with the treated limb, indicating an inability or reluctance to load the affected knee. Cameron ${ }^{10}$ studied sixty-eight patients with resurfacing comparing them to forty-three with retention. He concluded that retention was inferior because fewer could climb stairs normally, whereas differences in pain scores were not significant. Soudry et a ${ }^{29}$ even recommend routine resurfacing because of such deficit. Therefore rather inability to climb stair rather than anterior knee pain could be the reason for routine resurfacing. Most tasks in daily life load the patello femoral joint only little and it can be stated that these are presumably not affected by the strategy of resurfacing or not. It indicates there are not many parameters discriminative enough to set for when studying possible differences between resurfacing or not.

The less demanding tasks such as walking different distances (Locomotion), transferring different objects (Lift and Move) or getting up and down (Transfers) also showed functional preference for resurfacing but were not discriminative enough to provide statistical evidence. However, locomotion aspects as measured with the Minimod ${ }^{\circledR}$ does show a significant advantage in favour of patella resurfacing. The discrepancy between the non significant Dynaport Locomotion and significant Minimod ${ }^{\circledR}$ can be attributed to the fact that the Dynaport Locomotion is a clustered score and therefore may be less responsive that a true gait parameter.

Berti et a $\left.\right|^{5}$ was able to report significant differences as well. He studied 10 patients with patellar resurfacing and 10 patients without patellar resurfacing using motion analysis during stair climbing as well as the International Knee Society and the Hospital for Special Surgery scores: the clinician based scores turned to be significant and next the stair climbing tests showed a significant better result in favor of the resurfaced patellae as in our study. Pollo et a $\left.\right|^{25}$ could not demonstrate any difference either, although he studied only eighteen subjects and therefore lack of power could be the confounding factor.

The found differences can also be explained using the recommendations from the study of Maly et $a^{21}$, who demonstrated that self-report measures are strongly related to pain, whereas physical performance measures are strongly related to self-efficacy. The Dynaport ${ }^{\mathbb{Q}}$ Knee Test and Minimod ${ }^{\mathbb{Q}}$ test are regarded as truly objective where the KSS holds certain subjectiveness both from the 
treating surgeon as from the patient. The clinimetric aspect of different tests seems to be the key factor in determining any differences in the topic on patella resurfacing.

Several issues are beyond the scope of this paper, though potentially influential and worth addressing. We have not discussed in detail the design among prostheses in general that could inflict differences in patellofemoral dynamics, depending on the adaptation of the femoral trochlear groove and the native and/or the resurfaced patella. The choice whether to retain or substitute the posterior cruciate ligament can be influential. An anterior translation of the femoral condyles exists during knee flexion in a cruciate retaining knee replacement ${ }^{11}$. This might inflict an increase in patellofemoral contact forces, which was observed between 30 and 60 degrees of flexion in weightbearing conditions $^{33}$. The design in the prosthesis used in this study however includes an increased patellofemoral lever arm to reduce the moment in this joint during flexion-extension, possibly reducing patellofemoral pain risk. Posterior stabilized knee replacements might alter pain and functional measurements, although in general the choice between both options remains indecisive ${ }^{16}$.

Furthermore a discussion of post operative complications is also of influence on the choice of patella resurfacing. Lastly, the use of accelerometer based systems in this study results in significant differences. However it can be discussed whether a higher or lower measured value also can be interpreted as better or worse. A difference in step time cannot be explained as a superior result. It results in a difference anyhow, which has not been found using clinician based scores. Furthermore we acknowledge a potential bias rests in the choice of two surgeons participating. However we think we have selected a series that are treated according to the preferred method of both surgeons, which indicates that retention or resurfacing was performed according to their expertise. A single surgeon series, although being the gold standard, can be considered to include either of both options to be performed inferiorly, depending on the surgeon's preference.

We conclude that with current measurement tools available in orthopaedics as clinician based scores and self reported questionnaires, existing differences in patellar resurfacing, if any, cannot be recorded. However, a performance based knee test as used. Due to certain flaws in the design of the study claiming resurfacing the patella being superior as demonstrated is inappropriate. However this study demonstrates the relativity of the conventional clinical measurement tools. To establish the superiority of either of both options, a large randomised prospective trial with long term follow up and 
large patient numbers should be performed. To our opinion further studies investigating this topic, should not only focus on randomising large numbers of patients, but should also include next any of available performance based tools to examine patients provided that it is discriminative enough. Challenging the patello-femoral joint objectively seems to be a key parameter that could make the difference.

\section{Conflict of interest statement}

The authors have not received any financial support from third parties that could be of influence on this work. 


\section{LiterATURE}

1. Badhe N, Dewnany G, Livesley PJ (2001) Should the patella be replaced in total knee replacement? Int Orthop 25:97-99

2. Barrack RL (2003) Orthopaedic crossfire--All patellae should be resurfaced during primary total knee arthroplasty: in opposition. J Arthroplasty 18:35-38

3. Barrack RL, Bertot AJ, Wolfe MW, Waldman DA, Milicic M, Myers L (2001) Patellar resurfacing in total knee arthroplasty. A prospective, randomized, double-blind study with five to seven years of follow-up. J Bone Joint Surg Am 83-A:1376-1381

4. Bernstein J (1998) Resurfacing of the patella in total knee arthroplasty. A prospective, randomized, double-blind study. J Bone Joint Surg Am 80:925-926

5. Berti L, Benedetti MG, Ensini A, Catani F, Giannini S (2006) Clinical and biomechanical assessment of patella resurfacing in total knee arthroplasty. Clin Biomech (Bristol, Avon) 21:610-616

6. Bourne RB, Burnett RS (2004) The consequences of not resurfacing the patella. Clin Orthop Relat Res:166-169

7. Bourne RB, Rorabeck CH, Vaz M, Kramer J, Hardie R, Robertson D (1995) Resurfacing versus not resurfacing the patella during total knee replacement. Clin Orthop:156-161

8. Braakman M, Verburg AD, Bronsema G, van Leeuwen WM, Eeftinck MP (1995) The outcome of three methods of patellar resurfacing in total knee arthroplasty. Int Orthop 19:7-11

9. Burnett RS, Haydon CM, Rorabeck CH, Bourne RB (2004) Patella resurfacing versus nonresurfacing in total knee arthroplasty: results of a randomized controlled clinical trial at a minimum of 10 years' followup. Clin Orthop Relat Res:12-25

10. Cameron HU, Fedorkow DM (1982) The patella in total knee arthroplasty. Clin Orthop Relat Res:197-199

11. Dennis DA, Komistek RD, Colwell CE, Jr., Ranawat CS, Scott RD, Thornhill TS, Lapp MA (1998) In vivo anteroposterior femorotibial translation of total knee arthroplasty: a multicenter analysis. Clin Orthop Relat Res:47-57

12. van den Dikkenberg N, Meijer OG, van der Slikke RM, van Lummel RC, van Dieen JH, Pijls B, Benink RJ, Wuisman PI (2002) Measuring functional abilities of patients with knee problems: rationale and construction of the DynaPort knee test. Knee Surg Sports Traumatol Arthrosc 10:204-212

13. Enis JE (1993) Comparison of patellar resurfacing versus nonresurfacing in bilateral total knee arthroplasty. Clin Orthop Relat Res:310

14. Feller JA, Bartlett RJ, Lang DM (1996) Patellar resurfacing versus retention in total knee arthroplasty. J Bone Joint Surg Br 78:226-228 


\section{Chapter 6}

15. Hanssen AD (2003) Orthopaedic crossfire--All patellae should be resurfaced during primary total knee arthroplasty: in the affirmative. J Arthroplasty 18:31-34

16. Insall JN, Dorr LD, Scott RD, Scott WN (1989) Rationale of the Knee Society clinical rating system. Clin Orthop Relat Res:13-14

17. Jacobs WC, Clement DJ, Wymenga AB (2005) Retention versus sacrifice of the posterior cruciate ligament in total knee replacement for treatment of osteoarthritis and rheumatoid arthritis. Cochrane Database Syst Rev:CD004803

18. Keblish PA, Varma AK, Greenwald AS (1994) Patellar resurfacing or retention in total knee arthroplasty. A prospective study of patients with bilateral replacements. J Bone Joint Surg Br 76:930-937

19. Kleijn LL, van Hemert WL, Meijers WG, Kester AD, Lisowski L, Grimm B, Heyligers IC (2007) Functional improvement after unicompartmental knee replacement: a follow-up study with a performance based knee test. Knee Surg Sports Traumatol Arthrosc

20. Kreibich DN, Vaz M, Bourne RB, Rorabeck CH, Kim P, Hardie R, Kramer J, Kirkley A (1996) What is the best way of assessing outcome after total knee replacement? Clin Orthop Relat Res:221-225

21. Lehmann EL, D'Abrera HJM (1975) Nonparametrics. Statistical Methods Based on Ranks. . In:Holden-Day, San Francisco, pp 132-141

22. Maly MR, Costigan PA, Olney SJ (2006) Determinants of self-report outcome measures in people with knee osteoarthritis. Arch Phys Med Rehabil 87:96-104

23. Mayman D, Bourne RB, Rorabeck CH, Vaz M, Kramer J (2003) Resurfacing versus not resurfacing the patella in total knee arthroplasty: 8- to 10-year results. J Arthroplasty 18:541-545

24. Nizard RS, Biau D, Porcher R, Ravaud P, Bizot P, Hannouche D, Sedel L (2005) A metaanalysis of patellar replacement in total knee arthroplasty. Clin Orthop Relat Res:196-203

25. Peng CW, Tay BK, Lee BP (2003) Prospective trial of resurfaced patellaversus non-resurfaced patella in simultaneous bilateral total knee replacement. Singapore Med J 44:347-351

26. Pollo FE, Jackson RW, Koeter S, Ansari S, Motley GS, Rathjen KW (2000) Walking, chair rising, and stair climbing after total knee arthroplasty: patellar resurfacing versus nonresurfacing. Am J Knee Surg 13:103-108; discussion 108-109

27. Schroeder-Boersch H, Scheller G, Synnatschke M, Arnold P, Jani L (1998) [Patellar resurfacing. Results of a prospective randomized study]. Orthopade 27:642-650

28. Shih HN, Shih LY, Wong YC, Hsu RW (2004) Long-term changes of the nonresurfaced patella after total knee arthroplasty. J Bone Joint Surg Am 86-A:935-939

29. Shoji H (1998) Resurfacing of the patella in total knee arthroplasty. A prospective, randomized, double-blind study. J Bone Joint Surg Am 80:926

30. Soudry M, Mestriner LA, Binazzi R, Insall JN (1986) Total knee arthroplasty without patellar resurfacing. Clin Orthop Relat Res:166-170 


\section{Patella resurfacing}

31. Waters TS, Bentley G (2003) Patellar resurfacing in total knee arthroplasty. A prospective, randomized study. J Bone Joint Surg Am 85-A:212-217

32. Wood DJ, Smith AJ, Collopy D, White B, Brankov B, Bulsara MK (2002) Patellar resurfacing in total knee arthroplasty: a prospective, randomized trial. J Bone Joint Surg Am 84-A:187-193

33. Yoshiya S, Matsui N, Komistek RD, Dennis DA, Mahfouz M, Kurosaka M (2005) In vivo kinematic comparison of posterior cruciate-retaining and posterior stabilized total knee arthroplasties under passive and weight-bearing conditions. J Arthroplasty 20:777-783 


\section{ChAPTER 7}

Answers to the questions 
Chapter 7 
In this thesis the following research questions were posed. Based upon the conducted research the following answers can be formulated.

1. Are functional differences between unicompartmental knee replacement and total knee replacement are dependent upon the method of assessment employed?

Chapter two dealt with the issue of comparing UKR and TKR where both pre and postoperative status of these patients were studied. It has become evident that different measurement tools (WOMAC, KSS, SF36, the Dynaport ${ }^{\circledR}$ Knee test) that study the same item can provide different results and therefore different interpretations are possible.

2a. Can bone healing after open wedge high tibial osteotomy be reliably documented?

2b. How is the feasibility of ceramic implants in open wedge high tibial osteotomy?

Chapter three dealt with the possibility of replacing autologous bone grafts for OWHTO by the use of prefabricated Tricalciumphosphate wedges or granules. The outcome measurements on bone healing were done using a newly developed scoring system scoring system. This system has been proven to be reliable for this matter. Prefabricated $ß$ tricalciumphosphate in OWHTO is feasible.

3a. Is it possible to elucidate the true longevity of recovery after unicompartmental knee replacement?

3b. Is it possible to establish differences across the used assessment tools, with the knowledge that function could also be reflected in the ability to perform activities of daily living and this seems rather important and may be less related to range of motion or reported function scores?

Chapter four described differences among outcome measurements implying that outcome measurement have limitations such as ceiling effects and therefore resulted in different insights using other measurements. The Dynaport ${ }^{\circledR}$ Knee test proved that the longevity of recovery after unicompartimental knee replacement is longer than can be documented with KSS due to its ceiling effect and may take up to two years. 
4. Is faster postoperative recovery dependent upon a traditional approach to the knee joint when compared to an alternate muscle sparing technique? Is it of interest to investigate the true function and provide anatomic evidence for presented claims as a part of valuing own measurements?

Chapter five focused on the issue of two different approaches to the joint in knee arthroplasty. No major difference could be demonstrated in this study. The provided anatomical evidence showed that during both approaches important structures could be severed. Therefore the used tests likely do provide reliable results.

5. Could the indecisiveness about patellar resurfacing be attributed to the insufficient responsiveness of used measurement parameters in past trials, rather than assuming that no difference exists?

Chapter six discusses the fact that a possible non-existing difference could also be attributed to lack of responsiveness of scoring systems. Therefore it can be postulated that the question whether to resurface the patella or not may not have been studied adequately in the past and a difference does exist. 
Answers to the questions 


\section{Chapter 8}

\section{General discussion}


Chapter 8 


\section{General discussion}

This thesis was set up to create a mind setting for the orthopaedic surgeon to appreciate differences in outcome measurements and related interpretations of outcome after adult reconstructive knee surgery. It is important for various reasons to document follow-up, but also to consider the suitable tools for this. Clinimetric aspects come into play in this part, where tests have to be selected according to their validity and reproducibility. In this work measurement tools have been selected that have been proven in this view, or a study was conducted with a new developed tool, since no suitable alternative was available.

Clinimetrics is a methodologic discipline that focuses on the quality of measurements, such as diagnostic tools and disease outcome ${ }^{3}$. In outcome after knee replacement is was shown that outcome is dependent upon the evaluation method employed. It was outlined that scoring systems can be categorized in different groups that may serve the same purpose but arise from quite opposite, such as generic vs. disease specific and doctor vs. patient assessed. It can be concluded that different outcome measurements produce different results, suggesting different capabilities of the tests. Patients after UKR with obvious different demographics and indications compared to TKR may appear quite similar in recovery of function, whereas self reflected function scores show the opposite. The clinimetric aspect of this study was to document which tools are most suitable for which outcome parameter and to verify that expected differences may vary among used instruments. It is therefore of major importance which measurement tool is most suitable to discriminate between subjects at one point in time or to measure change over time. When the instrument for a study is not available it can be developed. One should always search intensively for any instrument available as it is often underestimated how long it takes to develop and evaluate a new instrument ${ }^{2}$.

The feasibility of using bone substitutes in open wedge high tibial osteotomy has been a good example. The objective of this study was to compare bone healing and bone remodelling in OWHTO patients with bone gaps filled with TCP granules to that of patients treated with TCP wedges as well as to assess the clinical use of TCP in OWHTO. To monitor osteotomy healing, a new radiological rating system was designed. The instrument showed good inter- and intraobserver reliability to verify its clinical applicability. In this procedure of adult knee reconstruction a safe use of void fillers has been documented with full incorporation radiologically. The clinimetric aspects reproducibility and agreement were used in this study. 
When appropriate selection of the instruments has been dealt with it is of interest to retest the longevity of recovery after unilateral knee replacement. Due to ceiling effects in existing tools (KSS) to document further improvement it previously resulted in the assumption that recovery is completed at one half year after surgery. This will be interpreted as a completed recovery of the treated affliction whereas in fact the KSS proved less suitable, since prolonged recovery with a better suitable instrument (Dynaport ${ }^{\circledR}$ Knee Score). Due to such ceiling affects it must be pointed out that also other scores have its limitations even to ones used that performed better in comparison. A modification of a score or the use of a different score should be considered here.

It was proved that prolonged recovery might take up to two years after UKR. It was demonstrated that KSS is not responsive enough. Any study that uses the KSS may hold this issue. Rating systems for total knee replacement are under great debate in literature ${ }^{1}$. Even specific questions may require the use of a different tool.

In this view multiple instruments were used to document different outcomes in the trial to two different surgical approaches in TKR. With the knowledge of differences in discrimination of different tools this study was set up with the hypothesis that early functional recovery would favour the more tissue sparing subvastus approach. As it has been shown only to matter in the very first days, as the extension lag only favoured, it was not able to conclude that no difference existed in function. Function was tested with the most suitable tool. As no difference was found basic research was conducted to verify our findings and showed that also significant damage may be inflicted in the considered less invasive subvastus approach.

Also the issue of patellofemoral resurfacing in total knee replacement can be studied with the knowledge that the best available instrument has not been used. The feasibility of performance-based tools was tested here. The Minimod, a gait measurement tool, did not show differences, whereas the Dynaport ${ }^{\circledR}$ Knee Score, a true performance gait tool did. Especially noticeable in this study is the difference that is found in the performance where it should matter the most: stair climbing. This has been shown to differ in favour of resurfacing, whereas in literature it has been suggested that pain during stair climbing is reduced. The clinimetric aspect of this study was to suggest that a more discriminative tool, with higher construct validity for the hypothesized problem, has been used. It is of much interest to take part in the continuing discussion of the resurfacing issue. Treatment should be performed according to the best available level of evidence. Since two excellent meta analyses have been published on this topic 
and both favour resurfacing it is still not clear why resurfacing is still routine. Most arguments do not vary much from 'I never do it' or 'to my opinion...' There is obviously a better answer needed in this topic but until then it is recommended to abandon patella retention. The opponents should perform trials to prove the obsoleteness of resurfacing rather than vice versa.

\section{Suggestions for further research and recommendations}

In this thesis several topics concerning adult reconstructive knee surgery were highlighted. Based on this work several issues are now relevant. It is advised to use objective functional assessment tools to complement generic, disease specific, doctor related and pain related scoring systems or questionnaires. Only then outcome measurements can be adequately appreciated.

It is strongly recommended to use specific terminology and definitions. Pain is very subjective. The use of a visual analogue scale will not explain the setting related to pain. Pain scores in WOMAC or SF 36 will do so. Functioning according to a patient should be assessed using these scores as well, contrary to objective functioning. Here is recommended to use SF 36 only in longer follow up and to consider the use of WOMAC in short-term trails. Both are of equal importance as patient's appreciation can be quite different from a doctor's appreciation. Function is a dynamic phenomenon, but is rather used to define knee flexion. Here an objective performance based tool should be used. In this view a critical appraisal to this work must be discussed. Although the Dynaport ${ }^{\circledR}$ Knee test has been shown reliable and reproducible, it holds 'a black box' where the input data is sent to the manufacturer of the system. Here it is analyzed and produces a score. The researcher has no insight into what procedure is followed. As it has been proved to be a promising and reliable tool it could be even more incorporated in knee related research as full insight into the mechanism is disclosed. In this view the Minimod or equal gait-test can be appreciated more thoroughly. But here another problem evolves. When subjects walk faster or in a higher step frequency is not clear whether this result should be interpreted as 'better' or 'worse'. In orthopaedics a score in a scale is appreciated more easily as may be contrary to basic science.

There is a no need of a new knee score or tools but rather a modification on existing ones. Most patients will subsequently do better given all technical and surgical related improvements made, where current scores do simply not anymore account for. In this view several questions need to be investigated. What is true early functional recovery after minimal invasive surgery? Which scores are suitable for short-term investigations and which apply for long-term 
follow-up? Which part of a general functional test is applicable in a specific research question?

In the view of more sensitive scoring systems it is of interest to perform a large randomised trial to finally clarify the issue of patella resurfacing, accounting for various technical and correct functional aspects. Is a further modification possible to current objective systems to simplify to use of it? Does a better score also mean a better performance? 


\section{LiTERATURE}

1. Davies AP (2002) Rating systems for total knee replacement. Knee 9:261-266

2. de Vet HC, Terwee CB, Bouter LM (2003) Current challenges in clinimetrics. J Clin Epidemiol 56:1137-1141

3. Feinstein A (1987) Clinimetrics. Yale University Press New Haven, CT 


\section{Chapter 9}

\section{Summary}


Chapter 9 


\section{SUMMARY}

To measure outcome exactly after a surgical procedure for knee osteoarthritis it is of importance to formulate adequate research questions. Furthermore it is of importance to carefully design a study and to use the appropriate measurement tools in it. The measurement tool should be available. Quality of measurement should include the quality of the instrument en the quality of the performance.

Chapter 1 gives a general introduction to relevant issues that are encountered in the treatment of knee osteoarthritis, outlines the methodologic discipline of clinimetrics and formulates research questions.

Chapter 2 discusses whether the outcome after knee replacement is dependent upon the type of measurement employed. It compares unicompartmental (UKR) to total knee replacement (TKR). In a prospective study 52 TKR patients were compared to 24 UKR at preoperative, three, six months and one year postoperative. The disease specific KSS and Womac (pain and function subscores), the generic SF36 (pain, function and patient perception subscores) and the DynaPort ${ }^{\circledR}$ Knee Test were utilized.

Preoperative UKR patients had significantly higher KSS function and the DynaPort ${ }^{\circledR}$ Knee Test, but despite being younger, with different indication, they were not different to TKR with regards to function and pain subscores of Womac and SF36. Regarding preoperative perception, UKR patients reported better physical and social function but subjectively felt worse than TKR patients regarding health, emotion and mental status.

At one year, postoperative perception scores for both groups increased significantly, with UKR retaining functional lead and UKR patients also felt superior regarding health, emotion and mental status $\sim$ Postoperative recovery regarding KSS, Womac, and SF36- pain was steep only during the first 3 months with near equal values for both TKR and UKR. It was found that SF36-Function recovery was not significant, but UKR also scored higher than TKR. Only functional scores by the DynaPort ${ }^{\circledR}$ Knee Test showed continued improvement and maintained the functional advantage of UKR patients throughout recovery.

UKR and TKR patients have different age demographics, indications and perceptions, but clinical outcome scores do not equally capture these differences, especially with regards to function.

Postoperative functional benefits of UKR seem to be due mainly to the superior preoperative conditions. Appreciation of recovery with generic, 
disease specific and functional measurements appear invaluable.

Chapter 3 studies the capacity of two forms of porous beta-tricalcium phosphate bone substitutes (TCP) to promote bone healing in open wedge high tibial osteotomy (OWHTO) was studied.

The X-rays of 27 osteotomies, with either TCP wedges or TCP granules as filling materia, to compare the bone healing rates and bone remodelling, at specific postoperative intervals. A new radiologic rating system for OWHTO was created and tested for clinical applicability. All osteotomies healed uneventfully and complete resorption of TCP was demonstrated at one year postoperative in $85 \%(n=23)$ of the procedures. In $44 \%(n=10)$ of these 23 procedures, the osteotomy site was no longer visible. No difference in bone healing rate and bone remodelling was found when comparing the use of granules to a wedge, and no adverse effects of TCP were observed. The good inter- $(k=0.6)$ and intraobserver $(k=0.6)$ reliability of the new radiologic rating system enables clinical use. Good bone healing was found in OWHTO with both wedges and granules of TCP.

Chapter 4 describes the true longevity of recovery after unicompartmental knee replacement with the DynaPort ${ }^{\circledR}$ Knee test. In a prospective study on 38 patients with a mean age of 62.2 years functional improvement was measured. Using Knee

Society Score (KSS) as a clinician based score and the DynaPort ${ }^{\circledR}$ Knee Test as a functional test measurements were performed at preoperative, three and six months, one and two years, after surgery.

The mean KSS preoperative was 44.0 and improved significantly to 81.7 at 3 months $(p<0.001)$ and to $87.4(p=0.025)$ at six months. No significant differences were noted after six months. The mean preoperative DynaPort ${ }^{\circledR}$ Knee Test score was 35.8 and at three months 43.6 ( $p<0.001), 48.6$ at six months $(p<0.001)$. No significant differences were noted after six months follow-up.

Of the Dynaport sub scores, the low demanding tasks Lift and Move and Locomotion, cease to improve beyond 6 months. The high demanding task Transfers only improved up to three months. However, the other high demanding tasks Rise and Descend showed improvement beyond one year after surgery, since the improvement from six months to two years was significant $(p=0.023)$. This study has found that functional recovery continues beyond six months and even up to two years. It seems only more challenging tests can discriminate on improvement beyond a point where questionnaires 
cease to improve. The use of objective measurement methods is advocated next to the clinician based scores and self reported questionnaires.

Chapter 5 reports a prospective randomized trial comparing two different approaches to the knee joint in total knee arthroplasty.

Measurements (KSS, WOMAC, PDI, VAS, ability to perform) were obtained at day one, day three, one week, six weeks and three months. The subvastus group $(n=20)$ showed only significantly less extension lag direct post operative $(p=0.038)$ compared to the parapatellar group $(n=20)$. Other scores were not significantly different. The DynaPort ${ }^{\circledR}$ Knee Test, an objective performance based tool could not demonstrate significant differences.

A blunt anatomical dissection was carried out and in both observational and histological examination a dense innervation of the distal vastus medialis was found. This innervation is at risk employing the subvastus approach. Both approaches harm the suprapatellar bursa. The vastus medialis sheath must be detached distally to open the knee joint. No true separate vastus medialis obliquus could be identified.

Comparable to literature only mild advantage employing the subvastus approach was found, but only early postoperative and not objectively. As this approach is also not suitable in every case we will continue to use the parapatellar approach.

Chapter 6 addresses the issue whether to resurface the patella or not during total knee arthroplasty. In this retrospective study 53 patients were included and divided into a resurfaced group $(n=31)$ and a non-resurfaced group ( $n=22$ ). Both groups were matched on age and longevity of follow up. Patients were clinically assessed using the Knee Society Score (KSS) at various time points. At final follow-up patients were also assessed once using the DynaPort ${ }^{\circledR}$ Knee Test and The Minimod ${ }^{\circledR}$ Gait Test.

The DynaPort ${ }^{\circledR}$ Knee Test showed a significant functional advantage for patients with a resurfaced patella (44 vs. $39.7(p=0.042)$ ), whereas KSS and The Minimod ${ }^{\circledR}$ Gait Test also favored resurfacing but were not significant.

Similar to other reports in literature, using the KSS it was not possible to identify significant difference between patella resurfacing or retaining in total knee arthroplasty, however using a performance based test it was possible to determine significant difference and this favoured the resurfaced patellae. The advantage of patella resurfacing may be less due to pain relief but due to a functional benefit during demanding motion tasks for which standard clinical 
scores do not account for sufficiently and objectively enough. For future clinical studies in this topic we recommend to complement the classical evaluation tools with an objective functional performance test.

Chapter 7 describes the answers to the research questions.

Chapter 8 is a general discussion.

Chapter 9 and 10 are an english and dutch summary 


\section{Chapter 10}

Samenvatting 
Chapter 10 


\section{SAMENVATting}

Voor het precies meten van het resultaat na een chirurgische ingreep voor gonartrose is het van belang adequate onderzoeksvragen te formuleren. Bovendien is het van belang om zorgvuldig het ontwerp van een studie te definiëren en het gebruik van de juiste meetinstrumenten te selecteren. Het meetinstrument moet beschikbaar zijn. Kwaliteit van de meting moet onder meer de kwaliteit van het instrument en de kwaliteit van de prestaties behelsen.

Hoofdstuk 1 geeft een algemene inleiding op relevante vraagstukken die zich voordoen bij de behandeling van gonartrose, met een overzicht van de methodologische discipline van clinimetrie en formuleert onderzoeksvragen.

Hoofdstuk 2 bespreekt de vraag of de uitkomst na knieprothese afhankelijk is van welk meetinstrument wordt gebruikt. Het vergelijkt unicompartmentele (UKR) met de totale knie prothese (TKR). In een prospectieve studie werden, preoperatief, drie, zes maanden en een jaar postoperatief, 52 TKR patiënten vergeleken met 24 UKR.

De aandoening specifieke KSS en WOMAC (pijn en functie subscores), de generieke SF36 (pijn, functie en perceptie-van-de-patiënt subscores) en de DynaPort ${ }^{\circledR}$ Knee Test werden gebruikt.

Preoperatief hadden UKR patiënten een significant hogere functie, KSS en DynaPort ${ }^{\circledR}$ Knee Test, maar ondanks het feit dat dit jongere patiënten zijn, met verschillende indicaties, zijn ze anders dan patiënten met een TKR met betrekking tot functie en pijn van de WOMAC en subscores van SF36.

Met betrekking tot preoperatieve perceptie, meldden UKR patiënten een betere fysieke en sociale functie maar bleven subjectief slechter dan TKR patiënten met betrekking tot de gezondheid, emotie en mentale toestand.

$\mathrm{Na}$ een jaar waren postoperatieve perceptie scores voor beide groepen gestegen, met behoud van functioneel voordeel van de UKR. Nu waren UKR patiënten ook superieur ten aanzien van gezondheid, emotie en mentale status.

Het postoperatief herstel met KSS, WOMAC en SF36-pijn was steil alleen gedurende de eerste 3 maanden met gelijke waarden voor zowel TKR en UKR. Het bleek dat SF36-functie herstel niet significant was, maar UKR scoorde ook hoger dan TKR.

Alleen functionele scores met de DynaPort ${ }^{\circledR}$ Knee Test toonden een verdere verbetering en UKR patiënten behielden het functionele voordeel.

UKR en TKR patiënten betreffen verschillende leeftijdsgroepen demografie, 
indicaties en percepties, maar de klinische uitkomst scores tonen deze verschillen niet in gelijke mate aan, met name met betrekking tot de functie.

Postoperatieve functionele voordelen van UKR lijken voornamelijk te komen door de betere preoperatieve condities. Beoordeling van herstel met generieke, ziekte specifieke en functionele metingen zijn van onschatbare waarde.

Hoofdstuk 3 bestudeert de capaciteit van twee vormen van poreuze betatricalciumfosfaat botvervangers (TCP) om botgenezing te bevorderen in een open wig hoge tibiakop osteotomie (OWHTO).

De röntgenfoto's van 27 osteotomieën, met ofwel TCP wiggen of TCPgranulaat als vulling werden vergeleken. Hierbij werd gekeken naar snelheid van genezing en botremodellering, op specifieke postoperatieve intervallen. Een nieuw radiologisch scoring-systeem voor OWHTO werd gecreëerd en ook getest op klinische toepasbaarheid. Alle osteotomieën werden zonder complicaties verricht en volledige resorptie van TCP werd aangetoond in $85 \%$ $(N=23)$ van de procedures een jaar na de operatie. In $44 \%(n=10)$ van deze 23 procedures, was de osteotomieplaats niet meer zichtbaar. Er werd geen verschil in snelheid van botgenezing gevonden bij het gebruik van TCP granulaat of een wig.

De goede inter- $(k=0,6)$ en intraobserver $(k=0,6)$ variabiliteit van de dit nieuwe radiologische scoring systeem maakt klinisch gebruik mogelijk. Goede botgenezing werd aangetoond in OWHTO met zowel wiggen als granulaat van TCP.

Hoofdstuk 4 beschrijft de werkelijke herstelduur na een unicompartmental knie prothese met behulp van de DynaPort ${ }^{\circledR}$ Knie Test.

In een prospectieve studie van 38 patiënten met een gemiddelde leeftijd van 62,2 jaar werd functionele verbetering gemeten. Met behulp van de Knee Score Society (KSS) als een klinische score en de DynaPort ${ }^{\circledR}$ Knee Test als een functionele test werden metingen uitgevoerd preoperatief, drie en zes maanden, een en twee jaar na de operatie.

De gemiddelde preoperatieve KSS bedroeg 44,0 en verbeterde aanzienlijk naar 81,7 na 3 maanden $(p<0,001)$ en $87,4(p=0,025)$ na zes maanden. $\mathrm{Er}$ waren geen significante verschillen na zes maanden. De gemiddelde preoperatieve DynaPort ${ }^{\circledR}$ Knee Test score was 35,8, na drie maanden 43,6 $(p<0,001)$ en 48,6 na zes maanden $(p<0,001)$. Er werden geen significante verschillen gevonden na zes maanden follow-up. 
Van de DynaPort sub scores, de lichte taken 'Lift and Move' en 'Locomotion', verbeterden na 6 maanden niet meer. De veeleisende taken 'Transfers' verbeterden tot drie maanden. Echter, de andere veeleisende taak 'Rise and Descend' vertoonde verbetering na een jaar na de ingreep, omdat de verbetering tussen zes maanden en twee jaar significant was $(p=0,023)$. Deze studie heeft uitgewezen dat functioneel herstel langer duurt dan zes maanden en zelfs tot twee jaar kan duren. Het lijkt dat alleen de meer onderscheidende tests kunnen discrimineren op verbetering, waar vragenlijsten geen verbetering meer tonen. Het gebruik van objectieve meetmethoden naast de klinische scores en zelf gerapporteerde vragenlijsten wordt aangeraden.

Hoofdstuk 5 beschrijft een prospectief gerandomiseerde studie waarin twee verschillende benaderingen van het kniegewricht tijdens een totale knie artroplastiek worden vergeleken.

Metingen (KSS, WOMAC, PDI, VAS) werden verkregen op de eerste dag, dag drie, een week, zes weken en drie maanden. De subvastus groep $(n=20)$ bleek alleen beduidend minder extensie beperking directe postoperatief $(p=0,038)$ te hebben in vergelijking met parapatellaire groep $(n=20)$. Andere scores waren niet significant verschillend. De DynaPort ${ }^{\circledR}$ Knee Test, kon geen significante verschillen aantonen.

Een anatomische dissectie werd uitgevoerd en zowel observationeel als

histologisch bleek er een dichte innervatie van de vastus medialis te bestaan. Deze innervatie is in gevaar in het geval van de subvastus benadering. Beide benaderingen schaden de bursa suprapatellaris. De mediale vastus medialis fascie moet worden geopend om het kniegewricht te openen. Geen echte aparte vastus medialis obliquus kon worden geïdentificeerd.

In vergelijking met de literatuur werd slechts mild voordeel ten faveure van de subvastus benadering gevonden, maar alleen vroeg postoperatief en niet objectief. Aangezien deze benadering ook niet geschikt is bij elke patiënt, blijven wij de parapatellaire benadering gebruiken.

Hoofdstuk 6 gaat in op de vraag of de patella wel of niet weer moet worden vervangen tijdens totale knie arthroplastiek. In een retrospectieve studie werden 53 patiënten geincludeerd en verdeeld in een vervangen groep $(n=31)$ and a niet-vervangen groep $(n=22)$. Beide groepen waren gematched op leeftijd en levensduur van de follow-up. De patiënten werden beoordeeld met de Knee Society Score (KSS), op verschillende tijdstippen. Tijdens de laatste follow-up van werden patiënten ook beoordeeld met behulp van de DynaPort ${ }^{\circledR}$ Knie-test 
en de Minimod ${ }^{\circledR}$ Gait Test.

De DynaPort ${ }^{\circledR}$ Knee Test toonde een significant functioneel voordeel voor patiënten met vervangen patella (44 versus $39,7(p=0,042)$ ), terwijl KSS en The Minimod ${ }^{\circledR}$ Gait Test ook voordeel suggereerden, maar niet significant waren.

Net als bij eerdere publicaties over dit onderwerp, was het niet mogelijk om met de KSS een significant verschil aan te tonen. Echter met het gebruik van een objectieve test was het wel mogelijk om een significant verschil vast te stellen en deze bleek in het voordeel van het vervangen van de patella. Het voordeel van het vervangen van de patella kan minder als gevolg zijn van verlichting van de pijn, maar meer als gevolg van een functioneel voordeel tijdens veeleisende taken waarvoor de standaard klinische scores niet objectief genoeg zijn. Voor toekomstige klinische studies naar dit onderwerp raden wij aan de klassieke scores aan te vullen met een objectieve functionele test.

Hoofdstuk 7 beantwoordt de onderzoeksvragen.

Hoofdstuk 8 geeft een algemene discussie.

Hoofdstuk 9 en 10 zijn een samenvatting in resp. Engels en Nederlands. 
List of publications 
List of publications 


\section{LIST OF PUBLICATIONS}

I. Curfs; M. van der Linde; B. Grimm; W. van Hemert.

Radiological prediction of posttraumatic Kyphosis after Thoracolumbar fracture. Submitted Eur J Spine

Wouter L.W. van Hemert, Rachel Senden, Bernd Grimm, Matthijs J.A. van de Linde, Arno Lataster, Ide C. Heyligers.

Rehabilitation after subvastus or parapatellar approach in total knee arthroplasty is comparable; a performance based trial with anatomical findings. Submitted Knee Surg Sports Traumatol Arthrosc

Wouter L.W. van Hemert; Lucas L.A Kleijn; Bernd Grimm; Will G.H. Meyers; Ide C. Heyligers.

Functional outcome after knee arthroplasty is dependent upon evaluation method employed. Eur J orthop surg traumatol (2009) 19: 415-422

Wouter L.W. van Hemert, Rachel Senden, Arnold D.M. Kester, Bernd Grimm, Matthijs J.A. van de Linde, Ide C. Heyligers.

Patell retention versus replacement in total knee arthroplasty; functional and clinimetric aspects? Arch Orthop Trauma Surg. 2009 Feb;129(2):259-65. Epub 2008 May 17.

Lucas L.A. Kleijn, Wouter L.W. van Hemert, Will G.H. Meijers, Arnold D.M. Kester, Lukas Lisowski, MD, Bernd Grimm, Ide C. Heyligers.

Functional improvement after unicompartmental knee replacement; a follow-up study with a performance based knee test. Knee Surg Sports Traumatol Arthrosc. 2007 Oct;15(10):1187-93.

Van Hemert W.L, Karel Willems, Patricia. G. Anderson, Ronald J. van Heerwaarden, Ate B Wymenga.

Tricalcium phosphate granules or rigid wedge preforms in open wedge high tibial osteotomy: a radiological study with a new evaluation system. Knee. 2004 Dec;11(6):451-6.

Wouter van Hemert, Bart Vrouenraets

Boekbespreking, Chirurgie, Bonjer et al, NTVG, 2003

Beumer A, van Hemert WL, Niesing R, Entius CA, Ginai AZ, Mulder PG, Swierstra BA.

Radiographic measurement of the distal tibiofibular syndesmosis has limited use. Clin Orthop Rel Res. 2004 Jun(423):227-34. 


\section{List of publications}

Beumer A, van Hemert WL, Swierstra BA, Jasper LE, Belkoff SM.

Biomechanical evaluation of the tibiofibular and tibiotalar ligaments of the ankle. Foot Ankle Int. 2003 May;24(5):426-9.

Beumer A, van Hemert WL, Swierstra BA, Jasper LE, Belkoff SM.

Biomechanical evaluation of clinical stress tests for syndesmotic ankle instability. Foot Ankle Int. 2003 Apr;24(4):358-63. 


\section{VoORdRachten}

Functional outcome after unicompartmental and total knee replacement depends on the used evaluation method. Posterpresentatie. NOF, Amsterdam, 2008

Is a performance based knee test able to differentiate between resurfaced and non resurfaced patellae? ORS/AAOS, San Diego, USA, February 2007

Functional improvement after unicompartmental knee replacement; a follow-up study with a performance based knee test. Posterpresentatie ESSKA, Innsbruck, May 2006

Een dubbele proximale femurfractuur. Casuspresentatie. AIOD cursus intramedullaire fixatie, Heerlen, juni 2004

Granule or rigid wedge tricalcium phosphate preforms in open wedge high tibial osteotomy. European Congress of Trauma, Posterpresentatie ESSKA, Athens, May 2004

Granule or rigid wedge tricalcium phosphate preforms in open wedge high tibial osteotomy. European Congress of Trauma, Synthes Bone Substitutes Symposium, Prague, May 2004

Granule or rigid wedge tricalcium phosphate preforms in open wedge high tibial osteotomy. Wetenschappelijke vergadering NOV, Amersfoort, januari 2003.

Granule or rigid wedge tricalcium phosphate preforms in open wedge high tibial osteotomy. Afdeling Traumatologie, Universiteit van Innsbruck, Oostenrijk, november 2002.

Biomechanical evaluation of the tibiofibular and tibiotalar ligaments of the ankle. Posterpresentatie ESSKA, Rome, May 2002

Biomechanical evaluation of the tibiofibular and tibiotalar ligaments of the ankle. Assistenten trauma symposium; Nederlandse Vereniging voor Traumatologie, januari 2002. 


\section{Dankwoord}


Dankwoord 


\section{DANKWOORD}

Een proefschrift schrijven tijdens de opleidingsperiode is een hele opgave. Vele uren zijn nodig voor het schrijven van protocollen, het uitvoeren van experimenten, analyseren van data en het samenbrengen van artikelen tot één geheel. Dit is principieel onmogelijk zonder de hulp van velen. Een ieder die bijgedragen heeft tot het tot stand komen van dit boekje en mijn opleiding tot orthopaedisch chirurg, van een geinteresseerde vraag tot revisies van artikelen, ben ik dank verschuldigd. Enkelen wil ik in het bijzonder noemen.

Prof. dr. G.H.I.M. Walenkamp, beste Geert, Ondanks dat je pas in de laatste fase bent betrokken geraakt, omdat zonder jouw dit boekje nu eenmaal geen echt boekje is, hebben je waardevolle kritieken, aanmoedingen en inspanningen geleid tot wat het nu is. Ik waardeer het dat je zonder reserves je naam wilde verbinden aan dit werk.

Leden van de beoordelingscommissie

Prof. dr. H. Kuipers, Prof. dr. M van Kleef, Prof. dr. S.K. Bulstra en Prof. dr. L.W. van Rhijn. Veel dank aan u allen voor de kundigheid en vooral snelheid van het beoordelen van het Manuscript in de zomervakantie. Met uw aanwijzingen won het geheel weer iets aan kwaliteit.

Dr. I.C. Heyligers, beste Ide

Ik kwam de Heerlense kliniek binnen met een artikel vanuit Nijmegen. Je hebt zeer waardevol en inhoudelijk bedacht hoe we dit tot een groter geheel konden brengen. Jouw gemak waarmee je in een perifere kliniek een fabuleus lopende researchstichting wist te realiseren is onwaarschijnlijk. Je bent een waar gemis voor de academische orthopaedie. Daarnaast heb je een opleidingsstructuur in Heerlen gerealiseerd die een voorbeeld mag zijn. Gelukkig blijft de kliniek altijd vooropstaan. Ik ben blij mijn steentje hieraan bij te mogen dragen.

Dr. B. Grimm, lieber Bernd, Vielleicht hattest du erwartet daß ich dir auf Deutsch adressieren würde. Ich bedanke mich sehr daß du immer bereit warst über die Wissenschaft zu diskutieren. Deine Begeisterung und das immer positives Aussehen ist wie eines Märchen. Ich freue mich jetzt endlich einmal nach Piesport und Bernkastel zu fahren... 
Dr. R van Heerwaarden, beste Ronald, In de tijd van prothesiologie is het niet eenvoudig een alternatieve koers te varen. Jouw boodschap over osteotomieën komt heel duidelijk over. Bedankt dat je keer op keer het artikel reviseerde, soms tot ergernis toe...

\section{A. Lataster, Beste Arno}

Met veel entousiasme belandde ik tijdens mijn academische jaar op je kamer alwaar we in eerste instantie ook met Henk van Mameren als jonge honden filosofeerden over hoe de subvastus anatomisch te tackelen. Samen hebben we vele uren op een voor mij onorthodoxe manier geprepareerd. Het is wonderbaarlijk hoe jij de musculoskeletale anatomie 'staande' weet te houden tussen zoals je zelf zegt: moleculen....... Op naar onze volgende projecten.

R. Senden, Beste Rachel,

Je hebt je op onvoorstelbare wijze ingezet in de praktisch uitvoering van onze projecten en je hebt je zodoende kunnen ontwikkelen tot een research professional met je eigen plekje op de afdeling. Jouw boekje zal zodoende ook veel betekenis hebben.

Alle voormalige studenten, Maarten, Ghislain, Tom en Carola, die hebben bijgedragen aan de Dynaport metingen ben ik dank verschuldigd.

Mijn paranimfen

Lucas Kleijn en Jan Martijn Kooter

leder is een professional op zijn eigen manier. Het mijn eer dat jullie bij de verdediging naast me staan!

Maatschap orthopaedie Heerlen

Beste Will Meyers, Matthijs van der Linde, Ide Heyligers, Steven Samyo, Jelle Schaafsma en Alphons Tonino, Elmar van den Bogert, Patrick Deckers

Jullie hebben allen bijgedragen tot de orthopaed die ik nu ben. Ik voelde me vereerd dat in een vroeg stadium in de opleiding jullie meer en meer lieten blijken mij in jullie club te willen hebben. De varieteit aan pathologie in deze kliniek is ongekend. Eenieder die tijd voor wetenschap wil krijgt dit ook. Will, jij als meest perifere orthopaed had in Brunssum een unieke database van patienten, die als basis diende voor twee artikelen. Matthijs, jouw welhaast verradelijk makkelijk uitziende operaties, hebben voor mij altijd als uitgangspunt gediend. Steven, ik vind het bijzonder dat we samen assistent geweest zijn in de kliniek waar we nu ook staflid zijn. Jelle, het was vreselijk te 
horen wat je overkwam. Je was altijd een nuchter humorisch persoon, wars van protesten tegen het etablissement. Door je gedwongen pensioen kunnen we helaas niet samen meer de wervels doen. Fons, je bent al even weg, maar je geest waart nog immer op OK 3 rond. Elmar en Patrick, leuk dat jullie nu eindelijk deel van de club zijn.

Secretaresses maatschap, research en polikliniek Zonder jullie is er geen maatschap, geen research en geen patiëntenzorg...

Vakgroep orthopaedie Academisch Ziekenhuis Maastricht Beste André van Ooy, Geert Walenkamp, Lodewijk van Rhijn, René ten Broeke, Mike van Steyn, Patrick Deckers, Henk Arens, Jan-Willem Duyzings, Carlinde de Boer, Heleen Staal, Paul Willems, Ruud Geesink, het was heel goed voor me eens een jaar in jullie kliniek te functioneren en zo de academische orthopaedie te zien.

Maatschap Heelkunde, SLAZ Amsterdam.

Beste Flip Steller, Toni Voorwinde, Rob Weller, Charles Boissevain, Wim van Tets en Jan Ultee. Jullie hebben in de warme Amsterdamse kliniek de heelkundige basis weten te leggen voor de verdere orthopaedische vorming. Het secretariaat was altijd een basis voor ons team. Ik heb het werkelijk fantastisch naar mijn zin gehad bij jullie.

Dr. B.A. Swierstra, Dr. A. Beumer; beste Bart en Annechien, In feite hebben jullie mijn toegang tot de orthopaedie geplaveid. In onze Rotterdamse tijd was het prettig dat ik op jullie kon rekenen in de ontwikkeling als jonge wetenschapper. Zie hier, ook mijn boekje. 'Ons' syndesmose project zal een van de beste herinneringen blijven uit mijn studietijd.

Dr. S.M. Belkoff, dear Steve

Thanks for the opportunity to conduct research in your lab. Your in- and output were invaluable to my scientific skills as they are now. I still remember you saying: 'thanks for all the statistic I had to wade through'. Then I learned the principles of ANOVA and Tukey's post hoc test...

Papa en mama,

Jullie hebben Tom en mij altijd gestimuleerd in onze ideeën, terwijl jullie het vroeger helemaal niet gemakkelijk hadden. We hebben beide onze eigen weg 
gekozen en zijn zeker niet express beiden in de uithoeken van Nederland beland. Jullie zijn een voorbeeld hoe er meegeleefd werd met school en sport. Het is fijn om uit zo'n warm nest te komen.

Wim van Hemert

Willem, mijn peetvader, we hebben altijd een bijzondere band gehad. Jij zei me dat ik maar dokter/doctor moest worden. Hora est!

Leo van Hemert

Het was fijn een tweede thuis te hebben in de weekenden in Amerika. Me and my Uncle went ridin' down... (for sushi).

Mireille, lieve schat, Last but certainly not least. Het is volbracht! Dit boekje is ook dankzij jou ontstaan. Wanneer we niet zo volhardend waren tijdens de opleiding was dit nooit gelukt. Het is fijn weer samen onder één dak te wonen. Ik hou van je. We gaan snel weer naar Parijs... 


\section{Curriculum vitae}


Wouter Leonard Willem van Hemert was born on the 14th of May 1977 in Numansdorp, The Netherlands, where he grew up as well. He attended primary school at the Welkerschool in Numansdorp from 1983 until 1989. That year he went to the Rijksscholengemeenschap in Oud-Beyerland, where he spent his years of middle school (VWO). He graduated in 1995 in the languages Dutch, English, German, Latin as well as Mathematics, Physics and Chemistry.

It was then he decided to go medical school at Erasmus University Rotterdam. During two years he was an editor in chief of the faculty journal 'O'Dokter'. As he got interested in Orthopaedic Surgery, he participated in research initiated about syndesmosis injuries of the ankle, which resulted in authorship on three publications.

Parts of this research were done at the Orthopaedic Biomechanics Laboratory of the University of Maryland (Baltimore, Md, USA) from September 1999 until February 2000 (Supervision S.M. Belkoff, PhD). He also participated in various practical experiments in the laboratory and clinical training at the R Adams Cowley Shock Trauma Center. After internships, his graduation followed in January 2002.

In February 2002 he started a five months research period at the St. Maartenskliniek at Nijmegen (A.B. Wymenga, MD, PhD) about high tibial osteotomy.

He commenced the two year training in General Surgery in the St Lucas Andreas Hospital, Amsterdam in July 2002 (E.Ph. Steller, MD, PhD).

In July 2004 training in Orthopaedic Surgery started at AtriumMC, Heerlen (I.C. Heyligers, MD, PhD), where he progressed on his thesis.

The academic period followed from January 2007 until December 2007 at the University Hospital Maastricht (A. van Ooij, MD, PhD) and registration as an Orthopaedic Surgeon was in July 2008. He then joined the orthopaedic group in AtriumMC, Heerlen, focusing on general orthopaedics, orthopaedic trauma, spine and foot ankle.

The author happily resides with Mireille Schelling. 
